\title{
"You can never be on one side alone": Some Young Somali-Kiwi Women's Narratives about Identity, Resettlement and Community Development in Wellington, Aotearoa New Zealand"
}

\author{
Emily Kathryn James
}

A thesis submitted to Victoria University of Wellington in partial fulfillment of requirements for the degree of Master of Development Studies

School of Geography, Environment and Earth Sciences

Victoria University of Wellington 


\begin{abstract}
This research investigates how young Somali women are navigating through the resettlement process while negotiating their own identities in Wellington, New Zealand. It is important as it addresses two main research gaps: 1) it focuses on research with young Somali women at university and 2) it offers a strength-based analysis. The research also addresses important development concerns about how former refugees can better contribute into their host societies. Employing the use of participatory methods within a feminist qualitative methodology, I created a project that enabled the young women to voice their opinions regarding identity construction, cultural maintenance and their goals for the future.
\end{abstract}

I conducted approximately 150 hours of ethnographic research at organisations that catered to former refugee needs. I found a young female Somali student who worked as my Cultural Advisor and enhanced my credibility and access within the Somali community. I then conducted a focus group and five individual interviews with young Somali women to hear their narratives about their resettlement experience and their advice on how to improve the process for others. I conducted five interviews with key informants at organisations that provide support services for former refugees. The key informants gave the policy perspective on refugee resettlement as well as advice on how support services and the government can approve the transition for former refugees.

The results of this study revealed that the young women did feel tension at times negotiating their Somali culture and that of their host society but found benefits in both. The importance of the family resettling successfully was vital for the young women especially the wellbeing of their mothers and other female elders. The key informants echoed these sentiments and voiced the necessity for more women-focused support services. The young women also will be facing a second resettlement process through their emigration to Australia as they search for more job opportunities and a better Somali cultural connection. 


\section{Acknowledgements}

This thesis would not have been possible without the amazing support and assistance from a great number of people who I would like to acknowledge. I would first like to thank the Development Studies department at Victoria University of Wellington for aiding in my research and providing a welcoming space for me to complete my work. I am deeply grateful to my amazing supervisor, Dr Sara Kindon, for being an invaluable mentor, support system and friend throughout the entire process. She helped introduce and navigate me through the realm of participatory research and allowed me to produce a project of which I am truly proud.

I want to say a huge thank you to the organisations and key informants that helped me make the first connections within the Somali community. The entire staff of the Wellington Somali Council, especially those working at the Homework Centre, were such a welcoming group and taught me so much about this incredible Somali community in Wellington.

I am indebted to my peers, friends and family for their constant support. A special thank you to my amazing parents who motivated me in times of anxiety and provided me with unconditional love. Another huge thank you to Kathryn Baldwin who acted as my international liaison so I could complete my project overseas. I am thankful to all of you.

Finally, immense gratitude to the amazing young Somali women who allowed me into their lives and shared their inspiring experiences with me. Every girl was patient, welcoming and so helpful during this research and I am forever indebted. And a special thank you to my Cultural Advisor who has no idea how important her assistance and friendship meant to me throughout this work. I hope that my work represents their views in a respectful manner and I can not wait to see the amazing things they accomplish in the future. 


\section{Table of Contents}

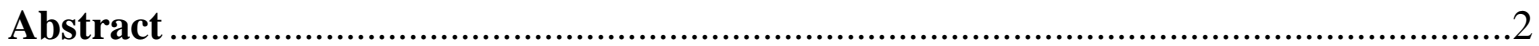

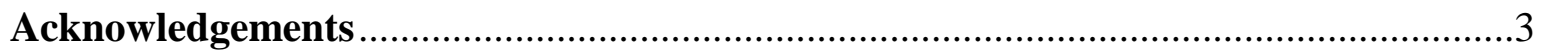

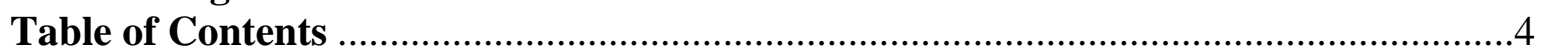

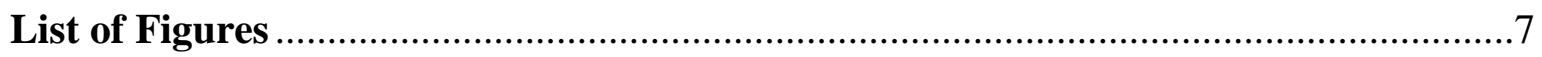

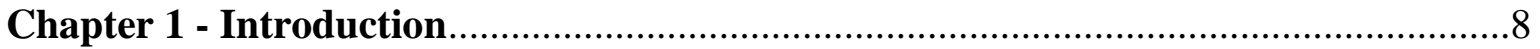

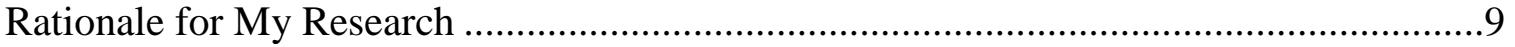

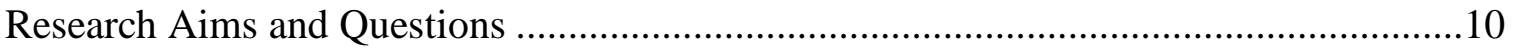

Development of My Methodology ................................................................................ 12

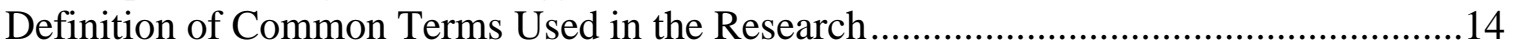

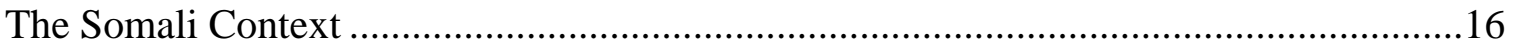

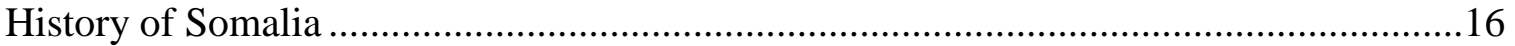

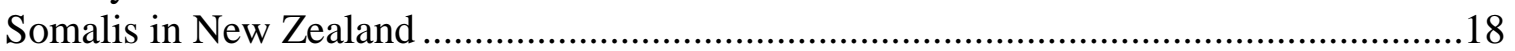

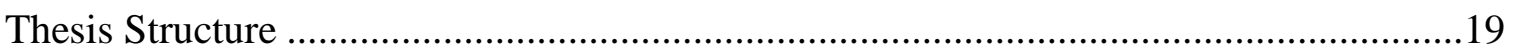

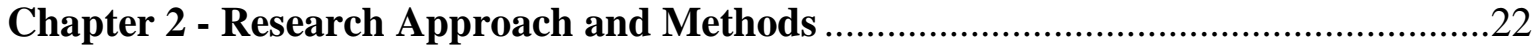

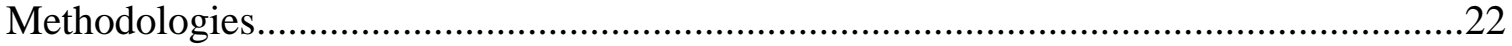

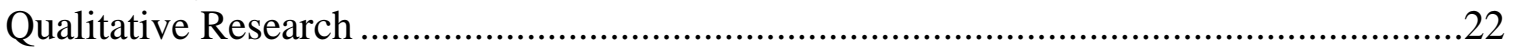

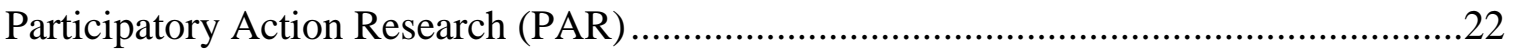

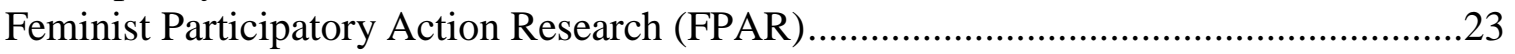

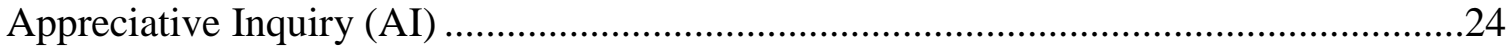

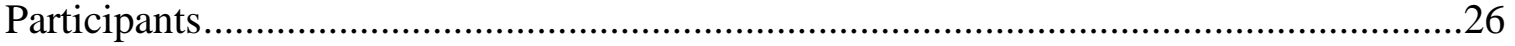

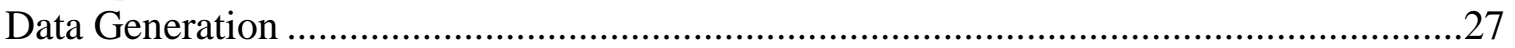

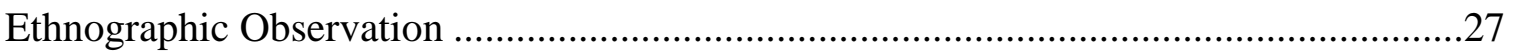

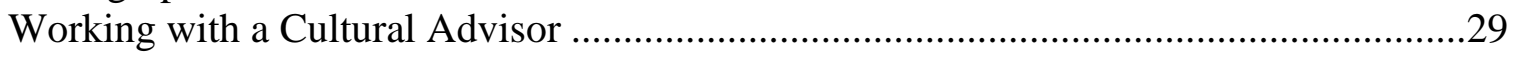

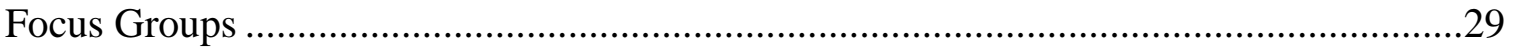

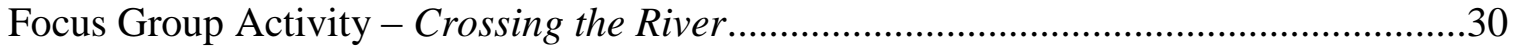

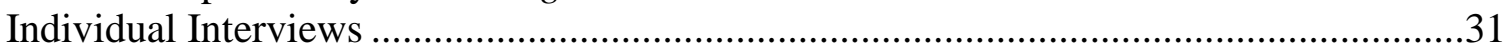

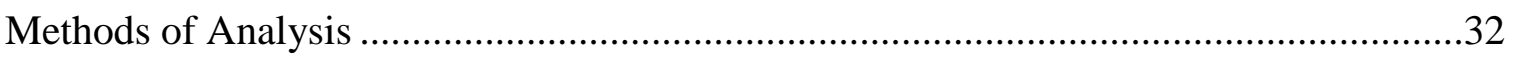

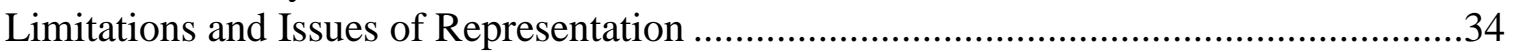

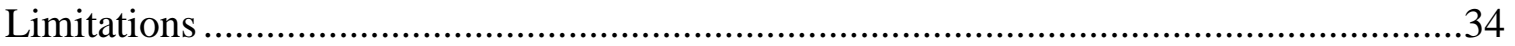

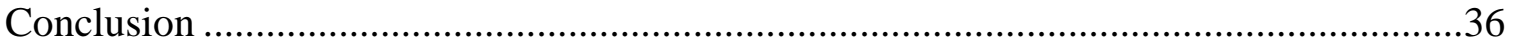

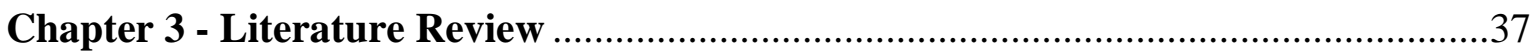

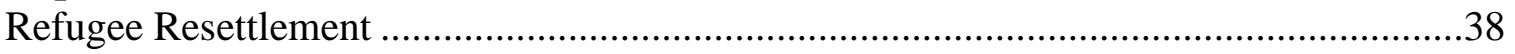

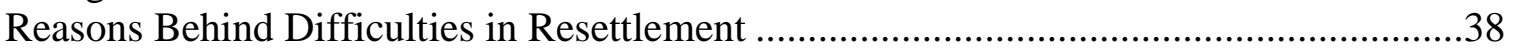

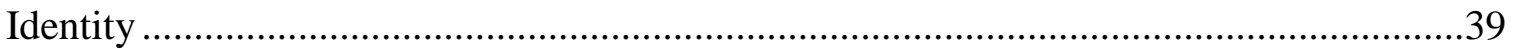

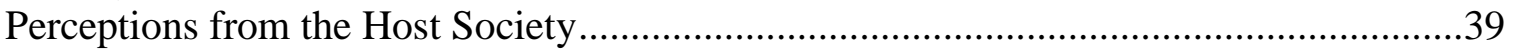

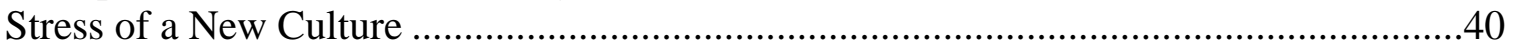

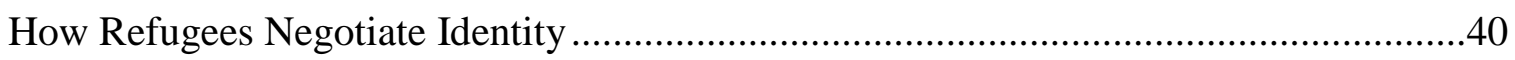

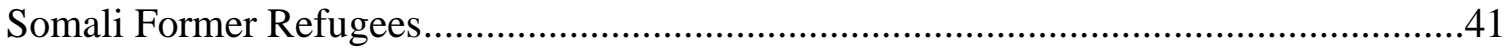

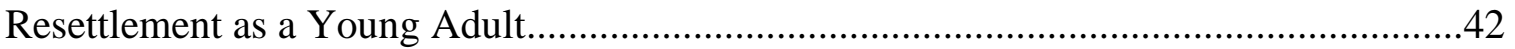

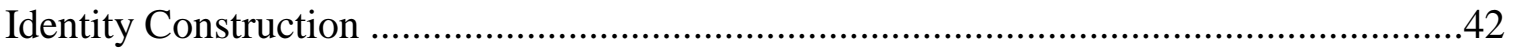

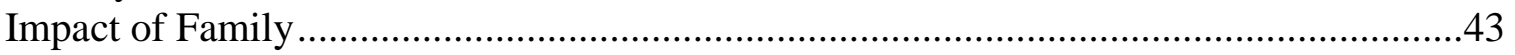

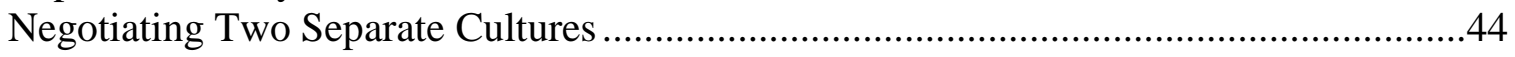

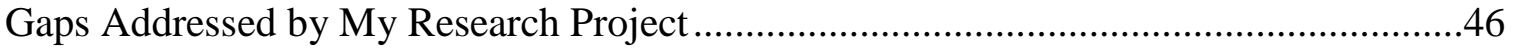

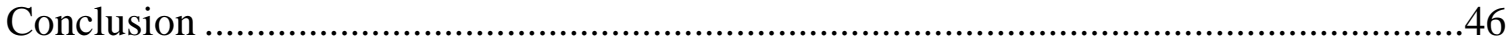


Chapter 4 - Maintaining and Creating Somali Identity in New Zealand ..................48

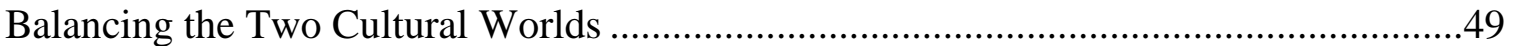

Intergenerational Differences in Maintaining Culture .................................................50

Being a "good” Somali-Kiwi: Reflections on Cultural Roles ........................................53

The Importance of Family for Young Somali Women .............................................55

The Influence of Parental Authority ......................................................................56

Anxiety about the Resettlement of the Older Generation ..............................................58

The Importance of Marriage for Young Somali Women...............................................60

Influences of Religion on Young Somali Women .....................................................62

Experience of Wearing the Headscarf .....................................................................64

Negotiating Gender Differences in the New Zealand Context .....................................67

Handling Kiwi Perceptions of Somali: Being a Somali-Kiwi .......................................69

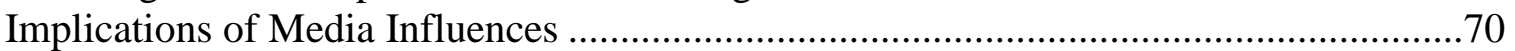

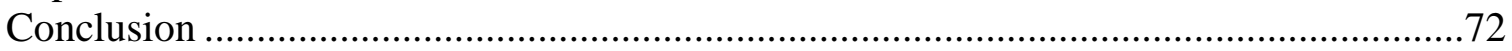

Chapter 5 - Influences on the Resettlement Process for Young Somali Women in

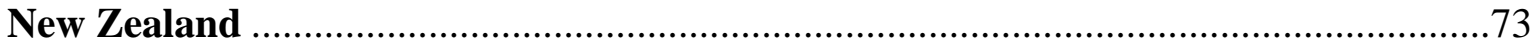

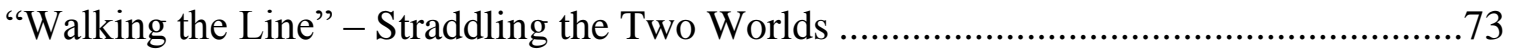

Reflections on the Influence of Cultural Maintenance on Resettlement ..........................74

Negotiating the Realm of Higher Education.............................................................. 75

"You Aren't Good Enough" - Reacting to Negative Comments Given and Cultural

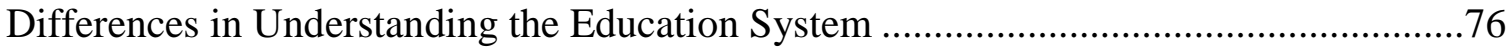

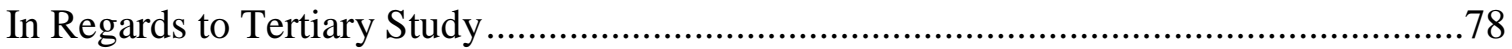

Considering the Transfer of Qualifications from Somalia........................................... 80

Emigration to Australia and its Implications for These Young Somali Women ...............81

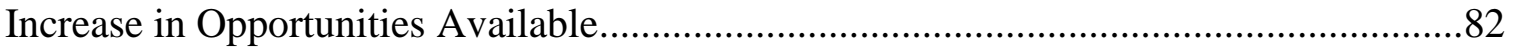

The Effect of Living within a Larger Somali Community ..........................................83

The Implications for New Zealand with the Emigration of Young Somali Women .........86

Their Recommendations for Future Refugees to Help Navigate the Resettlement

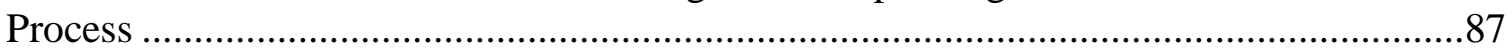

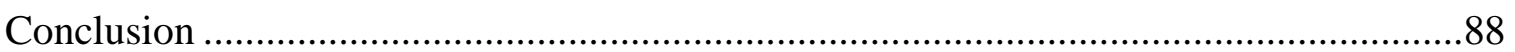

Chapter 6 - Views and Support Provided by Organisations in Wellington to Aid in

Resettlement for Young Somali Women ...............................................................90

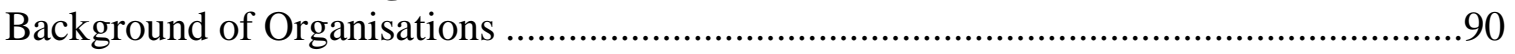

The Resettlement Process of Young Somali Women in New Zealand ...........................93

The Implication of Parental Roles in Regards to Resettlement .....................................93

Commenting on the Difference of Services Between Family Reunification and

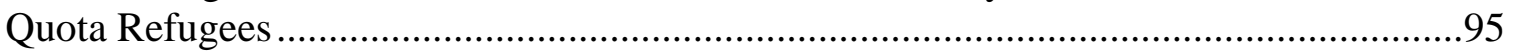

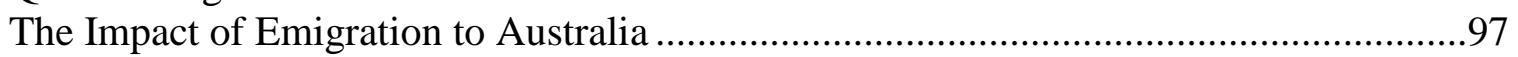

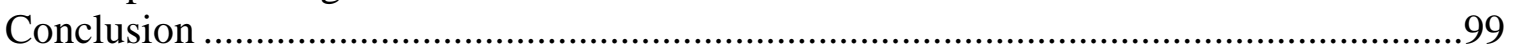

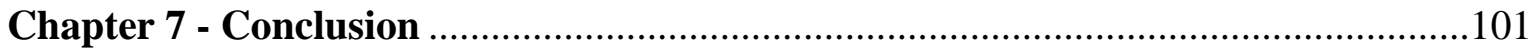

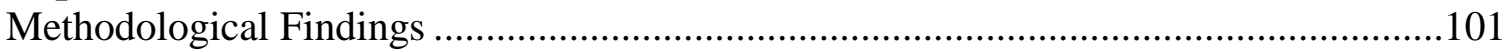

Summary of Findings Regarding Resettlement and Identity Construction ....................103

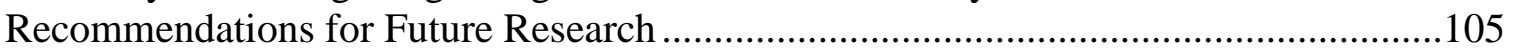

Suggestions to Support Services and Government Agencies ......................................107

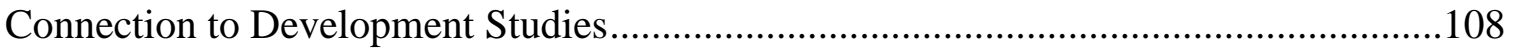

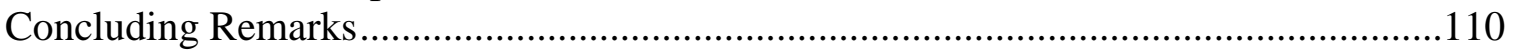




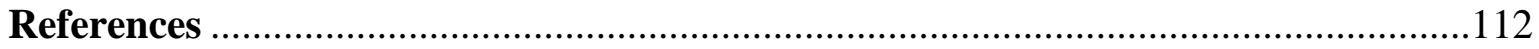

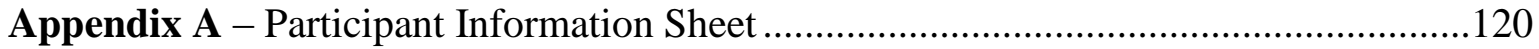

Appendix B - Consent to Participate in Research - Interviews .....................................122

Appendix C - Consent to Participate in Research - Focus Group .................................123

Appendix D - Semi-Structured Interview Script for Young Somali Women..................124

Appendix E - Semi-Structured Interview Script for Key Informants..........................125 


\section{List of Figures}

$\underline{\text { Figure I }}$

Crossing the River Focus Group Activity Photo......................................33 


\section{Chapter 1 - Introduction}

I was first introduced to the Somali community in Wellington through a course at Victoria University of Wellington. In the 2011 GEOG 404 course, we participated in a nationwide study that looked into the decrease in government funding for Refugee Study Grants and the implications it held for refugee-background students' studies. We conducted focus groups and semi-structured interviews with a range of former refugees from different countries and helped create an advocacy paper with ChangeMakers Refugee Forum ${ }^{1}$ and TESOLANZ ${ }^{2}$ to be submitted to the government for review. Through this work, I met amazing individuals who expressed the difficulties in adjusting to New Zealand and attempting to attend university or college with all their other responsibilities.

One focus group I helped to run with another GEOG 404 colleague was comprised of all men. We were worried that we were losing an important component of the community by not having any women in our group, but the participants detailed all the concerns they had for their female relatives and explained the many responsibilities that limited women from participating in our study that day. It was from the experience of that group that I decided I wanted to work with former refugee women and to explore how they experienced resettlement. Through volunteering at the university as well as interviews completed through the GEOG 404 project, I made a few connections with Somali female students and wished to focus on their experiences for my research.

Somali people first began arriving in New Zealand in 1993 and approximately 3,200 Somalis have been granted residency (Beaglehole, 2009). A group of Somali people established the Wellington Somali Council ten years ago to help support former refugees transition into New Zealand society. This transition can be a difficult one at times, especially for the young women in the community as they must handle balancing

\footnotetext{
${ }^{1}$ ChangeMakers is a non-government organisation representing refugee communities in Wellington in advocacy and research. More detail is given in Chapter Six.

${ }^{2}$ TESOLANZ stands for Teachers of English Speakers of Other Languages Aotearoa New Zealand and is a non-profit organisation of teachers and tutors who teach English to speakers of other languages
} 
both cultures. This is exemplified by honouring their religious customs such as wearing their headscarves in a pre-dominantly Christian or secular society.

In this chapter, I introduce my research aim and questions and discuss the way I created, implemented and produced a project with a group of young Somali women in Wellington. I first give the rationale for my research focus on the young women's experiences with resettlement and identity construction. I then introduce the research questions that guided me through my work. I also discuss the different methods and theories that guided my research throughout the entire process. Next, I explain the development of my methodology and how I went about conducting work with the young women. I then set the context for my study by giving a historical background of Somalia as well as the history of the community in Wellington. Finally, I give an overview of the following chapters.

\section{Rationale for My Research}

When deciding what areas to focus on for my research, I wanted to take into account aspects that were most relevant to the young women with whom I hoped I would be working. Since the girls had experienced resettlement first hand and were still feeling its implications, it seemed imperative to look into how this transition impacted their current goals. Resettlement is the process of adjusting into a new society, usually after a period of trauma for refugees (Hermans, 2001; Deepak, 2005). The individuals commonly undergo a great deal of stress in this move including adjusting to a new language, a new way of life and helping their own family navigate through these various differences (Lee, 2001; Fangen, 2006; Zetter, 2007). The resettlement process can dictate how well former refugees adjust into their new society so I thought it was necessary to take this into account when working with my participants.

The young women with whom I was working were at a transitional age in their lives so it was important to take into consideration how they were constructing their identity through this resettlement process. Identity construction can be more important for former refugee youth than other age groups because they tend to take on the cultural 
norms of the host society more quickly than their elders and will then act as a kind of cultural translator for their family (Phinney \& Devich Navarro, 1997; Hedegaard, 2005). Their identity can be impacted by perceptions of the host society, negative labels that are associated with being a refugee as well as the stress of balancing two cultures (Lee, 2001; Wilkinson, 2002; Zetter, 2007). Therefore I felt it was important to hear the experiences from the young women about how they related to their two cultures and how these relationships have impacted on their successes thus far.

Current research on refugee resettlement generally lacks a youth focus and young people are usually incorporated into adult research. There is also a gap in regards to experiences of university age students, as well as little attention to their goals and career paths and their overall resettlement experience (Wilkinson, 2002; Guerin \& Guerin, 2002; Phan, 2003; Gifford et al., 2007). Therefore I thought it would be most beneficial for the community to focus on young women studying at university and to ask positive questions about their educational and career goals in the wider context of their resettlement experiences.

\section{$\underline{\text { Research Aims and Questions }}$}

When I first began constructing this research, I wanted to create a participatory project that would allow the participants a chance to share their experiences of their resettlement process. Since I entered this project as a Development Studies student at Victoria University of Wellington, I first needed to create a project that would be relevant to the development field. Countries that receive refugees understand the importance of successful refugee resettlement for their country (NZIS, 2004). The New Zealand government recognises the importance of former refugees being included in society and feeling safe to express their culture to New Zealand society (NZIS, 2004).

There also tends to be gender inequality in refugee resettlement and power structures that limit women's rights and independence (Weeks \& Schensul, 1993; Kees van Donge, 2006). It is vital, if development projects are to be successful, that women are 
able to increase their self-reliance and change their situations for the better (Parameswaran, 2001; Irwin, 2006; Aziz et al., 2011). Women's success is also important for younger women in the community to succeed which will then aid generations of women to achieve rights and participate in development activities (Reese, 2002; Aziz et al., 2011; Chen \& Sheldon, 2012).

With these ideas in mind, I created three research questions to guide my project. The first question was:

- How does balancing two separate cultures affect the resettlement process for young Somali women?

I believed this question was important and relevant to the girls as they were practicing Muslim women in a secular/Christian society while also growing up in New Zealand. There constant negotiation between cultures was an aspect that was central to their resettlement process so I believed it critical to include in my project.

My second question built from the first:

- How does resettling in New Zealand society influence these young Somali women's self-identities and cultural maintenance?

Since the young women were negotiating two different cultures, I wanted to understand how the young women constructed their self-identities while maintaining their Somali culture in New Zealand society. I theorized that how well the young women could manage this balance could potentially have a huge impact on their perceptions of whether their resettlement had been successful or not.

Finally, since I wanted to relate the study more generally to the field of refugee resettlement, my third question was:

- What can be done in New Zealand to empower female former refugees?

This aspect was important to be able to link my research aims back to the development field. I wanted to finish with practical implications towards enabling former refugee women to be active change agents within their communities. 


\section{Development of my Methodology}

When I first began planning my thesis project, my desire was to engage with young Somali women on research that was meaningful and worked towards positive change. I planned on interacting with the women first through purely ethnographic observation to gain a better understanding of the community and their cultural traits to aid me in planning a culturally appropriate project. I planned to then run a few focus groups that would in turn help me come up with additional questions for the semi-structured interviews to follow. The focus of the research would be on the girls' opinions on their initial resettlement process and how it helped them create their goals for their future education and career paths.

In order to uphold the aims of producing a participatory project that was culturally appropriate, I decided I wanted to work with a Cultural Advisor (CA) that would help me come up with questions and activities that would benefit the young women and help me minimise my role as the facilitator. She has asked to remain anonymous in my research. I was able to find CA through work at the Drop-In Centre at Victoria University of Wellington ${ }^{3}$ who agreed to fill this role. CA was integral in helping me recruit participants and allowing them to feel safe to participate and speak their mind. I discuss our interactions and her contribution to the project further in Chapter 2.

Although I understood I was performing this project with the aims of completing a Masters thesis, I wanted to make sure I was also creating work that was engaging and meaningful for the young women. One idea that arose from conversations was about creating a weekly social group at the university where the girls could introduce aspects of their culture to other students to help bring about more positive perceptions about Somali culture. Due to circumstances that I discuss in greater detail in Chapter 2, this never came to fruition.

\footnotetext{
${ }^{3}$ A tutoring centre at Victoria University of Wellington geared towards helping Refugee-background students.
} 
After undertaking work in the GEOG 404 course mentioned earlier, I decided that a participatory action research approach would also be the best for my own research. PAR is a research approach that uses community-based methods to produce collaborative processes that engage participants (Briggs, 1995; Cahill, 2007; Kindon et al., 2007). PAR tends to focus on the importance of reflection and creating meaningful work by allowing participants to take ownership and by minimising the role of the facilitator (Visweswaran, 1997; Huisman, 2008). I also incorporated a feminist approach since I was working with an exclusively female group and I wanted to focus on the gender specific issues and accomplishments of these young women.

I also identified that Appreciative Inquiry (AI) could be useful. AI was created as a component of action research that focuses on the strengths and values of a group instead of the problems (Bushe, 1995; Reed, 2007; Cram, 2010). The idea is that using a positive approach can allow for the participants to build on accomplishments and become more successful in the future (Reed, 2007). The literature regarding refugee resettlement tends to focus on issues when discussing their situation, so I wanted to engage in research in a different way that documented their goals.

To begin my participatory research, I started by making connections within the Somali community through networking and ethnographic observation. This was an integral part of my research since I was an outsider to the culture and needed to begin building trust with the young women so they would later feel safe enough to discuss possibly sensitive topics. I began by volunteering at the Drop-In Centre at Victoria Univesity of Wellington and made connections at the Wellington Somali Council. I also tutored at the Homework Centre run by the Wellington Somali Council which provided afterschool tutoring for high school aged refugee-background students. I used these connections to later recruit participants for my project. Although the recruitment of participants was a difficult process which I discuss in Chapter 2, I was able to find girls that were willing to sit down with me and tell me their stories, opinions and advice for the future. 
Since I also worked closely with organisations in the community that provide refugee services when I was initially recruiting participants, I developed close connections with some of the employees there and decided it would be helpful to incorporate their experiences and opinions into my work. I performed semi-structured interviews with key informants using questions that grew out of the work with the young women.

\section{Definition of Common Terms Used in the Research}

Through focus groups and interviews with the girls, a few terms arose so often that I have adopted them here. I have chosen to define these terms as the girls themselves used them and use them this way in the thesis.

$\underline{K i w i}$ - A slang word to describe all New Zealanders.

Somali-Kiwi - A way the young women described themselves as belonging to two cultures. The girls saw themselves as coming from Somali descent but also being a citizen of New Zealand and thus a Kiwi as well.

$\underline{\text { Kiwi culture }}$ - The girls used this term to mean a variety of things. Usually it was in reference to the ways that were different from their Somali culture including heavy drinking, pre-dominantly Christian traditions and more gender mixing in social activities.

$\underline{\text { Somali culture }}$ - The young women used this term to explain Somali cultural traits that differed from New Zealand culture including Muslim traditions and holidays, differences in gender activities and certain food and apparel choices.

The Somali family unit - The girls would describe their family in a much looser context than the Western nuclear family. Their family unit would include more than parents and siblings but also aunts and uncles, grandparents, cousins and sometimes even close community members who were not related. This is similar to the 'whanau' in the Maori culture in New Zealand where the family unit is large and includes extended relatives. 
Some of the young women made the connection between these two cultures in Chapter Four.

The Somali community - The girls would reference their "community" meaning Somalis in the Wellington area. This could include Somali people anyone from the Somali culture with whom they interacted, attended the same mosque and participated in holiday festivities.

The terms 'culture' and 'community' were central aspects within this project and for the young women. Although I have given the definitions that the girls used above in ways that imply these things are somewhat static and clearly bounded, I recognize that culture and community are both fluid and evolving processes rather than fixed states. I have therefore complemented the girls' understandings with my own drawn from academic discussions to refer to 'culture' as a type of human capital built of social structures, identities and values that make up a group of people (Deepak, 2005; Hedegaard, 2005; Radcliffe, 2006; Liev, 2008). I also recognize that culture is something that is a component of every individual life, regardless of a person's political or economic situation (Radcliffe, 2006). Maintenance of culture is not only a relevant dimension of refugee resettlement, but the overall development field as well. For development practitioners, culture is crucial to integrate into development projects especially when there is a push for action towards positive social changes (Radcliffe, 2006).

Similar to 'culture', 'community' is a term that can have different definitions. In a broad sense, the word is about people being bound together due to a combination of shared traits or identities, such as religion, language, race or ethnicity (Dona \& Muggeridge, 2006; Liev, 2008). For refugee communities, there is usually a sense of a shared experience through the trauma and resettlement they have experienced and a desire to maintain identities and cultural values of their native country (Hermans, 2001; Deepak, 2005; Liev, 2008) This dimension was evident for the Somali community as they bonded over the experiences they had had as well as the desire to share their Islamic religion and maintain their cultural traditions. 


\section{The Somali Context}

\section{History of Somalia}

The country of Somalia is located on the Horn of Africa in the east, bordering the Indian Ocean and the Gulf of Aden (CIA Factbook, 2013; WSC, 2013). An influx of Muslim Arabs and Persians immigrated to the country around the $5^{\text {th }}$ century as the port boomed as a trading centre for the area (Metz, 1992; WSC, 2013). These traders are the most likely reason Islam was introduced into the area, however the main conversion occurred between the $11^{\text {th }}-13^{\text {th }}$ centuries (Metz, 1992). Somalia became a very successful trading port until the nineteenth century when European powers including Britain, France, Italy and Portugal began to colonise parts of the country (Metz, 1992; WSC, 2013). This process separated the country into different imperial states such as British Somaliland, French Somaliland, etc. (Metz, 1992). It was in this period that Somalia's first nationalist party, the Somali Youth League (SYL), was formed. This party played an integral part in leading the country to independence and on July $1^{\text {st }} 1960$ the nation became known as the Somali republic (Metz, 1992; CIA Factbook, 2013; WSC, 2013).

The country had a civilian government from 1960-1967 starting with the first president Aden Abdulle Osman yet there were issues with the north and the south parts of the country having different institutional views left over from the imperial days (Metz, 1992; WSC, 2013). In 1969, President Abdirashid Ali Sharmake was assassinated and a coup headed by Mohamed Siyad Barre began an authoritarian, revolutionary regime and changed the country's name to the Somali Democratic Republic (CIA Factbook, 2013; WSC, 2013). In 1977, Somalia invaded the Ogaden region of Ethiopia as Somali rebels were seeking independence and this continued until 1978 (Metz, 1992; WSC, 2013).

Siyad Barre's regime collapsed in 1991 and Somalia began its descent into anarchy (WSC, 2013). Civil war between different factions along with a horrendous drought brought a huge loss of Somali lives (WSC, 2013). In 2000, an interim government was implemented called the Transitional National Government (TNG) to bring order to the country (USCRIF, 2009; CIA Factbook, 2013). However, the TNG failed to bring about 
positive change and the UN intervened, holding a peace conference in 2005 to elect a new president (USCRIF, 2009; WSC, 2013). In 2006, the Union of Islamic Courts (UIC) arose to try and establish order, yet fell victim to radical faction influence (USCRIF, 2009; CIA Factbook, 2013). TFG and Ethiopian forces attempted to defeat the UIC which resulted in the organization developing into several groups, including the al-Shabaab which holds links to al-Qaeda (USCRIF, 2009). In 2009, the last of the Ethiopian forces left the country and President Sheikh Shariif Sheikh Ahmed was elected, a member of the moderate wing of UIC (USCRIF, 2009; WSC, 2013).

In Somalia, there exists a tribal system usually composed of people that share a common ancestry (CIA Factbook, 2013). The four tribes are named Darod, Dir, Hawiye and Isaaq and these are important social units in Somalia that often act politically (GBPU, 2001). These alliances are very important to the Somali people and can dictate marriages and who can interact with whom (GBPU, 2001). These alliances were recognised in Wellington and dictated who would participate in my project.

The current political situation in Somalia stands uncertain as they are in the process of building a federated parliamentary republic yet Sheik Shariff doesn't have enough international support to deal with the Islamic extremists in the country (CIA Factbook, 2013; WSC, 2013). The TFG decided to institute a political transition by August of 2012 and held elections in September 2012 with the new president becoming Hassan Sheikh Mahamud (CIA Factbook, 2013).

\section{$\underline{\text { Somalis in New Zealand }}$}

Due to a combination of civil war, famine and fighting between al-Shabaab and TGF, there have been approximately 1.1 million Internationally Displaced People including refugees which make Somalis the largest displaced population in the world (Waikato News, 2008; CIA Factbook, 2013). New Zealand is an interesting country in which to observe a specific refugee community resettling, as they are have one of the highest rates of refugee acceptance in the world proportionate to size of host population (Refugee Services NZ, 2009). In regards to Somalis in New Zealand, Somalis began 
arriving in the early 1990's and 1,500 refugees have arrived through the quota programme and the rest through family reunification (Beaglehole, 2009). The numbers of Somali refugees have decreased in the past decade as they are no longer arriving through the quota programme. Since 2000, 461 Somalis have arrived through the family reunification process (Immigration NZ, 2012).

There Somali presence in the Wellington community is shown through the various support services and organizations that exist in the area. The Wellington Somali Council was established in 2003 due to the large demand from the Somali community for an organisation that caters to their specific needs (WSC, 2013). The organisation was started and run by Somalis and currently still has Somalis holding positions on their Board. The Wellington Somali Council provides a great deal of support to the community including tutoring for students, classes and support groups for women and aid in dealing with government organisations such as Work \& Income. In addition, the Somali community plays a large role within the ChangeMakers Refugee Forum which is a non-governmental organisation that represents a variety of refugee communities in Wellington to aid in advocacy, research and community development.

\section{Thesis Structure}

\section{Chapter Two - Research Approach and Methods}

In my Research Approach and Methods chapter, I give an overview of the methodologies that guided my project. I discuss in detail the desire I had to implement a Feminist Participatory Action project with my participants and the benefits and challenges of pursuing that type of work. I also discuss the activities and types of work I did with the girls and how my methodologies influenced and produced these choices. 


\section{Chapter Three - Literature Review}

I synthesise key aspects of refugee resettlement literature, specifically for former refugee youth. I focus on how the research describes former refugee youth negotiating the process of resettlement including the concept of "switching" between cultures, reconstructing their identity in the new host society and the impact of their family on their school and career choices. I identify some gaps from the literature that my research attempts to address.

\section{Chapter Four - Maintaining and Creating Somali Identity in New Zealand}

For the first of my Findings chapters, I focus on how the young Somali women I worked with went about creating their identities in relation to both Somali and New Zealand cultures. I discuss the ways in which each girl handled this balance of cultures and the impacts that it had on their overall perception of inclusion into Kiwi culture.

I then go on to discuss other important factors that dictated the way the young women handled creating and maintaining an identity which took into account aspects of both Somali and Kiwi cultures. Familial relations played a huge role for the girls as the Somali culture puts a large emphasis on the importance of family in every aspect of their lives. The young women found it difficult at times to deal with the balancing act between attempting to fit into Kiwi culture as well as appeasing their parents and respecting their religious traditions that could limit them from certain Kiwi activities. The girls also went into great detail explaining the importance of wearing the headscarf for their religion and the implications and perceptions that arose from them wearing it in New Zealand society.

\section{Chapter Five - Influences on the Resettlement Process for Young Somali Women in}

\section{New Zealand}

In my next Findings chapter, I focus on the resettlement process for the young women and the aspects that help or hinder this transition. The first discussion looks at the girls' opinions and experiences navigating their way through tertiary study and they advice on making the process more culturally sensitive and encouraging for former refugees. 
I also focus on the concern and responsibility the young women feel for elders in their community and how their future goals reflect this desire to help their community. The young women felt concern especially for their mothers and came up with ideas on how to transfer their work qualifications from Somalia over to New Zealand to help them work and succeed again. The young women had a great deal of recommendations to help future refugees transition more easily into a new society and this revealed the maturity and reverence the young women held for their community.

Finally, in this chapter I reveal a topic that arose that was unforeseen and not mentioned in any of the literature. The young women explained how their community was experiencing a huge emigration to Australia to search for better job opportunities. Every participant was heading there at some point and every girl mentioned knowing a family member that already lived there. There wasn't a desire to leave New Zealand explicitly by the young women, but a necessity to find the best job opportunities and connection to a bigger Somali community in order to reach their goals and help their families.

Chapter Six - Views and Support Provided by Organisations in Wellington to Aid in $\underline{\text { Resettlement for Young Somali Women }}$

In my final Findings chapter, I attempt to round out the girls' narratives by interviewing key informants from organisations in Wellington that conduct services for former refugees. These employees discussed their experiences working with refugees through the resettlement process and their opinions on what helped in this process. The key informants echoed the sentiments of the young Somali women in explaining how the impact of the family, especially the success of the mother, had a huge influence on how well the girls would adjust into society. They were also able to give a different perspective on the policy side of resettlement including the difference in family reunification benefits and how the Australian emigration was impacting their organisations as well as the Somali community in Wellington. 


\section{Chapter Seven - Conclusion}

In my concluding chapter, I review and summarise the findings that arose of my work. I first review my methodological findings and how using these approaches benefited my project and my participants. I then discuss my findings in reference to my research aims and questions regarding balancing two cultures, identity construction and the young women's overall resettlement experience. I then give recommendations for future research that would be beneficial for overall refugee resettlement as well as suggestions to improve support services and government aid for refugees in Wellington and the connection back to the field of international development. Finally, I give my concluding remarks for my project. 


\section{Chapter 2 - Research Approach and Methods}

In this chapter I explain the methodologies with which I entered the research as well as the ones that arose out of the work. I first discuss the benefits of choosing a Participatory Action Approach, as well as the feminist and Appreciative Inquiry elements I explored throughout my research. I also disclose the way I went about generating data as well as the thematic analysis I employed. Finally I discuss limitations and aspects of representations that were used throughout my entire project.

\section{Qualitative Research}

\section{Methodologies}

Qualitative Research differs from Quantitative Research by steering away from focusing on statistics and focusing on the context with which the data is formed and collected (Reed, 2007). This approach acknowledges the importance of the research as both a creator and a result of the interactions between participants and the settings with which they are formed (Reed, 2007; Inhetveen, 2012). Stories, opinions and ideas cultivated in a social setting are the important factors in this type of work. I found it relevant for my study to focus on the stories, opinions and the contexts with which my data was collected from the young women rather than statistics about them. This type of research was also more consistent with my aim of conducting meaningful and respectful work which treated the young women as subjects of the research process.

\section{Participatory Action Research (PAR)}

PAR seeks to create change through collaborative and reflective action and analysis (Cahill, 2007; Kindon et al., 2007; Huisman, 2008). It uses methods that engage members of a community in a cyclical process of research, action and reflection, emphasising collaboration between researchers and participants (Briggs, 1995; BrydonMiller et al., 2003; Rew \& Rew, 2003; Kindon et al., 2007; Huisman, 2008). The aim is to investigate an issue relevant to the participants and work with them to change it for 
the better (Kindon et al., 2007; Huisman, 2008). PAR includes minimising the role of the facilitator to enable participant ownership of the project and to generate information developed in a meaningful and honest way (Visweswaran, 1997; Cahill, 2007; Aziz et al., 2011). Participation is the vital component in this methodology and means there is "a political commitment, collaborative processes and participatory worldview" (Kindon et al, 2007: 11).

\section{Feminist Participatory Action Research (FPAR)}

Feminist research has arisen due to the acknowledgment that there is persistent gender inequality in the world and women are an important group that do not always have the same access to rights or tools with which to make changes as men (Stacy, 1988; Parameswaran, 2001; Aziz et al., 2011). This is an important addition to this field of research as PAR is not always gender aware and can limit change for communities. Feminist participatory methods attempt to utilise principles that are not always available in other research areas such as self-reflection, reciprocity and activism which work to help marginalized groups (Taylor, 1998; Huisman, 2008).

This type of work can be beneficial because it enables participants to provide in-depth knowledge often left out of research (Kees van Donge, 2006). Frequently in development projects, only the powerful and/or male voices are heard which leaves out a huge component of the community. Taylor (1998) surmises that what comprises feminist methodology is an emphasis on gender, employing participatory methods, creating social action and a focus on women's experiences. And it is not just gathering data from women that makes it a feminist approach, but it is the process through which the women and the researcher journey together (Sharp, 2005; Huisman, 2008). Research should not be about studying women but about creating a study with women (Taylor, 1998; Irwin, 2006).

With Feminist PAR, the community tends to be comprised of a group of women and the researcher works toward social change and empowerment with them (Brydon-Miller et 
al., 2003; Huisman, 2008; Aziz et al., 2011). It is a collaboration that takes into account the women's histories and practices (Visweswaran, 1997; Cahill, 2007 Aziz et al., 2011). If the decisions and ideas come from within the community, the hope is that there will be increased participation to make sustainable change. The approach assumes that participants will be the most knowledgeable about their own lives and problems and will have a unique viewpoint that is vital in making decisions (Gibbon, 2002). Through PAR and Feminist PAR, researchers strive to honour those with whom they work and make the whole process beneficial and comfortable for all involved (Gatenby \& Humphries, 2000).

I chose to use a FPAR approach for a few reasons. The aim of my research was to not only immerse myself within the Somali community in Wellington and learn about Somali refugee-background women, but also to create an activity or project developed by this community. Since these women came from a refugee background, I thought using an approach that attempted to be culturally sensitive and respectful of personal interactions would be best (Parameswaran, 2001, Cahill, 2007). Since the research might encroach on sensitive topics and discussions, I wanted to make sure that every girl felt safe and able to present her opinions honestly and respectfully (Gatenby \& Humphries, 2000; Aziz et al., 2011).

\section{$\underline{\text { Appreciative Inquiry (AI) }}$}

Although I felt that a FPAR was the best fit for my epistemological orientation, I integrated aspects of Appreciative Inquiry (AI) when writing my questions for focus groups and interviews to ask questions in a positive way. This would allow participants to build on what has worked in the past rather than focus on the negative aspects of change in their communities (Reed, 2007).

Appreciative Inquiry was created as a reconfiguration of action research by David Cooperrider to move away from problem-solving and into appreciating strengths and values of an organization or community (Reed, 2007; Cram, 2010). Instead of creating 
questions that are negative or focus on the problems of an organization, AI asks positive questions about what works in the community and how to build on these to create more successful outcomes (Bushe, 1995; Reed, 2007; Cram, 2010). When people focus on the negative, the negative is often perpetuated and problems can occur. But if one focuses on what aids success, then one opens up room for possibilities and positive outlooks (Cooperrider \& Barrett, 1990; Whitney, 1998; Reed, 2007). Both PAR and AI have an emphasis on developing an understanding of the communities function and in investigating dynamics of power, but PAR has a problem-solving focus while AI attempts to document and foster solutions and successes (Reed, 2007).

Despite the wider research fatigue facing the Somali community, this AI orientation introduced a new way of embarking on projects and excited the participants. Resettlement research tends to focus on issues and challenges that are occurring and although these are important, I thought that it might be refreshing to look at the positive aspects of resettling in New Zealand and leave the girls feeling hopeful for their future as a result of their participation in my research.

During the process of creating and asking research questions, I made sure to use the guidelines of Appreciative Inquiry. Appreciative Inquiry has two different processes, the 4-D and 4-I cycle. I chose to use the 4-D cycle as a guideline for my research. The 4-D cycle has four phases: Discovery, Dreaming, Designing and Delivery (Whitney, 1998; Reed, 2007).

The Discovery phase is about finding out more about the organization or community and appreciating what gives it life. This was the ethnographic component of my research where I worked with the Wellington Somali Council and the Drop-In Centre at Victoria University to make connections within the Somali community and learn about the culture.

The second phase is the Dreaming phase where ideas are developed by a researcher with community members to envision the future. This was integral in the beginning 
conversations of the focus groups when I asked the girls about what they considered successful resettlement to be and how they viewed their futures.

The Designing phase is all about envisioning ideas for the future. This informed the activities I developed in the focus groups and helped to inform the design of the questions in in-depth interviews. The final stage is the Delivery phase in which the planning for action occurs. I had hoped to create a project with the girls to provide the tools for them to perform an activity or project on their own using the data we collected together in the future. Due to a variety of reasons which I discuss later, this did not eventuate.

A concern associated with AI is that by focusing on the positive, the researcher may avoid discussing issues or problems that plague the participants. The purpose of AI is not to avoid issues, but to build on successes to empower participants (Reed, 2007). When people focus on problems or negative aspects of the organization, they can become defensive and have a feeling of hopelessness (Cooperrider \& Barrett, 1990; Whitney, 1998). Yet when the focus is on the positive, research has found that participants are more likely to open up and be more receptive to creating change become more successful in problem solving (Reed, 2007). Conversations about problems can still arise, but they can be easier to handle or resolved when discussed with an appreciative stance (Patton, 2003). And research shows that people who have a positive outlook are more open-minded and motivated to action (Bushe, 2007).

\section{Participants}

My participants consisted of young Somali women and key representatives in organisations that help with refugee resettlement in Wellington. The Somali women were aged between 19-26 and were all currently or just recently attending university in Wellington. Every young woman had between 2-4 siblings and varied between being the eldest and youngest in their families. They had all arrived in New Zealand between 7-12 years of age; half of them had arrived through the quota programme and the other 
half had come through family reunification. All the girls were completely fluent in English and there was no need for an interpreter. My CA was on hand to help with recruitment of the girls and to allow them to feel safe and to make sure I was culturally appropriate.

The other participants were employees at organisations that helped with refugees in Wellington such as Refugee Services and the Wellington Somali Council. I interviewed five key representatives who had worked for their respective organisations for between 2-8 years. Two were Somali themselves and were able to give views on the resettlement process both from a personal as well as a professional perspective. All the interviews were held at their offices in each organisation.

\section{Data Generation}

\section{Ethnographic Observation}

To build an understanding of the Somali community and culture in Wellington before partaking in my research, I decided to conduct ethnographic observation, specifically feminist ethnography. Feminist ethnography can be a useful approach when working with groups from different cultural backgrounds as it gives the researcher a way to learn and immerse themselves in the community before attempting action (Stacey, 1988; Parameswaran, 2001). Observations gained from ethnographic work should be used to uncover women's experiences and perspectives so that research plans and projects can be beneficial and culturally appropriate for the group (Parameswaran, 2001; Richie, 2004; Huisman, 2008). Although it is important to create a safe space for women to share, there should also be an attempt to create positive social change (Gatenby \& Humphries, 2000).

For the first six months of my research, I carried out ethnographic observation and attempted to build relationships within the Somali community. I spent about 150 hours 
during that period tutoring at the Homework Centre run by the Wellington Somali Council in Newtown and the Drop-In Centre at Victoria University of Wellington. When I first arrived, I alerted the Council to my future plans for my thesis project, but focused more on making connections with the girls and listening to them talk about their culture and home life. This was also how I came to meet CA and began talking with her about my intended project and my need for a Cultural Advisor. She quickly became interested and we worked from then on.

When I started recruiting participants, we would meet regularly for coffee or for study sessions before I began conducting the focus group or interviews. I wanted to get to a point where when we reached our interview stage, it wouldn't be a daunting task and it may feel like more friends conversing than a formal affair. I refrained from taking field notes unless I had explicitly described my project to the girls and asked their permission. But the main purpose of this initial observation was to immerse myself within the community and to gain a better understanding of Somali culture and network.

Throughout the process, I kept a field diary to record all my thoughts, observations and ideas for my research. Immersing myself within the community and conducting participant observation here was critical to the success of my project as it alerted me to components of the Somali culture that would be helpful to my research. I learned about the tribal linkages in the community and how to negotiate that respectfully when recruiting participants. I came to understand the various holidays and religious traditions that I would need to be aware of when scheduling interviews and focus groups. This process allowed me to make key contacts within the community that led to me meeting my future participants.

The Somali community still holds to their tribal linkages held back in Africa to some extent so I had to make sure by bringing young women to work together I wasn't encroaching on those boundaries. I also had to make sure that their parents, especially their fathers, approved of the work I was doing. Although all the young women were adults in the eyes of New Zealand legislation, they still had to follow the rules of the 
men in their households. I did not have to get formal parental permission for my research as all my participants were over the age of 18 , but I did want to make sure that parents felt comfortable with the work I was doing. I often had to present additional information to their parents or speak with them to explain the purpose of my work with their daughters or nieces.

\section{Working with a Cultural Advisor}

As mentioned above, I employed one young woman as a Cultural Advisor to advise me on how to work with the women in ways that would benefit them and make them feel comfortable. I started the relationship with CA by slowly explaining to her my project while tutoring her and helping her outside the Drop-In Centre with her work. I wanted to make the relationship mutually beneficial and gain her trust before asking her to assist me.

CA lent me credibility within the Somali community and allowed me to network with key contacts. Although I was aware that working with only one advisor could cause some bias, it was not feasible with the time constraints of my work to try and find additional advisors for this project. We worked collaboratively to develop the focus groups and the interview questions. CA and I came up with only a slight structure to the script as these were to be semi-structured interviews and we wanted flexibility in order to discuss various topics as the conversations developed with the young Somali women. We focused on three main topics with the girls. The first was resettlement in New Zealand including what they experienced or their families experienced when they arrived here and what services they took advantage of while making that transition. Second, we discussed cultural maintenance and why the girls felt it was important and in what ways they balanced their two cultures. Finally, we talked about their recommendations to improve refugee resettlement in the future and for Somalis in their community at present. 


\section{$\underline{\text { Focus Groups }}$}

My initial plan was to hold a series of three focus groups with a group of 6-8 girls. This number seemed appropriate following the advice given in PAR literature about using smaller groups to allow more ability to share and hear everyone's perspective (Visweswaran, 1997; Aziz et al., 2011).) CA and I had met numerous times to plan out the schedule for each session and who would be interested in participating. The first session was going to be an informal session where I would further detail the point of the project and play some ice breaker games to get the girls comfortable with me. I would also allow them to ask questions and get more input on the way the next few sessions would go.

The second session would involve an interactive activity that CA and I had agreed upon. This was an activity I had done before in workshops with refugee-background students in the GEOG 404 course mentioned in Chapter One, and I laid out this activity along with a few other participatory activities for CA to choose from; this was the one she liked best. I thought that I would explain the instructions to the girls and facilitate throughout, but attempt to make this run by the girls as much as possible. This activity is detailed in the next section.

Finally the third activity would be a wrap-up and final discussion. We would discuss the themes that arose from the activity in the previous session and talk about possible questions to use for the interviews that would follow. Again, I would want this to be run mostly by the girls and I would facilitate.

However, it took a very long time to obtain University Ethics Approval, so CA and I began to lose participants and the focus groups did not go as planned. In addition, my thesis deadline was looming and CA had made sudden plans to move to Australia, so we had to change our game plan. We decided to run one focus group that would involve all aspects of the three sessions we had planned with a focus on the activity. The group turned out to only have three girls instead of the expected six, but we were able to 
complete the Crossing the River activity and get a basis of things to discuss in the interviews.

\section{Focus Group Activity - Crossing the River}

A large sheet of paper was laid out with two river banks drawn on it. Each participant was given a range of pieces of paper varying in shapes and colours. The girls were asked to write their name on one of the pieces of paper and lay it at one riverbank. Next, they were asked to write down a goal they have in their lives (could range from school related, to future career, to something they wish to accomplish, etc.) and put it down at the opposite riverbank. The facilitator then explained that the aim of the activity is to "cross" the river by using "stepping stones" to get to their future goals. These stepping stones were created by the participants on a number of pieces of paper and the participants wrote down things that will help them reach their goals. Next, participants were introduced to the "crocodiles" and they wrote down things that hinder or limit reaching their goals. Once everyone finished, the group looked for common themes between everyone's answers and discussed why these things help and hinder reaching their goals.

Participants were then given the option to create "bridges" over the "crocodiles". The group brainstormed and came up with solutions for each other's "crocodiles" and created ways to get over these obstacles that hinder them reaching their goals. This allowed the group to end on a positive note and focused on strengths and constructive outcomes that enhanced a sense of empowerment and activism.

I did this activity with the girls and it appeared to go over very well. We performed all the elements and would pause between if they young women wished to discuss or talk to each other about their responses. I then met with CA after to discuss our opinions and interpretations of what occurred and what we should pull out as relevant and important. We then composed interview questions from the themes that arose in the conversations in the focus group. 


\section{$\underline{\text { Individual Interviews }}$}

I completed semi-structured interviews with five Somali women first and then with five key representatives from the organisations in Wellington. I held all the interviews with the girls on Victoria University campus per their request. Throughout the process, I kept a field diary to record interactions, questions I had for the young women later and my thoughts on the activities we would perform. Before each interview, I explained the aim of the project and went over the consent form to get their informed consent. I tape recorded each interview, again with the consent of each participant. We started with the interview script and then digressed into a conversation as the young women began getting comfortable and talking about things they thought were relevant. As the process

progressed and with input of CA, I refined my questions to focus in on what the young women wanted to talk about.

I then interviewed five representatives from support organisations in Wellington. I drafted up a script using themes that had arisen with interviews from the young women with the help of my supervisor, Dr Sara Kindon. I followed the same procedures with the girls by explaining the project, gaining consent and taping each interview. I went to the office of each interviewee to make it as easy as possible for each participant. I then complied all of these interviews to transcribe and analyse further. I started by discussing the backgrounds of their organisations and their roles in each. Then I moved into the services they provided for refugees and specifically young Somali women. Finally I asked them to discuss their views on refugee resettlement as well as their recommendations and future plans to help make the resettlement process easier for refugees.

\section{Methods of Analysis}

Thematic analysis identifies patterned responses or themes from the data collected and organises it in a meaningful way (Braun \& Clarke, 2006). It is a flexible approach which focused more on common themes from all the participants rather than individual 
opinions (Miller et al., 2003). I pulled out themes that arose frequently in the focus group and each interview, and then ran them by CA to see if she agreed. We worked together to find the most common points that were brought up and organize them in ways that CA and I thought made sense. I hoped to increase the validity of my interpretation by constantly asking for input of my analysis from the participants and especially consistent support from CA.

Using thematic analysis in this approach allowed for me to analyse my variety of data, including visual representations from the focus groups. When the girls had performed the Crossing the River activity, they put all their 'stones' and 'crocodiles' into themes they created. We then discusses together what these themes meant, why they thought they reached similar conclusions on topics and ways this reflected their resettlement experience (see Figure I) I took photographs of the material and CA and I then used this to material to create the interview questions.

Figure I

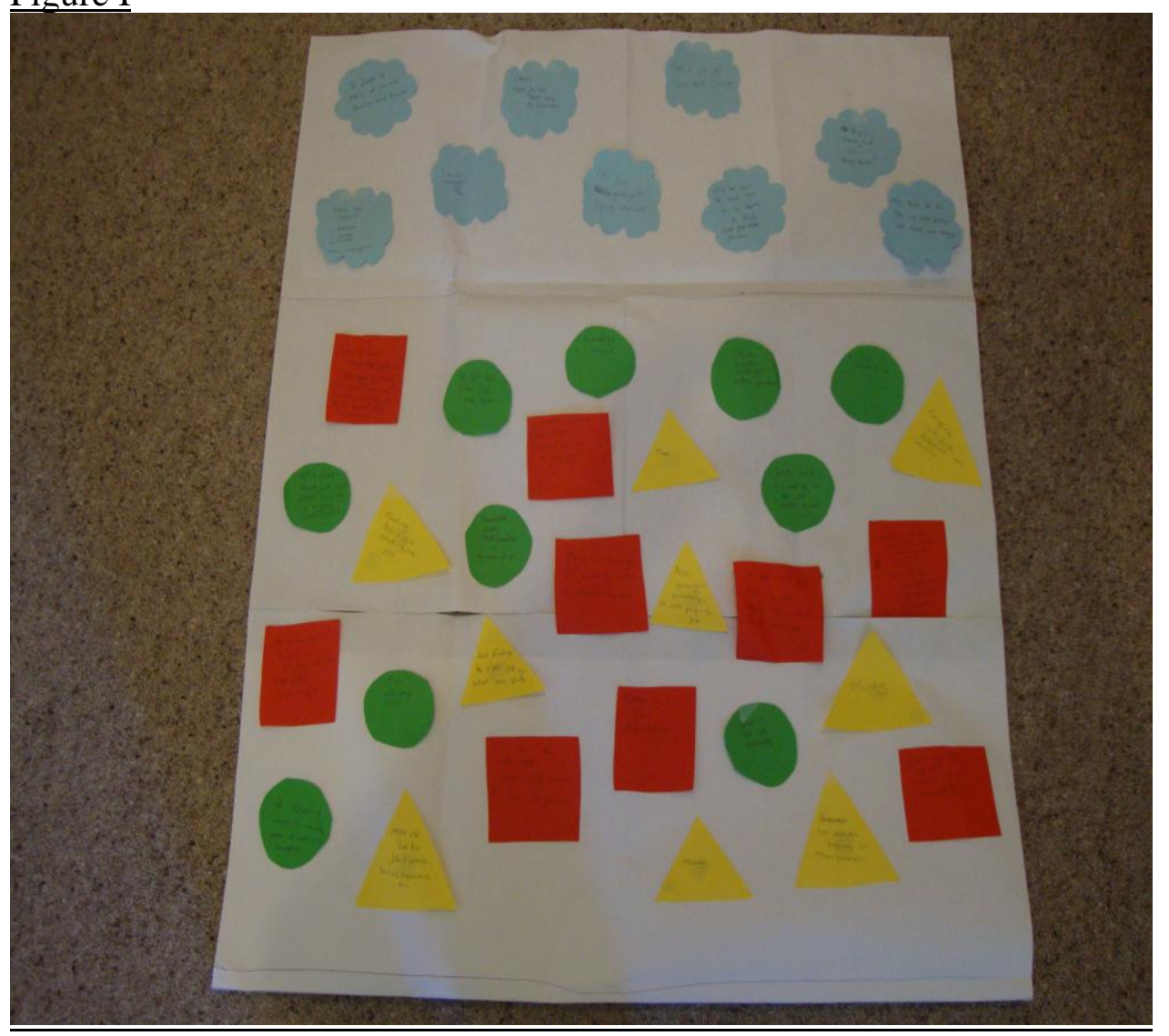




\section{Limitations and Issues of Representation}

\section{$\underline{\text { Limitations }}$}

As I attempted to embark on and produce a participatory approach with the young women, I encountered some limitations and challenges which changed the course of my project and the activities I hoped to complete.

The first challenge that arose was in regards to ethics approval at the university. Ethics approval took a great deal longer than I anticipated due to the fact that I was not able to explicitly detail the questions I would ask as I wanted CA and the girls to pick and decide what they wanted to discuss with me. By the time I had obtained permission from the University to conduct my research, most of the girls had taken on other obligations or no longer held interest. CA was able to get some new girls interested, but we both had to start over in recruiting. It was also right at the beginning of Ramadan which limited a great deal of enthusiasm from the girls. If I did not have such limiting time constraints in order to finish my thesis, I would have attempted to plan a time that was more convenient for the girls. The implications with working with a fewer number of participants could mean that my work shows less of the opinion of the whole Somali community, but I believe it also allowed me to create more in-depth conversations with the few participants I had which may not have been possible with a larger group.

I also faced some difficulties attempting a participatory approach with the young women. Often, the young women just wanted me to ask them questions and it was only after I had time to get to know them better and allow them to understand my project more fully would they want to come up with questions and take charge of the discussion. This was an issue also found in a study done with young Assyrian women in Wellington where they were happy to participate but preferred the facilitator to come up with the questions (Collie et al., 2010). This research also found that it takes time to build trust with the participants in order for real opinions of the participants to become apparent (Collie et al., 2010). If I had had more time, I would have liked to enable the girls to slowly build the project from the start. But this would have entailed a great deal 
more time than a Masters project provided. While encountering some of these limitations throughout the project, I would keep in mind suggestions from the various methodologies on how to be flexible on these occurrences.

In light of the preceding discussion of methodology, I think it is important to detail my own personal background and worldview since they had a large impact on how I interacted with the Wellington Somali community, the people involved in this project and the decisions I made throughout my research. I am a 25 year old American woman who came to New Zealand in 2011 to study. Although Kiwi culture is not a far stretch from my own, I did go through a period of adjustment and slight culture shock in my first few months here. While I understand my situation greatly differed from those of the refugee-background students with whom I worked, our relative 'outsiderness' meant that we were able to converse about New Zealand society and culture in a way that someone born here may not have been able to do.

I felt that the fact that I was an outsider to the Somali culture was also an advantage with the the young women as it allowed me the ability to ask questions they may not have asked each other. It also helped the young women to feel comfortable discussing and reflecting on their own culture with someone who was not a part of it. Therefore, the young women were able to discuss aspects of both cultures with me openly without worry of judgment. However, there were still subjects that the girls did not always feel comfortable discussing. The young women were aware of the stereotypes associated with Muslims as well as Somali people, so they were always sure to steer away from going into too much depth about gender roles, men of the household and association with Muslims and terrorism. Although they wished to fully participate in the study and help, the young women's first priority is protecting the reputation of their community and family members.

While analysing the data and writing up this thesis, I did encounter some issues of how to best represent the young women and key informants who participated in my study. As I was employing AI elements, I tried to keep the focus on the strengths and 
accomplishments of the girls. It was difficult at times though to come up with questions that were strength-based, as well as to handle conversations that took a negative direction. I wanted the girls to feel comfortable to share difficult experiences with me, but to not let them define the project.

I also had to navigate through how to best represent the participants in the thesis itself. When referring to the young women in reference to their 'refugee' label, I thought it was best to use 'former refugee' as it does not define the girls as refugee forever as they have now resettled. Also at times I would use 'refugee-background students' as this was term the students in the GEOG 404 project used and is a term common in the academic side of refugee resettlement. When using quotes, I had already discussed with the girls as part of the confidentiality agreement we made that their names would not be used. I wanted to use different names or reference something that was important to the girls, but as an outsider to the culture I did not feel comfortable making this decision without input from CA She made the decision that using Participant A, Participant B and then shortening this to PA, PB, would suffice. I used the same for key informants as Key Informant A and then shortened to KIA. I also gave her the name of Cultural Advisor, shortened to CA, to specify her role.

\section{Conclusion}

Because I wanted to create a meaningful and collaborative project with young Somali women, it was critical to find appropriate methodologies. Taking into account my background, Participatory Action Research, especially FPAR, was the best choice in order to create respectful, culturally appropriate and empowering work with the girls. Integrating aspects of Appreciative Inquiry was also imperative as most of the past research regarding refugee resettlement focused on negative aspects of experiences,

problems and the challenges faced by former refugees rather than on empowering successes and vitality. I faced a great deal of challenges and obstacles employing these approaches, but the depth of reflections it generated shows the power of these methods. Utlising these approaches along with the narratives the young women provide give new 
insights into the realm of resettlement and women's empowerment. Now that I have explained my various methods and approaches to ensure an appropriate project, I will next review the literature that is relevant to my research. 


\section{Chapter 3 - Literature Review}

Former refugees arriving in a new society and culture have a great deal to acclimatise to after a period of trauma during (their) relocation (Hermans, 2001; Deepak, 2005). This means there is a period of adjustment as they attempt to navigate through a new society, learn a new language and help their family get used to their new surroundings (Fangen, 2006). During this transitional period, dilemmas around identity construction emerge as former refugees attempt to handle their difference from the host society while attempting to belong (Lee, 2001; Deepak, 2005). A former refugee's identity is also impacted by the perceptions of people in the host society and their own internalisation of the label "refugee" or "outsider" (Wilkinson, 2002; Zetter, 2007). There has been a great deal of research done on this topic as it has a huge impact on how refugees resettle.

Identity construction may even be more crucial when researching refugee youth in regards to resettlement. Identity is a difficult word to define as it is a fluid and negotiable term that is a combination of a description one gives to themselves as well as a formation from outside perceptions (Bihi, 1999; Chen \& Sheldon, 2012). Adolescents are already going through a transitional time in their lives so to add adjustment to a new culture and country can bring extra challenges (Kumsa, 2006; Chen \& Sheldon, 2012). Young people from refugee backgrounds also tend to take on the cultural norms of the host society much faster than their elders. They face the challenge of balancing them as well as switching between the two worlds (Phinney \& Devich Navarro, 1997; Hedegaard, 2005). Young people from refugee backgrounds also take on many family responsibilities including helping with household duties, schooling, translation and negotiations with service agencies (Gifford et al., 2007). Former refugee youth have challenges and goals that differ from older people from refugee backgrounds in their community so it is important to create work and research for them specifically (Gifford et al., 2007). 
In this chapter, I explore literature about refugee resettlement looking the concept of identity that arises from this process. Then I discuss research about Somali people from refugee backgrounds, specifically women in New Zealand. Finally, I consider analyses about refugee background youth, specifically how writers have discussed how they handle identity construction, the impact of the family on their resettlement process, and the negotiation of two different cultures. I conclude by identifying the gaps in the literature that show future areas of study needed.

\section{$\underline{\text { Refugee Resettlement }}$}

According to the 1951 Refugee Convention, which established the UNHCR, a refugee is an individual who out of "fear of being persecuted due to race, religion, nationality, member of a particular social group or political opinion" needs to leave their country of origin (UNHCR, 2001-2013). Not only do refugees face the trauma of leaving their home under upsetting circumstances, but upon resettlement they must deal with a completely new culture and environment. A large number of studies have been conducted regarding the refugee resettlement process since this has large implications, not only for the individuals themselves, but also for host societies receiving them. Successful resettlement is not a guarantee when refugees arrive in a new society and often many continue to struggle to gain employment and feel included in the host society. To gauge what constitutes successful resettlement, most researchers have focused on the process of refugees' identity negotiations and how that affects their participation in the host society.

\section{Reasons behind Difficulties in Resettlement}

Resettlement is a difficult process for the majority of former refugees, but there are different ideas about why this is so (Deepak, 2005; Banki, 2006; Fangen, 2006). The two bodies of work that emerge in this area seem to focus on the lack of host society support, or a former refugee's challenges in adjusting. The first body of research believes the issue of resettlement is a result of the host nations not providing adequate support and resources to ensure refugees adjust (Banki, 2006; Hovil, 2007). Many of the governments of these countries are seen as not upholding UN Human Rights 
Requirements or their societies are thought to show discrimination (Banki, 2006; Hovil, 2007; Fiddian-Qasmiyeh and Qasmiyeh, 2010). The second body involves researchers claiming that difficulty with resettling is a result of refugee actions, specifically dealing with the shock of new cultural norms that limit successful resettlement (Hermans, 2001; Deepak, 2005; Fangen, 2006). A combination of a lack of language proficiency, adjusting to a different social status than one they were accustomed to back home and general confusion about new practices leads to difficulty in adapting (Fangen, 2006). Even with this division in conclusions, researchers agree that resettlement is a difficult process and that a large component of the issue is the way others and the former refugees themselves view their situation.

\section{Identity}

The concept of identity is centrally important to the resettlement process. The main areas of research focus have been on the host society's perceptions of refugees. These often include ideas that former refugees struggle with mental health issues including post-traumatic stress, strain from dealing with a new culture and negotiations about their changing identities.

\section{Perceptions from the Host Society}

Some researchers have chosen to investigate how the host society views the refugee population and this includes Western thoughts on mental health issues within this demographic (Wilkinson, 2002; Phan, 2003; Ellis et al, 2004; Zetter, 2007). Due to the trauma former refugees may have endured in their home countries and through their relocation process, they may face certain mental illnesses including post-traumatic stress (Phan, 2003; Zetter, 2007). Although it is helpful to distinguish possible issues with refugees' mental health and how that can affect their resettlement, it is important to not focus on that primarily. Research needs to look into other aspects that could contribute to hindering successful resettlement as well as consider their resilience and capabilities to endure. 


\section{Stress of a New Culture}

Studies seem to reach a consensus that most former refugees attempt to handle their new situation by either blending aspects of the host with their own or switching between them when appropriate (Schapiro, 1988; Lee, 2001; Deepak, 2005). This method of dealing with a new culture may be influenced by familial relations and the amount of stress the family dealt with before migrating (Abrams, 1999). Many of the studies suggested that this transition to a new culture is especially demanding on former refugee youth as they usually pick up the new cultural norms more quickly than older generations and as a result take on more responsibilities to help their families (Aiken, 1999; Reese, 2002; Rudmin, 2003; Bek-Pedersen, 2006). Former refugee youth must somehow attempt to fit in by accepting the dominant culture, yet do not want to offend elders of their community who wish to save their heritage (Devich-Navarro \& Phinney, 2002; Fangen, 2006). When former refugees express difficulty of feeling included and accepted in their new home, the experience is often attributed to this constant pull between two worlds.

\section{How Refugees Negotiate Identity}

The concept of identity is important because the way in which former refugees construct their self-perception in this new environment will determine if they will become active participants in the community (Barnes, 2001; Devich-Navarro \& Phinney, 2002). If people from refugee backgrounds do not feel like they belong, they will not become active participants and therefore have difficulty adjusting (Berry, 2001; Fiddian-Qasmiyeh \& Qasmiyeh, 2010). This feeling of not being including in the host society can have adverse effects on both the former refugees and the host country. However, the studies diverge on how former refugees deal with this identity crisis in order to adjust to their surroundings. Some studies claim that if former refugees are able to stick in their own communities to maintain ties to their homeland, or even be able to venture back home, they will be able to let go of the past and move forward (Dona \& Muggeridge, 2006). Others found that how former refugees construct their identity is dependent on the host society and how the nation views refugees and treats them as a 
result (Banki, 2006; Hovil, 2007; Fiddian-Qasmiyeh \& Qasmiyeh, 2010). The third body of work found that it is through the use of particular positive narratives and sense of self-identity that refugees are able to deal with their new situation and process what has occurred (Devich-Navarro \& Phinney, 2002; Kumsa, 2006; Eastmond, 2007; Collie et al., 2010). This third area of research is especially useful because it combines the first two while expanding on the capabilities of the former refugees themselves. A multitude of reasons resulting in the challenges of negotiating identity and it is important to focus on all these different circumstances in order to gain a better insight of how they impact the resettlement process.

\section{$\underline{\text { Somali Former Refugees }}$}

Out of the multitude of studies completed on specific ethnic groups of former refugees globally, there is one group that stands out. Somali former refugees as an ethnic group seem to encounter the process of resettlement and negotiating identity differently than other resettled peoples. In studies done in both the UK and Norway, Somali refugees faced greater hardships of poor housing, increased unemployment and illiteracy issues more than any other immigrant group (Fangen, 2006). A Finnish study also found that Somali refugees faced more racist crimes and discrimination against them than any other refugee group in that country (Alitolppa-Niitamo, 2004).

One contributing factor to these experiences is the combination of gender and Islam. In a study conducted in New Zealand, Somali women were found to have a hard time negotiating their Islamic identity both in mostly secular private and public spheres (Guerin and Guerin, 2002). This was also apparent in a study done in Christchurch secondary schools where Somali young men had a more difficult time adjusting to school due to the difficulties of cultural differences (Humpage, 2009). This experience resulted in lower grades, increased dropout rates and more aggression felt by Somali youth than students from other ethnic backgrounds (Humpage, 2009). These findings are in accordance with the studies of Somali refugees done elsewhere in the world (Fangen, 2006). Jasperse's study on how Muslim women perceive discrimination in New Zealand found that wearing of the headscarf did attract negative attention for the 
women (Jasperse, 2009). This discrimination resulted in heightened stress levels and impacted the way they adjusted in New Zealand (Jasperse, 2009).

Within the broader literature above, not a great deal specifically focuses on Somali women. Within the little research on this topic, it seems women and girls handle resettlement differently than men because they often take control of the household duties and care for the children. This work can isolate them and make it harder for them to assimilate into the new society (Humpage, 2009). Women also can experience greater discrimination in regards to their faith since they wear their head-scarves as noted above (Guerin \& Guerin, 2002; Jasperse, 2009). These factors can add to the difficulty experienced by Somali women when adjusting to life in New Zealand.

\section{Resettlement as a Young Adult}

\section{Identity Construction}

Former refugee young people often experience resettlement as young adults where they have recently undergone great trauma in regards to their displacement before they must negotiate entering a completely new society (Joyce et al., 2010). Then youth must negotiate perceptions from the host society members and feelings of being different (Chatty, 2007). The youth also can take the host society's culture and identity into account and this can lead them to question their own identity and culture (Rocha, 2012). This process can be seen when youth struggle with the desire to adopt certain cultural traits from the host society that might clash with their native culture, such as clothing choices or social activities (Gifford et al., 2007). For youth, specifically between 18-30 years old, the concept of identity is crucial in self-exploration and for finding self-worth (Chen \& Sheldon, 2012). Former refugee youth consider how their actions will affect their own communities and family and their identity will go through many transformations through this identity construction process (Reese, 2002; Collie et al, 2010). Identity construction is a necessary process that young former refugees need to 
go through in order to feel a connection to their new country and to be included into their new society (Kumsa, 2006).

Kumsa (2006) studied young Oromo refugees in Toronto, an ethnic group from parts of Kenya and Ethiopia, and explained how the perceptions of the new host community can impact the need to construct a new identity. Young refugees can have a more difficult time dealing with the perception of the host community on their own family and culture and can take this on more personally than their elders (Reese, 2002; Kumsa, 2006). Often this label of 'refugee' can be difficult and since the young people may be in a transitional phase in their life anyway, they can internalise and it can have negative impacts on their identity (Kumsa, 2006). These perceptions from the host society can also show up in schools where former refugee youth can feel a lack of cultural sensitivity and not enough support services to help them achieve (Horner et al., 2006; O'Rourke, 2011). If the young people do not feel included at school or in the overall host society, it can greatly dictate how they will adjust and be able to work towards their future goals (Reese, 2002).

\section{Impact of Family}

Although it varies between different refugee background communities, the impact of familial relationships is often integral to the ways young people handle the resettlement process. Family produces a key link into their heritage and a feeling of connectedness (Bek-Pedersen \& Montgomery, 2006). Studies have found that various social networks, feeling connected to their surroundings and the importance of a stable home are key to refugee youth resettling and finding success (Gifford et al., 2007). The Ministry of Youth Affairs in New Zealand understands the importance for youth to feel connected to the host society as they created a national strategy in order to provide resources for youth to engage in society and better the overall well-being for the country (MYANZ, 2002). Therefore, if the family is struggling and dealing with impoverished conditions, this can greatly impact young people in school or at work and how connected or disconnected they feel to their new surroundings (Guerin \& Guerin, 2002). 
Since family is such a large aspect of young people's lives, they will go out of their way to help them any way possible. This can include handling translations or taking on extra work to help the overall income of the family. It has also been found that education systems are not always culturally appropriate for former refugee youth and it can be difficult for them to attempt to navigate this system due to lack of the proper language skills, trauma from the resettlement experience and an overall lack of a sense of belonging (O'Rourke, 2011). Such responsibilities and dilemmas can have a huge impact on the young people and produce stress (Chatty, 2007).

Often, young people will acculturate or take on the cultural norms of the host country much more quickly than their parents, which can then add conflict and added stress (Chen \& Sheldon, 2012). The attitudes of the parents or family members can also dictate young people's resettlement experiences. If young people perceive their parents as more accepting into the host society, then they themselves will feel a better sense of connectedness and belonging as well (Chen \& Sheldon, 2012). It is important for these young people to feel that they can open up about the pressures they face and their family life in order to solve possible familial conflicts and allow the whole family to more forward in the resettlement process (Lustig et al., 2004). Allowing young people to express these feelings is so vital because often youth are seen to internalise these feelings and feel the pressure of fitting into the host society more than others in the community, so it is imperative to allow some type of outlet (Bek-Pedersen \& Montgomery, 2006; Humpage; 2009). However, more often research is done about the entire refugee community and not young people specifically which can limit the knowledge about the impact of the resettlement process on the young people (Abrams, 1999; Collie et al., 2010). It is vital to take note of the impact of the family on the resettlement process for the youth, but also research young people's needs and opinions separately from those of their elders.

\section{Negotiating Two Separate Cultures}

Former refugee youth grapple with the unique balance of negotiating between two separate cultures. "Cultural switching" occurs in order to handle two separate cultures 
(Deepak, 2005; Hedegaard, 2005). Young people come up with a way to negotiate handling two separate cultures while attempting to appease both (Phinney \& Devich Navarro, 1997; Hedegaard, 2005). Since the young people are at a more adaptable age when they arrive compared to their parents, they are able to pick up the cultural norms from the host-country quickly but still will try to honour their home culture for their parents (Deepak, 2005; Hedegaard, 2005). While undergoing this negotiation, researchers have found that the young people often will develop various behaviours and identities to be able to switch between different cultural situations (Gifford et al., 2007). There can be variation between youth on how much they switch or the ways they negotiate these two cultures. Some reports found that youth tend to lean more towards the culture that is more dominant, often the host country, in order to fit in (Hedegaard, 2005). Others found that the youth would often hold strong ties to both cultures and attempt to blend them in their lives or switch between them often (Phinney and Devich Navarro, 1997; Deepak, 2005; Hedegaard, 2005). Although this was a common theme in youth resettlement research, there was a bit of caution from some researchers finding that this constant switch between cultures can have negative impacts on the young people's senses of identity and well-being (Lee, 2001; Hedegaard, 2005).

A similar, yet alternative idea was found in a study done by Zarine Rocha (2012) about Chinese-Kiwis in New Zealand and how they dealt with their biculturalism. She claimed they had a mixed identity or "mixedness". The participants in this study detailed how they had multiple worlds in which to participate in and this brought about an "in-between space" in which they created an identity from both (Rocha, 2012). Rocha details this as a positive aspect of their biculturalism because it brought about a new way of thinking and a unique identity that only the coming together of two different cultures can produce. Although it was not a study done on specifically refugee youth, it brought up relevant themes regarding those who handle two distinct cultures in their lives. 


\section{Gaps Addressed by My Research Project}

There is not a great deal of research about refugee youth under the age of 25 even though they tend to account for about half of the global refugee population (Chatty, 2007). In addition, research that does cover refugee youth does not tend to investigate factors that result in successful outcomes or their future goals (Gifford et al., 2007). There is an apparent lack of strength-based research regarding refugee resettlement and not much researching former refugee's accomplishments (Gifford et al., 2007; Reed, 2007). In much of the research, there was a great deal about young refugees in terms of career paths and educational pathways, but a great deal left out of their actual resettlement experience (Wilkinson, 2002; Phan, 2003). The focus of literature on youth experiences seems to be around secondary schools rather than young people at the university level (Guerin \& Guerin 2002; Joyce et al., 2010). With my research, I will address these gaps by focusing on young Somali women at university and gaining their personal accounts and opinions into their own resettlement process.

In addition, refugee youth are often referred to as adults in certain studies or just put in the adult category in research without getting on specific attention to their own identity (Kumsa, 2006). And if they are given their own project or research, it is too often about their past and what has happened in their lives instead of their future goals and what they can bring to their new host country (Kumsa, 2006). It could greatly enhance refugee resettlement research to perform work with specifically refugee youth to find out their opinions on their own experiences, their future goals and what they believe they can bring to improve their new country.

\section{Conclusion}

Investigating the concept of refugee identity and how it relates to successful resettlement is important to ensure the mental, emotional and physical safety of refugees throughout the world. In proportion to population, New Zealand has one of the highest rates of acceptance of refugees in the world receiving 750 refugees annually, so it is an interesting place of study (NZ Immigration, 2012). Collie et al. (2010) show a 
successful model of conducting refugee identity research within a specific community. There have been few studies completed regarding Somali former refugees and these have been focused on secondary school children or the entire population. From the literature about young refugees in regards to resettlement, there were definite gaps and recommendations for future research. There was a call from most of the researchers for more research on young refugees in general and specifically those between the ages of 18-30. Also, there seems to be an increased need to ask about their future goals and to focus on the positive aspects and successes in their resettlement process. By focusing on aspects that may not be as heavily researched such as the experiences of young Somali refugee women in New Zealand, I will add to the depth of the overall knowledge of refugee resettlement and hopefully help make the transition a bit easier for future residents. 


\section{Chapter 4 - Maintaining and Creating Somali Identity in New Zealand}

Before this project, I had a limited knowledge about Somali culture as a whole, let alone in a New Zealand context. So in my initial discussions with the young Somali women, I learned a lot about not only Somali culture itself but the culture seen through the Kiwi lens. As an American, I was able to participate with the young women in viewing certain aspects of Kiwi culture as an outsider and understanding the confusion and misunderstandings they experienced. The girls were all recent or current students, and were therefore considered successful in heading towards fulfillment of their goals, so they all felt comfortable discussing how they felt resettling in New Zealand. They also all migrated to New Zealand at a young age so they themselves did not perceive to experience a high degree of trauma in moving to New Zealand. This fact allowed them to open up a good deal to me about their experiences growing up as a Somali-Kiwi.

Culture was at the centre of every discussion, interview and focus group I conducted with the girls. It was an integral component in each of their lives and since they had an interesting dynamic of balancing two separate cultures, it was something the young women had conflicting feelings about. They loved both cultures and were proud to be members of both, but at times did find it difficult to balance each in their lives.

There arose three main themes when conversing with the girls about their unique Somali identities in New Zealand. All the girls discussed the challenges and rewards of balancing the two cultures and negotiating the intergenerational differences in maintaining their Somali culture. There was even a use of slang and different terms by the young women to explain their different cultures, which I reviewed in Chapter One. The girls all held a strong desire to keep their Islamic religion intact even though they found difficulties in maintaining it in a predominantly secular/Christian society. The young women also had to fill an ambassador type role in handling Kiwi perceptions of their culture and their heritage for their families. In this chapter, I first discuss the young women's' reflections on balancing both their New Zealand and Somali cultures. 
Then I look into the impact of family and the influence of religion on the girls' resettlement process before finally looking into the young women's reflections on differences in their Kiwi and Somali cultures.

\section{Balancing the Two Cultural Worlds}

Since the young women arrived at a young age, most of them cannot remember a time when they were not negotiating their way through both Somali and New Zealand cultural realms. They went to school and socialized with their friends, but once they went home, they followed customs and traditions completely unlike those found in mainstream New Zealand. Their parents and elders in the community spent most of their lives back in Africa and therefore still held a great attachment to belief systems from there. Obviously they wished the younger generation to succeed and prosper in this new society, but also desired to instill a sense of their roots in the girls and have them identify with their Somali heritage. Yet the girls had a yearning to fit in and be accepted by their New Zealand friends which could at times conflict with their home life. This could cause a bit of tension and culture clash for the young women.

The girls differed in the ways they handled this negotiation of the two cultures. Some felt a strong connection to their Somali heritage and although enjoyed living in New Zealand, found it imperative to keep a strong connection to Somalia central to their identity. Key Informant D (KID) was able to give an interesting view since she was a young Somali female student and also working at Wellington Somali Council and she explained this saying, "These are my beliefs and this is my culture and I need to hold on to it despite the culture I'm living in now. So yeah there are definitely boundaries that I had to keep within." (KID Interview, 03/10/12). Others favoured Kiwi culture as Participant A (PA) explained it was because she had "been here for so long it's just like that's the culture I want." (PA Interview, 24/08/12). Other girls didn't want to follow much of the Somali culture except for their Islamic religion. The majority of the young women found a balanced approach where they were able to take qualities of each culture to appease both sides. They decided to take pride in their 
differences and use it as a chance to show each side of their culture. But even with this positive attitude, the girls still acknowledged the struggle that came from attempting this stance, as Participant D (PD)'s reflections made clear, “...you are trying to maintain your culture, like you want to live the way your parents used to live. And you live in another country where your friends are going out, they' re doing this and that. So there is a culture clash. Like if you follow your friends, then you're stepping away from your culture and leaving your culture behind. And if you stay with your culture like "OK, I live in this country, I'm not getting along with people." So yeah, sometimes you'll feel there's a bit of culture clash going on." (PD Interview, 10/10/12).

Growing up with this constant negotiation between the two worlds was tough at times for the girls, but none of them ever voiced any desire to live a different way or without either culture. The young women exhibited what was referred in the literature as 'cultural switching' where young people will develop different behaviours to shift between different cultural situations (Gifford et al., 2007). Yet even though the girls quickly picked up Kiwi traits, they wished to still honour their home culture and appease their parents. This aspect of their lives was evident in singular studies elsewhere (Deepak, 2005; Hedegaard, 2005). They all had pride for where they came from and enjoyed acting as ambassadors for their culture and religion in a New Zealand setting. When negotiating between these two worlds, the young women discussed two main topics: the differences between the generations in their community when dealing with New Zealand life as well as the negotiation of being a "good" Somali and Kiwi.

\section{$\underline{\text { Intergenerational Differences in Maintaining Culture }}$}

Although the young women had a strong interest in Somali cultural traditions and religious beliefs, they expressed differences between themselves and their parents' views on how best to maintain their culture. These girls grew up in New Zealand and viewed it as their home, but their parents spent most of their lives in Africa and may have a stronger desire to keep their traditions alive in this new country. This difference 
also occurred between the girls and older siblings in the same family. Many Somali families are quite large so even though these girls arrived to New Zealand at a young age, most had siblings that were a lot older during the move. It was difficult at times to have such large variances within families on the difficulty of adapting to this new society. Key Informant B (KIB) who worked as a volunteer at Refugee Services noticed this variance with Somali families. She would watch the younger children quickly integrate into society through their schooling and picking up the English language with minor difficulty. Yet the older girls in the family were confined to the home and rarely interacted with New Zealand citizens. KIB reflected on the differences in sibling resettlement and how older siblings" “...lives are just so different yet they all live in the same home and they're all from the same family." (KIB Interview, 07/09/12).

Older siblings, like Participant B (PB), reflected on the ease with which her younger siblings have fitted into New Zealand society and their greater participation. For example, she noted that, "they can't speak any African languages as fluently cause at home we speak Ethiopian and Somali. But yeah, they haven't really maintained the language, the cultural sense as much. They kind of more Kiwi. Maybe they do like, they go to gymnastics, netball, I didn't really do stuff like that, so they kinda immersed themselves into kiwi culture.”(PB Interview, 29/08/12).

In addition to having younger siblings who may relate more to the Kiwi culture, the young women would often have to act as a type of cultural ambassador as well as a literal translator for their elders. This increased responsibility was a common theme for young former refugees noted in literature (Chatty, 2007; Chen \& Sheldon, 2012). Young people often would also take on extra work to help the family income and handle translations for their parents (Chatty, 2007). The girls at times could find this stressful but as PB spoke about her neighbour, they maintained a sense of admiration for their elders and the respect they have for their culture. "You see women, like my neighbour is my best friend's mom, she has been in the country the same time as us and she still speaks her language fluently. She doesn't speak a word of English. 
And she sees that as an important way of keeping her own culture."(PB Interview, 29/08/12).

But it is not always the girls helping out their older family members. The girls all felt that their older siblings and mothers would often teach them and remind them about their cultural heritage, which for CA was good because as she said, "at the end of the day that we have someone in the house that tells us to never forget where you came from, you know, at the same time making friends but don't forget where you came from which always gives you traditions."(CA Interview, 17/08/12). The girls found this invaluable and respected for holding on to their roots and being proud of where they came from.

It was so important for the young women to help their elders while also learning about their Somali culture since family is so significant in the Somali community. One interesting observation was a comparison given by one of the young women between the Somali community and that of the Maori culture within New Zealand. The Somalis tend to identify with the lifestyles of the Maori people instead of Pakehas because the Maori tend to put more emphasis on family units as well as hold different traditions and cultural meanings than Pakeha Kiwis. Yet although the Maori people do have many differences than the mainstream culture, they are still considered New Zealanders and it seemed to give the Somali community a blueprint of sorts in which they can keep their culture and yet still be a part of the Kiwi society.

The girls all voiced appreciation for this emphasis on family in their culture and so although there were differences in the way they handled acculturation, they still felt connected and close with their elders. No matter the temptations or difficulties presented by conflict in cultures, they never wished to have any other relationship with their elders or to take away either culture in their lives. They were proud of both cultures and happy to be given the opportunity to participate in both Somali and New Zealand cultures. 


\section{Being a "good" Somali-Kiwi: Reflections on Cultural Roles}

For the young women, it wasn't just a matter of navigating between the two cultures, but also following the customs of each to be an appropriate participant of both realms. It was difficult at times because what it means to be a "good" Kiwi sometimes conflicted with being a "good" Somali. The girls would explain the tension it can cause attempting to play both roles and appease both sides.

Each girl took different approaches to how they found a balance between being a 'proper' Kiwi Somali but there were some trends between them. Learning to cook Somali food and wearing the traditional headscarf and long skirt was something all the girls did even though they found it difficult to locate Somali clothes in New Zealand. This was another reminder to the girls on the difference between cultures, as CA explains, "It's hard to find Muslim, my culture clothes in New Zealand because there are no shops that are Muslim except this one at the moment."(CA Interview, $17 / 08 / 12)$.

Besides sharing the desires to cook Somali food and wear traditional clothes, the girls' opinions differed about to what extent they should take other aspects of Somali culture into Kiwi society. The girls differed on how they felt about their parents enforcing rules on maintaining the Somali culture. Some believed their parents were doing the best they could and realized it must be a bit difficult for them to handle their children growing up in a different culture. PD explains this further saying young refugees "came from a different culture and then they come to a new one. So they want to take that culture, you know that place that they living at the moment, and it's hard on their parents. (PD Interview, 10/10/12).

While others thought that parents should be a little more relaxed and allow their children to take on more of the Kiwi culture since they are living here at present. Some of the girls told stories about how they would find a bit of tension with their parents' decisions in what social activities they were allowed to attend. Although birthdays are 
not celebrated in the Somali culture, parents tended to be lenient in allowing their children to attend friends' parties. However the girls were not allowed to attend sleepovers because their cultural traditions restricting them from sleeping at a nonrelative's house and it could be a bit awkward to try and explain to their Kiwi friends why they couldn't attend.

PB remembers this desire to fit in saying, "There were the kiwi kids and you tried to be like them. And no matter what you think, "Can I go do this and this" even though it's something that is different to your culture. Like sleepovers, and your parents are quite against it. It's something you try to always fit into. You try to blend and gel them together."(PB Interview, 29/08/12). Decisions by the parents on what the girls were allowed to do was important for the girls' resettlement because the literature has shown how the opinions of the parents can have a direct influence on the views of their children (Chen \& Sheldon, 2012). If young people perceive that their parents and elders are accepting of the host culture and are active participants themselves, then the girls will feel more inclusion and connectedness as well (Chen \& Sheldon, 2012).

In conversations, the girls brought up a few things out of the Kiwi culture that although they grew up with, they still find odd. Excessive drinking was something every person found disturbing and something that not one of the girls envied or wished to participate in. Relationships between couples were another point of confusion for the girls. Although the young women differed on criteria of whom they would want to date, they all agreed on the rules of cohabitation. The girls were confused about the prospect of leaving their parent's house at a young age and living with your partner. CA explained her confusion further when she said, “...in my culture, no you are not allowed to move the house. If you are a girl, unless you get married to someone, and maybe in boys it's different but in girls it's not. In kiwi's culture, like, you can't, you know, but when you turn 18 you can move out the house. And, why would you want to do that when you have your mother and father like looking after you and providing everything you need, you know?"(CA Interview, 17/08/12). The girls all 
had a strong attachment to their Islamic religious beliefs but varied on aspects of the Somali culture that they wanted to follow.

Yet even with the differences in their opinions about how to balance the two cultures, there were aspects of their lives that were relevant in both their Somali and Kiwi cultures. The importance of family and marriage were two components that although originally stemmed from their Somali culture, all the young women made sure to find a way to merge it with their Kiwi lifestyle.

\section{The Importance of Family for Young Somali Women}

Within the Somali culture, family is without a doubt the most important component in each person's life. Whenever we discussed contrasts between Kiwi and Somali culture, every young woman brought up the difference in the significance of family. For some of the girls who came to New Zealand at a later age, they were amazed at the way some Kiwis handled familial relationships, such as PD who commented that, "We have such like a connecting, close family. That's one thing that amazed me when I came to New Zealand and then I see people who tell me that they lived in Wellington and then they haven't seen their Mom for like years and years. And I was like, "How does that work? Is she dead?" "No, she's alive." So yeah, family is the most important thing in our culture."(PD Interview, 10/10/12).

The family unit is such an important factor for these girls, so it has an enormous impact on their resettlement into New Zealand. If their family is struggling or someone in their family unit is not doing well, it affects every other facet of their life. Throughout conversations with the girls, there were two main categories that affected their wellbeing and success in reaching their goals: handling parental authority and dealing with stress regarding the resettlement of the older generation. 


\section{The Influence of Parental Authority}

Many teenagers and young adults can feel their parents are an unwanted presence in their social life. The girls grew up with not only parents acting as a disciplinarian, but also reminding them of the cultural guidelines and rules they need to follow. The girls told stories about how it would sometimes be difficult understanding why they were allowed to go to birthday parties when they do not celebrate that in their own culture but then sleepovers were not allowed. Any social situations where there was gender mixing could be uncomfortable and parents would differ a bit on what they would allow their children to do.

The parents would also want to remind their children about their heritage and wanted them to participate in cultural customs such as cooking Somali food and celebrating Somali holidays so they wouldn't lose their traditions growing up in this new environment. The young women came at such a young age, that New Zealand is home to them and this culture makes sense. Their parents are the ones who remember their culture back home and take it on as their responsibility to impart this knowledge and the importance of its maintenance on their children. As Participant C (PC), a mother and a citizen of New Zealand for over 20 years said, "[I]keep on telling her "At the end of the day, first you are Somali, regardless if you have the Kiwi accent or not, at the end of the day you a Somali, you are a Muslim woman. There's expectations on you on each side of it." (PC Interview, 31/08/12).

It seemed that the parents not only wanted to keep the cultural traditions like the religious observations and wearing the Somali apparel alive for their children, but also make sure they appease the community as a whole. This is a common desire for young former refugees when they are attempting to negotiate switching between cultures. Young people will continue to practice customs of their home culture to keep a connection to their parents and their community (Phinney \& Devich Navarro, 1997; Hedegaard, 2005; Gifford et al., 2007). The Somali community in New Zealand is small and everyone knows each other, so it is important to have children that follow the rules and exhibit aspects of the culture appropriately in order to avoid family shame. PA 
explained the importance of following these customs, "I wouldn't mind wearing shorts but my mother is not OK with it. It's like "family shame" and I'm like ok, for the sake of the family and the shame. "(PA Interview, 24/08/12). It was important for the young women to understand how they can handle both cultures in their lives because as PA explained, "[You] can never be on one side alone.” (PA Interview, $31 / 08 / 12)$.

Since the girls spent the majority of their life in New Zealand, Somali culture did not come as easily to them as women who grew up in Somalia. They needed someone to impart this knowledge as they grew up in New Zealand society and share the meaning of traditions and cultural customs. The mother was often the one filling this role for cultural guidance and every girl spoke of the relationship with her mother in positive ways. However, if the mother or an older female in their life was struggling to cope, this would have a huge negative impact on the young women's life. Therefore the wellbeing of the older generation greatly impacted the success for the younger people of the community. PB explained the impact of allowing older women in the community to succeed when she said that young women “...can see that that's not all I can equate to, there is more out there for me. That's something really important because especially in my year there were a lot of Somali girls that didn't see "oh I can just work as a cleaner. That's all I need to do. I'll eventually get married, there's nothing more for me". (PB Interview, 29/08/12). The impact of the community on the young women is a correlation reflected in the literature as well. It was found that a stable home and a feeling of connectedness to their surroundings through their community were necessary for young former refugees to resettle (Gifford et al., 2007). So if the community is having difficult adjusting or a family is in impoverished conditions, the young people will have trouble at school or work (Guerin \& Guerin, 2002; Gifford et al., 2007).

If the girls in the community see their mothers out and working and adapting to their new surroundings, then they have role models to show them it is possible to succeed even if there are obstacles. Their mothers tend to be the life force within each family 
because they are the ones that keep the household running and manage the children. Additionally, most Somali families that have been resettled here tend to have solo mothers so they must fill both parental roles while trying to navigate this foreign country.

Within conversations with the young women, the topic of their fathers never arose. I know that a couple of them definitely had their fathers here in New Zealand, so it wasn't always a matter of a father being far away or deceased. In conversations with members of organisations that worked with the Somali community, the man of the household would often come up in conversation. He is the one who works and brings in the money and is usually the final say in decisions within the family. So it is interesting how the young women never spoke about him, especially in regards to parental authority or attempting to follow the rules of the community. Since they spoke at length about their mother's struggles to adapt and ways to help, maybe it is due to their father's ease in finding work and socializing that they do not find a reason to worry about them. The bond between mother and daughters was clearly strong and came through in every discussion we had. This relationship is critical for the young women because the literature suggests that it is critical for the success of the youth's resettlement that they feel a connection to their parents and they feel their parents' feel included in the society as well (Chen \& Sheldon, 2012).

\section{Anxiety about the Resettlement of the Older Generation}

Although the focus of my questions in the interviews with the young women was about their resettlement and adjustment in New Zealand, the conversation would often turn to how the older generation in their community was handling it. Often with teenagers there is a sense of rebellion and detachment from parents and families, but due to the great emphasis put on family within the Somali community, it seemed to be the opposite with these girls. 
All the young women were acutely aware of much more difficult it was for their mothers and aunties to assimilate to this new environment than it was for them. Usually when questions were asked about programmes that would benefit people their age, the young women would redirect to things that could help the older members of their community. CA showed this when she said, “teenagers don't need help as long as they know English and there is the older people...they need to work but they don't know English. I think if you are a teenager and you know English than I think you don't really need help." (CA Interview, 17/08/12).

The young women commented quite a bit on the issues their mothers or aunties faced and how it impacts everyone in the family. The mothers would stay at home with their children to run the household and would begin to feel incredibly isolated and depressed. This would upset the girls as they felt that their elders gave up a lot so that they could go and pursue an education and succeed in New Zealand society. PD explained the repercussions of staying at home when she said, "sometimes they feel isolated, they can't speak the language, they might not be able to drive to go to the supermarket and at times, they become depressed just staying at home." (PD Interview, 10/10/12). The young women would often discuss ideas for services and support systems that could help their mothers and aunties feel more included and successful in their new home.

There also seemed to be a bit of defensiveness towards their elders saying that Kiwis were not aware of what they had to face. Misconceptions arose about most aspects of the young women's lives including their religion, their culture and their home country. But nothing seemed to bother them more than misunderstanding regarding their families. PD explained some of the cultural differences when she said, "In our religion, you can't just go to the public gym, like you need a place for only women. So things like that. Because if you just bring someone and then you leave them there, they will either get lost and not know what they're doing or I mean, they will be foreigners forever. I don't think that's the aim for the governments to bring people and then leave them alone without helping them." (PD Interview, 10/10/12). Often, 
young former refugees will have a more difficult time handling the perception of the host society on their own community and will interalise this more than their elders (Reese, 2002; Kumsa, 2006). This can then have a negative impact on the former refugee youths' identity and dictate whether they will adjust and work successfully towards their future goals (Kumsa, 2006).

The close-knit aspect of the girl's community was an important aspect in their lives and it was a component they all voiced their agreeableness towards. So it is impossible to focus primarily on young women's resettlement and their success without allowing for improvement in the lives of their family members as well. Due to the level of intimacy their community shares, everyone needs to feel included and successful in order for the community to work.

\section{The Importance of Marriage for Young Somali Women}

Marriage was a relevant topic for each of the young women, no matter their upbringing, education or career goals. There was a great deal of talk about the type of men they wanted to marry, the girls' future role as wives and when they hoped to have a family. Some of the girls were already in relationships that they knew would turn into marriage and all mentioned it in their future plans. All the young women discussed it as a future prospect they were looking forward to and an aspect of their culture they really appreciated. PD explained her respect for this custom when she said, "We came from our culture...or country where men are the dominant in the house. They provide for their family... which is actually good. It's one of the things I like about my culture is that if you are married, you don't have to worry about what you're going to eat so the man will take that responsibility." (PD Interview, 10/10/12).

It seemed that it was the older generation living in New Zealand who were more resistant to the girls getting married at a young age. Culture would dictate dating rituals, such as not being alone with a boy without supervision but it appeared that also the parents wished the girls to adapt a bit more of the Kiwi culture in this regard by focusing on school first and boys later. Often parents would discuss how they had 
arranged marriages at a young age and now that they lived in a different society, they didn't wish their children to follow in their footsteps. PC expressed this desire of her daughter to approach marriage differently when she said, “And I keep on telling her, “Until...I don't want to hear about men until you finish your degree first." (PC Interview, 31/08/12). This was a good example of how within the practice of cultural switching, former refugee youth will often lean more towards the culture that is most dominant, often the host society in order to fit in (Hedegaard, 2005). The young women were showing this by not getting married till they were done with school or had achieved their goals.

Although the young women and their elders might differ on when and how they will marry, there was one aspect they all agreed on; the man must be Muslim. Even the girls that wished to rebel the most from Somali culture and live a more Kiwi lifestyle concurred that their future husbands would be Muslim. As seemed true with most other aspects of the girls' beliefs, they would vary a great deal about cultural aspects and certain traditions but their Islamic religion was always centrally important factor in their lives and they never disagreed on following those customs. PA explained her mother's opinion on her future husband when she said her mother thinks "As long as he is a Muslim, I don't care". My mom is like OK." (PA Interview, 24/08/12).

The prospect of marriage was exciting and important to the young women, but the fact that they hadn't entered into this commitment yet was apparent in the fact that they were all able to focus on school and work commitments. Women that arrived at an older age or who were already married had a much different experience dealing with resettlement. PC explained her reflections as a married women within the Somali community when she said, "As a woman within the community, the priority is to have a husband and have children. Education they believe...they said "whether you have a PhD or not, at the end of the day you'll end up in the kitchen. What is the point?" (PC Interview, 31/08/12). 
Marriage was also placed in discussions regarding returning to visit Somalia. The girls explained how if they returned they would have to deal with wedding prospects and be reminded of their duty to find a suitable husband. Some of the girls joked about how they are more attractive to men back in Somalia because of their status as a New Zealand citizen. PA said, "At the moment, it depends like, it depends on if you have a passport, people just marry you for the passport."(PA Interview, 24/08/12).

Whether a woman arrived married or not was a huge indicator of how her adjustment period in New Zealand would go. Often these married women would feel incredibly isolated as they had to stay home to take care of their household and tend to the children. It would be difficult for women to fit any sort of study or work into their schedule which then makes it quite difficult to adjust into this new society.

Therefore it was quite a balancing act to postpone the excitement of marriage in order to not limit their chances of succeeding in their future career. The girls would often take the advice of their older siblings and parents and put off any prospects of settling down till they were more settled in their work field. They understood and often commentated on how they felt privileged to be able to take advantage of the resources given to them in New Zealand while still having the ability to later partake in cultural traditions. They all wished to honor what they families had done for them in moving them here by being as successful as they could be and reaching the goals they and their families set for themselves.

\section{Influences of Religion on Young Somali Women}

Religion was often an integral component in the young girls' lives. It arose in every interview and conversation with the young women and was a driving force behind most of their decisions and their attitudes. Religion is a presence that reminded the girls of their heritage and linkage to Somalia as well as a differentiation between their culture and Kiwi culture. It seemed that their Muslim identity may have been heightened within families in New Zealand due to the country being predominantly Christian. Whereas 
back home these religious customs would be the norm, the girls were aware that being in a place where they are the minority allowed them to reflect on aspects of the religion that are different and permitted them to reaffirm why they want to follow these traditions and guidelines.

Often in conversations, things about Kiwi culture that conflicted with their religion would arise and the girls would discuss their confusion and distaste for people performing the acts. One aspect that came up in every discussion was drinking. As a Muslim, male or female, you are not allowed to drink and the Somalis thought that the apparent excessive drinking in New Zealand was concerning. Even young girls that favoured the Kiwi culture to their own did not agree with the drinking aspect. PA explained that "It says in the Koran you can't drink." (PA Interview, 24/08/12).

They also noted that it is not just the fact that people tend to drink excessively in this New Zealand, especially at a young age, but that most social activities revolve around drinking and it could make them feel awkward and not included if they didn't participate. PC felt this discomfort and explained, "it looks like all the social activities is around drinking. So a person who doesn't drink, you feel quite uncomfortable because $I$ hate this smell of the beer or the smell of the wine, it just puts me off."(PC Interview, 31/08/12).

Additionally, it can be tough attempting to follow Islamic rituals and traditions that conflict with practices in New Zealand. One topic that came up with the girls often was in regards to fasting during Ramadan. Interviews were mostly conducted in late September and October when Ramadan had ended recently, so it could have also been fresh in their mind. But it still carried importance in their lives and they discussed how it can be an obstacle in focusing on school and performing it in New Zealand allowed for much more temptation to break the fast. CA discussed this difficult balancing act and how in Somalia they “....used to have a whole day off when we were like all Muslim because of the Ramadan and after that we used to get off after Ramadan...we celebrate so we used to get off as well. But in here you don't get it 
because like there are less Muslims and it's not compulsory that you have to be in holiday. But I think it's kind of hard while you fast and study because of Ramadan you can't eat anything. That makes it hard a little bit, like especially at uni." (CA Interview, 17/08/12).

For the young women, practicing Islam in New Zealand gave them a vehicle with which to stay connected to their home culture but also brought about some challenges in fitting in to the Kiwi culture. The literature suggests that this constant switching between cultures can have negative impacts on the formation of the young peoples' identity (Lee, 2001; Hedegaard, 2005).

Associated with this idea of 'switching', there arose three main subjects in our conversations which the young women saw the most impact in their lives: wearing the headscarf, navigating the clash in gender roles between cultures and their feelings on the main differences in their two cultures.

\section{Experience of Wearing the Headscarf}

The headscarf may be the most important factor for the young women in terms of negotiations about their religion and culture in New Zealand because it is a physically visible symbol of both. It sets them apart from Kiwi culture in the most obvious way and it is something they feel can trigger the most discrimination and curiosity from New Zealanders. Most of the young women grew up in New Zealand, so they were used to answering questions, getting odd looks at times and handling some setbacks due to their headscarf. It seemed that since they grew up in this environment, it did not bother them as much as people who came at an older age. It also highlights gender differences in resettlement experiences for Muslims as the men do not have any visible aspects highlighting their religion or culture and allow them to feel that they fit in more easily.

The biggest aspect that the young women discussed in regards to the headscarf was the discrimination associated with it. They did not express anger about this, just a comment on how most Kiwis were ignorant about what it meant to wear the headscarf. Some 
attributed this lack of knowledge to the fact that there were not many Muslims around before refugees began arriving in New Zealand. CA explained how many Kiwis were not aware of her religion and that "... a lot of people saying that I knew, like kiwi friends that say that they have never seen someone who is wearing a scarf."(CA Interview, 17/08/12).

The young women did not seem to experience a great deal of discrimination themselves, but the one obstacle they did present was in regards to finding a job. Many of the girls have had great difficulty attempting to get a job while wearing the scarf. The girls had numerous stories about friends or experiences they themselves had with difficulty in finding a job. CA expressed this view when she said that there are "people that complains about being racist but like they didn't get a job because of the scarf they wear and people tells them like "why are you wearing the scarf", you know? But I personally didn't have that kind of experience which is good."(CA Interview, 17/08/12). PB added to this opinion when she tried to apply for jobs, "I had a job application over the phone and I said "I wear a scarf is that OK?" and the lady said "No, actually don't bother coming in for the interview". I think it does, it's like a big factor for employers for some reason in New Zealand. I think it's just keeping up the company's image or something."(PB Interview, 29/08/12). This difficult with women resettling echoes the research which shows that Muslim former refugee women often experience resettlement differently while wearing the headscarf and can often feel more discrimination than others (Guerin \& Guerin, 2002).

The headscarf however is not just a symbol of their religion and beliefs, but is frequently connected to their status as a former refugee. The perception from the young women was that the only people wearing headscarves in their area were former refugees and this instantly created a label for them when they wore the scarf. The topic of migrants arose due to the fact that these women looked similar to them, minus the head scarf and yet they would have an easier time adjusting and finding work. As Key Informant A (KIA), an employee at the Wellington Somali Council, explained, “...when [migrants] arrive here, migrant have a different chance in terms of getting jobs 
and access. I always ask this of my daughter and I say "do you know...do you think if you take off your head scarf you would get a job? And you would just pretend to be a migrant or someone else?"(KIA Interview, 05/09/12).

The young women also discussed how they dealt with a lot of Kiwi misconceptions regarding the head scarf and its meaning. One stereotype the girls faced was the fact that all Muslim men are very oppressive and that the head scarf is forced on these women without their consent. PB expressed this view that "they think somebody makes you wear the scarf, somebody makes you dress the way you want. But it's your own beliefs and values."(PB Interview, 29/08/12). The girls seemed to be more upset by this aspect of ignorance then anything relating to the hardships in finding a job. This concern is a common one for former refugee youth as they often take the host society's culture and identity into account when adapting to their new surroundings and can internalise it more than their elders (Chatty, 2007; Rocha, 2012).

Practicing a minority religion in a different culture seemed to allow the young women to reflect on what it means to be a Muslim as well as act as an ambassador for their religion. The girls discussed how often there are misconceptions about what it means to be a Muslim from Somalia and how often they get mixed up with Arab Muslims. The girls all discussed how there are separations between their culture and their religion and that this separation is often misunderstood by outsiders. The girls discussed how the main difference was the cultural influences that impact the way they practice their religion, for instance the long skirts. PA explained the differences between her culture and religion when she said, “... and some people say it's wrong to like wear like jeans, that's not Somali culture but the Koran says it's OK as long as you wear modest. Not too tight, but as long as it fits, it's fine. In the Koran it says your whole head must be covered, some people show it because it's culture. They end up calling it Islam, it's like no, that's wrong. So you have to separate the two." (PA Interview, 24/08/12). 
Although they stated a few inconveniences in regards to wearing the head scarf, all the young women were very proud of their belief systems and had all made their own decision to continue wearing it in this new culture. They viewed it as a way to keep ties with their culture and community and to reaffirm their belief in their religion. They all seemed to be used to answering curious questions from peers.

\section{$\underline{\text { Negotiating Gender Differences in the New Zealand Context }}$}

For young Somali women, there are gender roles inherent both in their culture and in their religious beliefs that should be followed. But there tends to be a bit of confusion and tension when they grow up in a society that has a different set of cultural rules for the sexes. The girls discussed how they want to fit in and participate in Kiwi culture but in a way that allows them to stay true to their own traditions and beliefs.

The head scarf was a way for the young Somali women to practice their religion and stay true to their belief systems, but it also set them apart from the mainstream in New Zealand culture as noted above. It commonly arose in conversations how resettlement was a different process for men and women based on gender. KID explained that gender differences are “...not like a definite thing but probably because there's more activities for boys so they've got their sports and whatever to attend. I guess it's easier for them to fit in because they don't have the attire." (KID Interview, 03/10/12). PD agreed with this view when she discussed how the main defining factor between genders "is the clothes that they wear, obviously women have to cover where guys they just dress up normally and if they walk down the streets, I'm sure they won't get that staring." (PD Interview, 10/10/12). Although the young women never voiced any desire to stop wearing the scarf, there did arise a slight irritation that boys did not have the same trials in showcasing their religious beliefs to the public.

The girls also had the interesting dynamic of dealing with misconceptions or stereotypes within the Kiwi population, as well as conflicting feelings of their own while growing up within two cultures. The research confirms this is a common occurrence with former refugee youth can struggle with cultural traits from the host society that might conflict 
with their own culture (Gifford et al., 2007; Humpage, 2009). In the Somali culture, it is common for women to be in charge of children and running the household while men went out and worked. PC explained her difficult schedule as a woman that she was “doing 4 papers a semester and had my child to look after and I was still the woman of the house, cleaning and cooking for the family of 9, it was tiring. But then, as a woman that's your expectation, you leave the country, your role is that. And there is no negotiation around that."(PC Interview, 31/08/12).

For young women, this was not as common as it was for their older sisters or mothers. Those that arrived at an older age were prepared for these roles yet the girls who grew up in this culture where gender mixing was much more common and gender roles were a bit different were not. Most of the girls accepted this aspect and balanced it as best they could. A few of the girls, however, experienced some resentment and favoured the way Kiwi culture handled gender differences. PA held some resentment when she explained that in her opinion, "guys get to do whatever they please. Like literally, whatever they please. The girl must cook for them. It's like, Mom, this is New Zealand, it's not fair. If you want to make me do chores here, he also has to do chores. Why should I clean his socks, vacuum his room. That's unfair." (PA Interview, 24/08/12).

Most of the women did not view it as a "right" or "wrong" issue, but a tough balancing act for all those involved. They understood that especially for the older people in the Somali community, this was an uncomfortable issue and that they need to try and follow these rules to make their community happy. The girls understood that their families weren't doing this to make their lives difficult or as a punishment, but that this was the culture they came from and they were just trying to adapt to this new way of life just like them. Research shows that often former refugee youth will take great consideration into how their actions can help or hinder their communities success in adjustment and will want to help anyway they can (Reese, 2002). The girls did agree that women and men resettle differently due to these differences and that initiatives towards resettlement should reflect those variances. As a previous volunteer for 
Refugee Services, KIB explained these differences in the resettlement process especially for women from an Islamic culture. She said, "It's really inappropriate for that sort of, that mixing of the genders in really public spaces. I think...yeah it's a fundamental sort of principle throughout all the different cultures and $I$ think it's...it must be quite threatening or scary for both the women and the men. So I would definitely identify that as a barrier, having...you know thinking about successful initiatives like I really think they need to be gender specific." (KIB Interview, 07/09/12).

The young women were all acutely aware of the differences faced in regards to resettlement between the genders, but were also incredible positive about how far women are able to go in this society. All of the girls had high aspirations, most were attending school and they seemed to be optimistic in the future of their community. None of them would let any obstacles or perceptions of discrimination hold them back from participating as a constructive citizen in New Zealand and reaching the goals they had set out for themselves.

\section{Handling Kiwi Perceptions of Somalis: Being a Somali-Kiwi}

As noted previously, the young women all came to New Zealand at a young age so they grew up negotiating these two cultures and handling questions from curious peers from the beginning. For their parents and older siblings, they may not have had to really examine their traditions or beliefs because they may have lived in a community where everyone shared those values. But for these girls, they were raised in a place where they were a minority and were constantly questioned about why they participate in these activities or traditions. Therefore at a young age they had to begin to understand themselves why these things were important and when faced with an alternative culture, see if it was still something they wished to pursue. CA explained this when she said, "People are asking me questions why I am wearing the scarf, why am I, you know, keeping my traditions while living in New Zealand, you know, New Zealand is a free country why don't I just join the Kiwis, you know? But, I guess that it's 
important to keep your culture, that shows that you are proud of who you are, at the same time you show other people you have a different culture and you maintain it while you live in a different country." (CA Interview, 17/08/12). PB reflected on the importance of keeping her culture as well as she said, "it's important to have roots in to pass those roots down to the younger generation. Because you are Kiwi, but then again in a sense, you are still African or Somalia, east African. And to have those roots, its kinda, you still have your roots back home. No matter what, you still have a sense of identity." (PB Interview, 29/08/12).

It was sometimes difficult to try to explain to Kiwis why they couldn't do a certain activity or why they had to behave a certain way. In a way, it meant they had to constantly reaffirm their desire to follow this path and stay true to their cultural heritage. Especially as a teenager where rebellion is the norm, the Somali girls needed to have a strong understanding on the significance of these traditions and why it is important to follow them. PB explained this further when she said people from New Zealand “...didn't understand why I couldn't wear short skirts or the singlets with the concert uniforms and stuff. So I think sometimes I had to kinda reinforce "Oh I can't do that because of my culture" and then that would be it." (PB Interview, 29/08/12).

Since the young Somali women grew up in New Zealand but also had a large Somali cultural influence at home, they began to take on a role as ambassador for both cultures in each realm. Often the girls would act as translators and run errands for their families and then answer questions and explain their Somali culture to Kiwis. Between all the conversations, there arose three factors that greatly impacted the young girls in handling Kiwi perceptions of Somalis: media influences, the stereotypes of terrorism associated with Muslims and the stereotype that all refugees wish to return to Africa. 


\section{$\underline{\text { Implications of Media Influences }}$}

Media influence was a factor that came up with most of the young women in regards to negative perceptions of Somalis in New Zealand. The Somali population has dwindled since the 1990's and the girls say that with the smaller population it is harder to break stereotypes about their culture. Most of the girls said that before university, they were one of the only Somalis in their school and had to deal with a great deal of stereotypes in regards to them being both Somali and Muslim.

Most of what Kiwis know about Somalia is from the media which tends to be negative. The girls brought up various stories about Somali pirates, famine, war and disease in Africa that Kiwis thought were true of all Somalis. PA explained how poorly Somalia is depicted in the media when she said, "In my opinion, we are not all from the same area, there is a whole country, you have to know the country, the continent and all this stuff. The media just portrays a certain area where everybody goes crazy."(PA Interview, 24/08/12).

They would also joke about the ignorance of Kiwis regarding Africa as a whole. One of the first times I met the girls in an informal setting, they asked me what the capital of Africa was and laughed when I asked of which country. They take a light-hearted approach in Kiwis lack of knowledge about Africa and use it as a sense of unity among their own community. PB discussed this further, "there is the misconception that a lot of the people that are refugees, like some other refugees, are uneducated or they come from like what you see on TV with the UNICEF ads and stuff. "Oh, is that how you grew up?" They don't know that your parents could have worked the United Nations or your dad could have been an accountant back home." (PB Interview, 29/08/12). PC echoed this reflection when she explained "the media portrays Somalis killing each other, Somalis fighting. And so there is...people think we are barbaric kind of community who just there, blood thirsty community, so they are like...some of them are told "I hope you're not Somali" by just looking at them." (PC Interview, 31/08/12). 
Some of the girls did feel that it could be hard at times to have their peers carry these views on their home country, but they believed that by building up a Somali community in the area and informing their own peers about the truth of their home country, they can slowly turn around the impressions of Somalia in New Zealand.

\section{Conclusion}

For these young women, creating their identities as Somali-Kiwis was difficult yet necessary. They arrived at a young age so they were raised in New Zealand, yet lived within homes connected to and reflective of a different world. They had to simultaneously learn the Somali culture from their elders while helping them adjust to Kiwi society. They were given a type of ambassadorial role for each culture to change perceptions of each and show that both had enduring and positive qualities. And all of this had to be managed while attending school, working and helping out with familial obligations. It was quite a large task that at times could be overwhelming for the girls.

However each young woman I worked with had a sense of grace and maturity. They told numerous stories about stereotypes they had to face in regards to their home country, their culture and their religion and how it was challenging, but also an opportunity to change people's perceptions. At home, instead of focusing on the challenges that their elders and community were facing, they would come up with success stories they faced as well as future ideas to improve their situations. This balancing act just empowered the young women to work harder, dream bigger and be a constructive participant in each culture. 


\section{Chapter 5 - Influences on the Resettlement Process for Some Young Somali Women in New Zealand}

For a refugee, resettlement is both a goal and a process. Most of the young women didn't remember arriving in New Zealand and experienced the initial resettlement process through their elders. They continued to handle their own struggles within a society that is not always prepared to handle their specific cultural needs. They constantly renegotiated their roles in society by handling Kiwi perceptions of their culture and dealing with various stresses in their lives while still trying to reach their goals.

All the young women described differently what they thought "successful resettlement" meant but they shared common themes. Having a degree of independence and selfsufficiency was the main idea they identified as well as having confidence and pride in their culture and themselves. To achieve that level of success, the young women discussed the various things they needed to do and handle to resettle. In this chapter I will discuss these elements which include maintaining and balancing both their Kiwi and Somali cultures, navigating the realms of higher education, immigrating to Australia and their own recommendations for future refugee resettlement.

\section{"Walking the Line" - Straddling the Two Worlds}

For the young women, balancing their two cultures was not just about maintaining their heritage, but was also seen as a survival tactic. The girls needed to learn how to be able to move between both cultures to successfully communicate and function in each realm. All the young women were very aware of this situation and had no issue describing the ways in which they did this. In the previous chapter, I discussed how the young women felt about growing up in two differing cultural worlds and why they felt it was important to keep both present in the lives. However, in addition to reflecting on the reasons for keeping both cultures, the girls also realised it had a huge impact on how they resettled in New Zealand society. 


\section{$\underline{\text { Reflections on the Influence of Cultural Maintenance on Resettlement }}$}

In the previous chapter, the girls went into great detail on their reflections of the importance of keeping their heritage as well as adapting to the culture in which they grew up. Yet cultural maintenance also influenced their perceived resettlement into New Zealand. The girls all viewed what it meant to be "successfully resettled" differently yet independence was a central theme. The girls believed that if they were able to get a good job after attending university, then they would be able to support their families and not depend on others for assistance. Reaching this point of self-sufficiency was something the young women all aspired to and felt that it would allow them a great sense of pride in their lives.

In order to achieve all this, the girls believed that they had to find a balance and a confidence in both their cultures. The young women were reflexive about their situations and were able to envision how their actions now will impact their future. The young women all realised that they would face some obstacles in attempting to balance these two cultures but believed it was worth it to reach success in their future. PD expressed it didn't matter if hurdles occurred, the girls needed to be strong in their convictions. "Like if you want to maintain your culture, there's nothing stopping you. Like New Zealand is a good place, there are some people who are like racist or doesn't like you as a person...or your religion or your color or whatever you wear, but the majority of the people understand. You can practice your religion if you want, you can maintain your culture." (PD Interview, 10/10/12). It appeared that the girls didn't choose to focus on the hardships, but concentrated on staying true to themselves and what they believed in.

In addition to a sense of independence as an aspect of "successful resettlement", the girls felt it was important to have pride in their two cultures in order for people to respect them. The young women all felt that if they didn't have a sense of assurance in who they were, they would never be successful in school or their future career. As KIA explained, "If you don't acknowledge who you are, if you are not proud who you 
are, no one is going to acknowledge you and be proud of you." (KIA Interview, 05/09/12). The girls thought they needed to be confident with themselves at a young age to feel empowered enough to achieve their goals.

The handling of two separate cultures, in this case the New Zealand and Somali culture, was reflected in the literature often referred to as "cultural switching" where young people develop the ability to transition between various cultural norms in order to fit into both the cultural realms (Phinney \& Devich Navarro, 1997; Deepak, 2005; Hedegaard, 2005). The young women showed this when they discussed different occasions where they would use New Zealand slang or go to birthday parties for their Kiwi friends but then act differently in their home setting. All the young women arrived in New Zealand at a young age and were able to pick up Kiwi cultural norms quickly and then acted as a cultural translators for their families. The literature echoed this occurrence as a normal yet complicated negotiation as young people often have a strong desire to fit in to the host society, yet try to appease and aid their home culture and community (Deepak, 2005; Hedegaard, 2005).

\section{Negotiating the Realm of Higher Education}

For Kiwis living in New Zealand, attending a university or some form of higher education is the best avenue through which to get a job and enter a career. For all the young Somali women I worked with, higher education was important and relevant as they were attending university during my research. Therefore, reaching higher education was an incredibly relevant and important aspect of their lives. Beginning university is a turning point for many young people as they gain independence and begin life as an adult. The girls all felt these aspects, but also had to endure the stress of entering a new community with whom to share their culture and manage perceptions of who they were and where they came from.

The young women all enjoyed studying and meeting new people, but they did describe some obstacles they had to face to get to this point in their educational career and to 
maintain success. The young women explained that it was sometimes difficult to navigate what they needed to achieve in high school to get to university and that there were not that many support services tailored for their specific needs. The young women also explained how an increase in positive encouragement from key people in schools and support services could have made a huge impact to their success at school.

\section{"You Aren't Good Enough" - Reacting to Negative Comments Given and Cultural Differences in Understanding the Education System}

The young women felt that in order for girls like them to succeed in school, they didn't just need more support services but also positive encouragement from people in the education system. The girls felt that if there were more people encouraging refugeebackground students to navigate the system and be told they are capable of handling university work, then there would be more Somali women at the university level. PB gives an example saying, "In the high school a lot of the girls got told, when they said "I want to go to university", they got told "don't bother, you're not going to make it. Just do like a course or like a cooking program or a sewing class or something". So I think more encouragement from schools for girls to go for higher education would be something that's needed." (PB Interview, 29/08/12). This perception of a lack of positive encouragement can greatly impact young people because they often internalise certain labels such as "refugee" and this can impact how included they feel in the new society and impact how well they adjust (Barnes, 2001; Reese, 2002; Kumsa, 2006). For the young women, this feeling of not being included or believed in lessened their sense that they could continue onto higher education and reach their goals.

For the girls who remember when they first started school in New Zealand, like PD, they described how difficult school was initially. PD explained how school was "... the hardest thing I think I faced when I came here. Well I didn't speak English, so that was a big barrier. And the culture, you know, not having friends, not having the people that you grew up with. That was hard. But yeah, as time went on, I think I 
overcame. "(PD Interview, 10/10/12). Additionally, the girls had a hard time branching out beyond their culture and exploring the opportunities in New Zealand. The young women discussed how many Somali girls wanted to be nurses because that was a job that was seen as important and stable in their culture, but that they wished more girls would branch out and explore different opportunities. KID explains that "before it was mostly nursing, nursing, nursing. But now we are kind of branching out, so there's girls doing accounting, development studies..." (KID Interview, 03/10/12). Yet it seems that although the young women who remember coming to New Zealand felt this anxiety initially with the education system, they overcame any issues and made it to the university level.

For the rest of the young women, they experienced this confusion about the New Zealand education system through their mother's confusion. Usually their mothers came over here as a solo parent and had to endure a great deal of stress trying to support their family and allow them to adjust into this new society. The young women all said how their mothers wanted an active part in their children's education, but had a hard time understanding and it would upset them. PC explained how the confusion felt to her firsthand when she said, "Even the parent it's hard with communication. What does failure look in New Zealand? We don't know. I could not get my head around it, I still don't. I didn't understand... if these papers are different level in the same class, what does that mean? And maybe the way I'm asking the question, I couldn't frame it into a way that she can understand, the teacher. I gave up asking questions, I give up trying to understand what she was. So I just listen and sit." (PC Interview, 31/08/12). For the young women, knowing that their mothers' underwent this difficulty upset them and made it harder for them to feel included in the new society. Yet even with these obstacles, both their mothers and the young women themselves were extremely happy to be attending school in New Zealand and the possibilities that meant for their future.

The young women also worried about members of their community who were older. As discussed in the previous chapter, community and family are an immensely important 
component in the Somali culture, so it makes sense the girls would be concerned about their entire community. This is a common concern and stress for young former refugee people as they often take on the responsibility and stresses of their own community in addition to their own (Aiken, 1999; Reese, 2002; Rudmin, 2003; Bek-Pedersen, 2006). Often older Somali women are put in language classes as they are too old to attend high school. However, these classes are often seen as almost glorified babysitting groups and do not seem to encourage higher learning. KIA remembers her experience, "When I came here, I think was like 26 years old and I joined a class and I didn't want it after two days. I walked out because the class was not what I wanted. It was just...I have to look at this coloring book, beautiful book, covered by fish and colorful fish. And I have to draw and I have to knit and I was 25 years old! (Laughs). I didn't want it. These classes are subsidized by or fund by the city council and this is not what any intelligent person wanted to do, especially when they are young" (KIA Interview, 05/09/12). Again, it is not enough for the young women to improve their own situation in order to succeed, but they want to enhance the lives of their whole community. The success of their community is also imperative for

the perceived well-being and success for the young women (Gifford et al., 2007). If the young women do not feel they have a stable home life or family members are not succeeding, they will have difficulty adapting to their surroundings and succeeding in their goals (Guerin \& Guerin, 2002; Gifford et al., 2007).

\section{$\underline{\text { In Regards to Tertiary Study }}$}

Since all the young women I worked with were at university, they talked mostly about the positive and negative aspects that were associated with tertiary study. Discussing their opinions and experiences regarding tertiary study was important because there was very little literature regarding former refugee young people at the university level (Guerin \& Guerin 2002; Horner et al., 2006; Humpage 2009; Joyce et al., 2010; O'Rourke, 2011). The girls all were successful in gaining access to university, but they still reflected on some aspects that were difficult and may limit others from reaching their educational potential. 
Before going into the details behind what was difficult with tertiary study, the young women all explained how the main reason obstacles occurred was due to the small number of Somalis at their high schools. When a certain population is small, it is difficult to find services that understand their needs and how best to help. KID attended Massey University where there was a very small Somali population so in regards to support services there were "not very culturally appropriate ones. I mean I'm sure there would be at other universities where there's a bigger population, but at Massey there's...I think there's like a handful of Somali at the uni, so not culturally appropriate as much"(KID Interview, 03/10/12). Others turned to members of their community and family members above them to help since they lacked assistance at school or university. PD had this experience and thought to herself, “Thank God I have family members like relatives who've gone to university. So they kind of guided me, but I didn't have any guidance from the school or from anyone else actually. "(PD Interview, 10/10/12). Although all the young women I worked with were still able to achieve their educational goals despite these hurdles, lack of academic support systems may be something that limits more girls from gaining entrance into universities.

The young women all agreed that there was not enough support or guidance in high school to allow them to fully understand what they would need to gain acceptance into university. There was confusion regarding what qualifications one needed for university entry, the difference between core and elective courses as well as what degree to choose. PB explained her degree confusion because she "didn't know about 'Development [Studies]' before coming or finding papers. So it was kinda trial and error kind of thing. And I stumbled into Geography." (PB Interview, 29/08/12). For most of the young women it seemed that getting into university required a great deal of help from their own community and navigation through their own determination instead of help from any school services.

This situation did change for most of the young women once they reached university. The girls all claimed to use some sort of service provided by Victoria University, 
mostly the Drop-In Centre. This service is a tutoring centre provided by the university that is for refugee-background students and run by students and overseen by an academic staff member. PA said that she often went to the Drop-In Centre and that "they are really nice and really helpful people. I like them." (PA Interview, 24/08/12). The young women also discovered that there was a much larger community of international people at university and this helped them feel more accepted. PD explained how it was much easier to explain her culture to people who also shared a different culture from Kiwis. "When I started uni, like I met people from different countries, all over the world who are interested in knowing about your culture and why you wear the headscarf, and when you studying together and when you tell them, "Ah I have to go to pray", they'll be like, "Oh yup, we know what you're doing." (PD Interview, 10/10/12). So although the girls felt a lot of hardship and faced obstacles to get into university, once there they felt it was much easier to fit in and feel accepted than it had been in high school.

\section{Considering the Transfer of Qualifications from Somalia}

In regards to higher education, the girls all faced a number of hurdles, but they understood that they did have an advantage in their community because they grew up in this society. For their mothers and aunties who grew up and built their entire lives in Africa, they have a more difficult time transferring their jobs and goals into this completely new culture. Often, since their qualifications do not translate to New Zealand, they are forced to do cleaning jobs or stay at home with the children.

PB explained how this aspect sometimes gives Kiwis an unfair perception of their families. She says that Kiwis do not know “...that your parents could have worked at the United Nations or your dad could have been an accountant back home. But coming here, because the qualifications don't like come back to New Zealand the way they do back home, that's why they've had to become taxi drivers and stuff. So there is a misconception that you, Africans are what's seen on TV and they are not really the reality." (PB Interview, 29/08/12). 
As this was a distressing and important topic for the girls, they all offered advice on how to remedy it for other women. Most advice revolved around a way to transfer qualifications from Africa to New Zealand. The young women were upset that with everything else their elders had to deal with regarding this transition, they also had to start over in their careers. PD explained her thoughts on the importance of this programme, " I think something like something to try and get the skills that people once had back home developed now that they're here and not just disregarded and make them start from the bottom up again." (PD Interview, 10/10/12). Again, it was imperative for the girls to feel like their elder's lives could be improved upon so then they could feel successful as well.

\section{Emigration to Australia and its Implications for These Young Somali Women}

Unexpectedly, a topic arose in every single interview and focus group when the young women and I were discussing future plans. This topic was the emigration to Australia by a large portion of the Somali community in New Zealand. After the first couple of interviews, I noticed that every girl discussed how they were heading to Australia within the year or after they graduated. I began asking questions probing into why this seemed to be a popular choice. Apparently, due to the lack of job opportunities here and the larger communities established there, Australia is seen as a much easier place to make money. Therefore, Australia has become a much more appealing place for these girls to go once they graduate from school to start their careers instead of New Zealand. The emigration to Australia was not found in the literature. All the literature on resettlement focused on coming into the host society, but nothing about trying to leave and resettle again.

Even though it seemed each young woman was going to Australia at some point, that didn't mean each girl desired to do so. Some of the young women had a real dilemma dealing with the decision to go as they felt New Zealand was their home and they wished to stay. PA shows this concern when she said, "I don't want to go... I don't 
want to go to Melbourne. Why go to Australia? I grew up here, it's me. But it's not my position. I'm not happy." (PA from Focus Group, 06/09/12). PA was unhappy that her parents were forcing her to leave New Zealand, but understood that it wasn't her decision.

Yet even with these trepidations, all the young women were headed there eventually and described in detail the reasons for the move. They explained the opportunities that are available for them when they move, the benefits of having a larger Somali community and the implications that has on their future success.

\section{Increase in Opportunities Available}

In New Zealand, the Somali community has a strong desire to find better pay and job opportunities. And as KID explains, it may be a more imperative move for Somalis rather than other groups because "... if you're a community that needs to work your way up, you need to go do it in a place where that's more possible." (KID Interview, 03/10/12). Since they had an important need to support their families and succeed with their resettlement, many people from Somali communities nationwide had the drive to do whatever they needed to survive, which meant moving to Australia.

One impact of moving to Australia for the young women was more opportunities to gain qualifications. It seemed that in New Zealand, all the girls I spoke with were juggling quite a few obligations. They were attending university, working part-time, and dealing with a lot of family responsibilities. Obviously, this could get a bit overwhelming and some of the girls had to cut out some obligations to make it work. CA had decided to pause her studies to be able to work some more to support her family. She mentioned how one appeal of Australia was that there were more people in her situation which helped her not feel alone. She explained, "When I went to Melbourne, mostly none of them are studying uni, they all have a job. So that kind of makes me, encourages me to get a job, not think about why didn't I just finish uni straight away, you know? It just makes me go there, get a job, and then make a decision next year on what I'm going to do." (CA Interview, 17/08/12). It seemed 
that when there were other people who were going through similar struggles as the young women, it allowed them to feel empowered to not give up and keep working towards their goals.

In addition to increased opportunities for qualifications, the young women were attracted to the plethora of jobs and an increase in pay rates. The girls would talk about how they needed to help with their families and needed money to study, so getting a good job was imperative to their perceived well-being. PD described this attraction, "So the money that they're getting paid is a lot, they get \$30 dollars an hour, so that's one thing that could attract people. If I can earn this much, you know in an hour, whereas in New Zealand maybe it's going to take two, three hours to earn. So that's maybe one of the reasons." (PD Interview, 10/10/12). The young women also talked about how most of their families are still trying to bring over relatives through the family reunification process but it is an incredibly pricey procedure. These costs makes gaining employment and helping with their families even more imperative.

\section{The Effect of Living within a Larger Somali Community}

Although the girls all agreed that job opportunities were the main reason they were moving, they admitted to a larger Somali community being another important factor. All the young women had discussed how the Somali community in Wellington was fairly small and they usually didn't meet people outside of their family until university. This made it quite difficult to feel connected to their Somali heritage which is an incredibly important aspect of their culture.

The community was also one of the main avenues of support for the families when they transitioned into New Zealand and many of the girls explained how they could not have done it without them. CA explained how having people in your community help you when you arrive is incredibly useful. She said, "When you are new to the country you need to know where everything is. But if you don't have someone to show you around then you kinda get lost or you can do the wrong thing. It was really helpful for my aunties to be here and show us around and everything like be ready for us." 
(CA Interview, 17/08/12). The girls also explained how nice it would be to have this large community in Australia where they wouldn't feel so alone with their beliefs and they would be able to fit in more easily. The girls, although all proud of their culture, did have struggles practicing within a foreign culture. So to relieve some of that pressure could make their lives a bit easier and allow them to focus on work or school. The women also discussed how it can be hard for their mothers and aunties to make new friends and have a social life. They were all worried about the isolation the older women sometimes feel and how depressed they could be. This larger community allows for greater networking and for women who are going through similar circumstances to find solace with each other. PC further explained this, "And I think it's also hard to make friends in New Zealand. It's not easy to make friends. If you have a bigger community, you don't have a need for that. Yeah, you already have that support. You have a lot of things happening." (PC Interview, 31/08/12). As mentioned previously, the girls hold a great deal of respect for their elders, so when they are in a better place emotionally and feeling connected, then the girls feel more positive as well.

Due to the larger number of Somalis in Australia, the girls perceived the Somali culture received less discrimination than in New Zealand. They claimed wearing the head scarf in public and at work was much more accepted in Australia and detailed the impact that can have on their success. The girls all were doing well in school and with work, but the pressure of maintaining their culture had an impact on their stress levels and the young women were excited about the prospect of alleviating that stress a bit.

Given the ability to be surrounded by aspects of their home culture again really excited the girls. They all explained how there were so many cultural shops, restaurants and places to buy appropriate clothing in Australia which was lacking in New Zealand. KID explained, "there was just tonnes and tonnes of very cultural Somali things. So there were Somali restaurants and there was like a mixture like in every suburb kind of thing, pretty much, like in every suburb. And everything was kind of catered for Somalis. You would have Somali accountants and Somali stores..." (KID Interview, 03/10/12). Being surrounded by their own culture also allowed the 
community to feel more accepted and perceived less discrimination about their beliefs. When there were a large number of people practicing the same traditions, they were less susceptible to people making negative comments about it.

The girls described "successful resettlement" in terms of independence and feeling like a contributing member of society. But in order to do this, they felt that they needed to be confident and comfortable with who they are and thought this is easier achieved in a place where there are more members of their own community. Some of the girls felt that in New Zealand, they are only seen as African or a refugee and didn't feel that they could always reach their full potential. KIA discussed how they all want to become the best of themselves and 'you just want to change because you can't always just be a refugee and you need the growth, education and become a member of a society and useful contributor to society. Get education and so Australia offers that." (KIA Interview, 05/09/12). For these young women, successful resettlement was more than just finding a job and making money, they wanted to be proud of the life they have made for themselves and the people that they have become. And feeling culturally accepted and confident can bring about that kind of change.

Although the main point of living in a larger Somali community was for the emotional and cultural aspects, there was a financial gain for the girls as well. The young women discussed how with the larger communities, there are much more Somali-run businesses which then hire Somalis as employees. This not only grants more culturally appropriate job opportunities for the girls, but also allows for more Somali items such as food and clothing to be available.

Yet even with all these benefits, many of the girls were still hesitant about leaving their home in New Zealand. Since most of them had grown up here, they viewed Wellington as their home and they were not so eager to leave. Many of the girls wished that a larger Somali community could be built in Wellington and remedy some of those issues. However, the girls were aware that the job opportunities in Australia make it hard to resist and it could be difficult for New Zealand to support a larger community. KID 
further explains this dilemma by saying, "I guess for the refugees it's good to build up a community, but I guess it would be a strain on government agencies. Because there will be more support needed in one area and what if there is not enough resources? So it's definitely good for the refugees themselves, not so much on the local government." (KID Interview, 03/10/12). Despite their concerns, the girls were all likely to succumb to the allure of Australia. This is an interesting component of these young women's resettlement because usually resettlement means integrating into a new community and becoming active participants in the society. But with New Zealand, due to its small size and lack of enough opportunities, successful resettlement deals with leaving New Zealand and being successful in another country.

The Implications for New Zealand with the Emigration of Young Somali $\underline{\text { Women }}$

Although all the girls had the intention to move to Australia in the near future, they were already beginning to feel the effects of living in New Zealand with many other Somalis gone. As mentioned again and again, community is such a central aspect of all Somalis lives and to have that community dwindle can make a huge impact. The already decreasing numbers were felt at community events and gatherings and the young women worried about what fewer people could mean for the community's cultural maintenance. KID joked that she didn't think any Somalis will be left in New Zealand soon, "Give it some time and it will be like a thing in the past. Like, "Back in the day when Somalis used to live here...." (KID Interview, 03/10/12). For the Somalis that are left here, they will feel a huge cultural loss and possible increased isolation.

In addition to the people feeling an impact from the move, organisations that cater to the population are being affected. A lot of the organisations are already feeling a financial pinch and are beginning to rely a great deal on volunteers and private donors. But if the population numbers drop and there is not as much perceived aid that needs to be administered, the organisations could lose a great deal of funding and not be able to continue. The young women were worried about this aspect as they hoped that elders in 
the community who may not make the trip to Australia would be OK on their own here and if they would lose the aid that they have come to depend on. Again, disturbance in their community or for their elders greatly upset the girls and made it harder for them to leave.

\section{Their Recommendations for Future Refugees to Help Navigate the Resettlement Process}

All the young women I worked with were aware of the unique position they were in by being Somali but growing up in New Zealand. Since they saw themselves as insiders to both cultures, they also felt that they acted as ambassadors to each side and had the distinctive view-point to give constructive advice on how to remedy issues for future refugees navigating this transition period. Not only did they have many ideas on how to improve the situation, but they wished to express them and help those in the future have an easier time than they did.

First, the young women discussed how support services could improve the lives of refugees, particularly women. The girls saw that the women of their community tended to have a harder time adjusting to this new society and they believed that services should attempt to reflect that. KIA described her opinions on helping women by exclaiming, "Educate women open schools that are useful. So when women walk out and finish their school, she has the ability to take care of her own family, go to offices and able to fill out her own forms and not always depend on people. And she can help her children with homework. There is nothing the same as helping your child with something. I know a lot of women are not changing their pursuit when they felt this is a failure and nobody is giving us the education or the resources we need." (KIA Interview, 05/09/12). KID also added the usefulness of feeling independent by saying, "Successful resettlement would be to be happy, comfortable, secure and to be gaining independence. It's kind of being empowered to do your own thing. And to sustain yourself to an extent." (KID Interview, 
03/10/12). By helping the women feel independent and successful, they will start a cycle where young women begin to do the same.

Secondly, the girls discussed how one of the problems with refugees first coming to New Zealand is they hold a great deal of expectations that are unrealistic. PC describes this further saying, "They are coming with a lot of expectations. They think they moment they land, they think they'll have a good house, they'll have a good living standard, it's very safe and they'll find a job. That's the expectation that you are coming with. Otherwise, you'll have an education and you'll have a job immediately after finishing your education. But that needs to be clearly explained or clearly passed that message to them of what's realistic." (PC Interview, 31/08/12). When these expectations are not met and their life here is much different to what they thought, they begin to feel a sense of desperation, depression and anxiety. The girls all felt that if they were given more realistic portrayal of what will occur and how to handle it, they would have been more successful.

Lastly, the young women felt that it could be helpful to really emphasise the support services that are catered for them in their communities. The young girls explained that the accounts they heard from their elders was that the Mangere Refugee Centre, where refugees spend the first 6 weeks when they arrive in New Zealand, spent a great deal of time discussing overall services, but nothing specific to the areas to which they were heading. The Wellington Somali Council attempts to alleviate some of those issues by providing orientation services that explain the services and benefits they are entitled to in Wellington. The young women all thought this was a beneficial service and would like to see this in other areas of the country as well.

\section{Conclusion}

Resettlement was a different process for the young women than most other refugees as they grew up in New Zealand yet watched their elders struggle through this transition. The girls faced their resettlement by attempting to handle succeeding as a Kiwi in New Zealand and helping their community navigate as a Somali. Although the young women 
discussed this maintenance of two cultures as being difficult at times, they all professed a love for New Zealand and view it as their home. Resettlement meant something slightly different to each girl, but each woman felt that the process included feeling confident and comfortable celebrating their cultures, having the ability to gain meaningful employment and be able to support their families independently. The mass emigration to Australia was an unexpected aspect of their lives that the girls felt was meaningful in the ongoing resettlement adjustment. Their intended move to a new country highlights the determination of these young women to do whatever it takes to support their families and reach their own goals. The relocation process is not an easy one and most of the girls loved New Zealand and didn't want to leave, but they will do what is necessary for their families and their own future.

All these young women hold a maturity beyond their years and constantly want to help others and make their community better for every person. The girls wished to give advice on resettlement to future refugees because they have lived through it, experienced both cultures and were able to persevere. It's impressive to me that through all the hardship and turmoil they and their communities have dealt with, they hold no remorse or anger and use their experiences as fuel to not only achieve great things, but to impart their knowledge to better the experience for future refugees. It is this selfless attitude and the wisdom of and generosity of this community that I believe allows them to successful handle any obstacle they face. 


\section{Chapter 6 - Views and Support Provided by Organisations in Wellington to Aid in Resettlement for Young Somali Women}

Various support services and organisations within New Zealand featured regularly in the interviews with young Somali women. Whether they encountered the services directly or through their family's experiences, these organisations were a huge component of the girls' resettlement processes. In this chapter, I present the perspectives of some key stakeholders within these organisations: Refugee Services and the Wellington Somali Council.

These two organisations held close relationships with the Somali community and offered unique perspectives into resettlement. The organisations usually employed a large number of refugees which gave the employees an interesting advantage of partaking in the transition both on a personal and professional level.

In this chapter, I discuss the opinions of some representatives and workers in these organisations in regards to the resettlement of young Somali women in Wellington. I first provide a brief background of these organisations. I then present key stakeholders' opinions about the influence of family on the girls' resettlement and the impacts of Australian emigration and restrictive funding on the organisations' success.

\section{$\underline{\text { Background of Organisations }}$}

There are many organisations that cater to former refugees within New Zealand. The young women I spoke with mentioned a few key ones that they and their families closely worked with during their resettlement transition. One of these organisations was Refugee Services. Refugee Services has been in existence for 40 years in New Zealand helping with the resettlement transition for refugees. It was started by an Inter-church commission to represent the faith community in helping with refugee resettlement (Refugee Services, 2009). In 2004, the organisation underwent a large restriction of its governance including a formation of a Board to oversee functions and by 2008 it was 
officially named Refugee Services Aotearoa NZ (Refugee Services, 2009). Recently, Refugee Services became a part of New Zealand Red Cross which will change its funding and governance structure to provide better support and services to former refugees in New Zealand (Refugee Services, 2009).

Refugee Services provide 400 support services each year and rely heavily on the 100 volunteers they utilise to aid in refugee resettlement (Refugee Services, 2009).The volunteers in Refugee Services first get an orientation about the overall New Zealand refugee system and what happens up at the Mangere centre in Auckland. The Mangere Refugee Centre in Auckland is the first stop for quota refugees where they spend their first six weeks entering the county. The former refugees complete an orientation programme there which focuses on English classes and information about law, customs and living in New Zealand (NZ Immigration, 2013). The former refugees are then placed in a town in New Zealand with a Refugee Services office such as Auckland, Hamilton, Wellington or Christchurch to name a few (Refugee Services, 2009). The Refugee Services volunteers then receive some training on how to effectively communicate with people from different cultures, but not about any particular cultural groups. KIB explained how this wasn't a problem though because "the thing with Refugee Services is there is a volunteer coordinator and they do have a number of cross-cultural workers, so if like an issue came up that really was affecting you or like was holding up the family's progress, you could always go back in those initial stages to the coordinator." (KIB Interview, 07/09/12).

Once the training is complete, the volunteers are put into teams of about three or four and are assigned to a family. They then stay with that family for six months helping them with daily activities such as setting up their house, getting groceries, helping with support services such as Work \& Income, enrolling their children in school, going to the doctor and navigating through the public transport system. The role of the volunteer is to try and help the families with their initial settlement period and prepare them to function in New Zealand society on their own. 
Another organisation that played a huge part in the young women's lives was the Wellington Somali Council. The Somali Council was started by the Somali community in 2003 because they saw a real need to reach out and provide services to those who didn't know what was available to them. KID explained how there was "... a huge demand for it, huge demand. But this was before the [Australian] migration started, there would have been about 1,500 Somali just in the Wellington region." (KID Interview, 03/10/12). The Wellington Somali Council employs six full-time employees in the office and rely heavily on volunteer assistance. These employees include a social worker, an accountant, a community development manager and various cross-cultural workers (Wellington Somali Council, 2013). They also have a Board that consists of three Board Members and one Advisor (Wellington Somali Council, 2013). In terms of funding, the Wellington Somali Council used to receive a great deal from the Capital and Coast District Health Board, but as Key Informant E (KIE), an employee at the Wellington Somali Council, explained, a great deal of that has been decreased with a government administration change. Most of the council's funding now comes from their own fundraising, private donors and relying heavily on volunteers.

The council provides various resources and services to help the Somali community in Wellington. One of the services they provide is to help people understand the benefits they are entitled to through Work and Income and understanding budgeting and banking. KIA explained the wide variety of people the Council can help by saying, "We have a social worker and a cross culture worker, who are helping any new family that arrive. But not only that, but also the people who already been here for many, many years and still day-to-day need help, in terms of housing, health and other appointments." (KIA Interview, 05/09/12). The Council is a place where the community knows they can go to get assistance no matter how long they have lived or what their problem might be.

The Wellington Somali Council also provides a great deal of classes and meetings for people, especially women, so they can find a place to meet with friends and feel better connected to their community. The council provides a great deal of activities for the 
community including a Boys Soccer Team, a Homework Centre and Holiday

Programme for young people, and various groups for women including Zumba, a

sewing club and a Women's Group that discuss various topics such as nutrition and the importance of breastfeeding (Wellington Somali Council, 2013). Although the Council attempts to help all members of the Somali community, they do like to focus classes and efforts on women to ensure they do not feel isolated. Key Informant C (KIC), an employee of the Wellington Somali Council, describes some of the things they offer for women, "We have Zumba and fitness classes that we are just starting and [they're] very popular. And we also have a sewing group. We also provide a sort of like a place to meet for women where we have an organization come in to talk to them about different topics like diet, WINZ benefits, how to keep your house warm with the Sustainability Trust. We had one about breastfeeding and nutrition during pregnancy. So that's specifically for women. We run the women's meeting group, it's every fortnight." (KIC Interview, 12/09/12).

\section{The Resettlement Process of Young Somali Women in New Zealand}

One of the main factors influencing successful resettlement of young Somali women was identified as family. Organisational representatives all confirmed how the close knit community of the Somali in Wellington is vital to their survival and an important component in maintaining their culture, but can also be a reason the girls have difficulties in resettling. Two main aspects the key workers in the organisations attributed to the girls' resettlement process was the roles of their parents and the impact to their families regarding family reunification services compared to quota refugee services.

\section{The Implication of Parental Roles in Regards to Resettlement}

The key informants from the organisations detailed how the role of parents in the girl's lives had a huge impact on the way the young women would resettle into the 
community. The young women described themselves how the successes of their mothers and other older women in the community were incredibly important and the key informants from these organisations confirmed their perspectives.

The representatives detailed how often daughters followed their mothers' paths or gave up school or work to help with their families if they were not doing well. The connection between mother and daughter in the Somali community was described as being incredibly strong so that one does not succeed or feel they have resettled without the other. KIA, a translator and volunteer for the Wellington Somali Council, gave an example by describing the bond she felt with her own daughter when she said, "I just adore her. Yes me and my daughter, we understand each other(...)Yeah and I like her and I love her and she's a beautiful young woman and I'm sure she's going to achieve all her goals. We're always together." (KIA Interview, 05/09/12). This bond is not only important for the young women's bond to their family, but also in their response and perception of their resettlement. The literature explained how the attitudes of the parents play a key role in how the young people respond to the transition. If parents are supportive and have a positive perception of the new society, than the young people will also feel success and inclusion (Chen \& Sheldon, 2012). The key informants from the organisations realised that to truly help the young women resettle, they needed to take a look at their mothers' and older sisters' resettlement process as well.

As mentioned before, the young women did not really discuss their fathers or other male presences in their lives. Yet, the representatives from these organisations all indicated that the man of the household was a very large indicator of how successfully these young women would succeed in New Zealand society. Often it is the fathers or men in the community that decide if it is appropriate for young women to attend certain classes if they are co-ed, or if they can participate in a sports team. KIB explained this further when she noticed that some of the older girls were not able to attend English classes because men were present. She decided to start her own class for these girls, but still found that the men of the community were a bit concerned. She explained," If someone new was coming in, sometimes their husband or their father would come 
along, basically to meet me and to just check out the situation and make sure that they're weren't strange men in this home, that it was women, obviously to meet the man of the household and check that he was alright with what was going on. And sometimes, they would come and sit with the man of the house off into another room, you know? It was kind of like they were keeping an eye on us." (KIB Interview, 07/09/12). She explained that such actions were performed without malicious intent. These men wanted to make sure their Somali cultural values were respected and were also trying to navigate and find their place in this new culture. That said, their decisions about what is appropriate had a huge influence on what young women were allowed to do and not do within this new society.

\section{Commenting on the Difference of Services Between Family Reunification} and Quota Refugees

As mentioned previously, it is impossible to focus on the young women's resettlement independent of the wider resettlement processes of their community both in New Zealand and back in Africa. The process of family reunification was something the girls talked about often and the organisations echoed its significance. However, family reunification is a huge process that takes a great deal of money and time and once the family members have come over, their struggles do not completely end. The girls often discussed how family members coming through the reunification process had to go through a great deal of stress once they arrived and the resettlement process differed greatly from those coming through the quota system. Since there are no longer Somalis coming through the quota system, this was a pertinent subject for both the young women and the organisations with which I talked.

Family reunification was incredibly important to the girls and often acted as a larger driver for them to go to school and get a good job so they could save up money to bring over family members. But they were also concerned about resettlement and how it can be difficult for new family to adjust to life in New Zealand. As detailed earlier, refugees coming through the quota system receive a transition period in the Mangere Centre and then a Refugee Services volunteer in their new town. However, family reunification 
refugees do not receive any of these services and their resettlement depends on their family members. This situation can make their transition difficult.

This lack of services for family reunification and resettlement was seen as a problem. This is in accordance with some body of research on refugee resettlement as the host society not also providing adequate services to support refugee resettlement (Banki, 2006; Hovil, 2007). A host country is responsible for upholding UN Human Rights Requirements when they assume the responsibility of taking in refugees and this includes providing services to help with the transition (Hovil, 2007; Fiddian-Qasmiyeh and Qasmiyeh, 2010). Key informants echoed this sentiment when they noted that even though these refugees are coming to meet up with their families, they still face the same issues and still need support to navigate through New Zealand systems. Often their family members are busy or are still facing their own resettlement problems and are not adequately equipped to help them. If they are bringing their children with them, this can add further stress and discomfort to the situation.

Key informants were well aware of these discrepancies and had trouble attempting to help. They did not receive funding for anyone other than quota refugees. KIB described how Refugee Services attempted to help saying refugees under family reunification aren't "technically [not] supposed to get assistance from Refugee Services but basically if...yeah, for a few cases that I've worked on the family came through the quota systems, has this relationship with a Refugee Services, has managed to find one of their children or their father or their sister, has got them over and Refugee Services basically "We can give you one volunteer to kind of help out." And it's been a little bit ad hoc. But unfortunately...yeah I think it's a huge issue that they don't...they're not eligible I think for like the benefit and all the other things that assistance that quota refugees are. " (KIB Interview, 07/09/12).The Somali Council also understood that they needed to change the way they provided services for refugees coming in through family reunification. KIE explained, "We work with them because they won't fit the criteria for Refugee Services. And what we do is sort of like an emergency kind of support. We help them...like getting their benefits if they're 
entitled, sorting the housing and English courses, well school for the ones who need it." (KIE Interview, 12/09/12). Family reunification puts organisations in a difficult position to fill in the gaps left by the government in providing services for these groups, but they were doing their best to help people resettle and succeed in New Zealand.

\section{The Impact of Emigration to Australia}

Emigration to Australia, as noted earlier, was a prominent issue in my discussions with the young women. They expressed their reasons for planning to make the journey in the future as well as the implications for their community. It was imperative to get opinions and inputs from the informants on this emigration because there is a large gap in the literature regarding resettlement into a second country. The key informants also noticed this exodus from the Somali community and shared in opinions about its impacts on the Somali community in Wellington and their own organisations.

Key informants felt a real cultural loss with people leaving the community and found it hard to implement more projects with decreasing numbers. They also worried about those who were left in Wellington, especially older members of the community, without their family members or friends around them. These organisations took great pride in the fact that they were run and implemented by former refugees, but this is becoming increasingly hard to do with less Somalis in the area. KIC explained how the Somali Council was feeling the loss saying, "First our board, they all left. We only have two people and one is very...still in the hospital going through rehab. We only have one person in the board, one Somali." (KIC Interview, 12/09/12). Emigration was greatly effecting these organisations when their key stakeholders and employees are leaving the country.

With decreasing numbers in the Somali community, there were also fears for the overall future of the Somali Council, in particular changes in the government, a lowering number of Somalis in the community and a decrease in private donor funding have all 
left these organisations with limited resources and a decrease in staff. Such cuts had implications for the support they were able to provide.

One area the organisations wished to improve was support for women and youth. As noted earlier, it can often be difficult for Somali women to attend English classes or other events if men are present. However, due to limited funding, there is not always a great deal they can do to provide women-only services. KIB explained, "It would be amazing to say we have two classrooms running simultaneously, one for men, one for women. But A. there's not the additional classroom, and B. there is not the additional teacher or salary for a teacher. And so it has to be mixed, like that's just kind of the reality." (KIB Interview, 07/09/12). KIC also described the classes the Somali Council would like to start for women such as "more sports like swimming classes and stuff like that for women. We also want to have projects that put the seed for them to become independent and work from home or whatever. That's why we have the sewing group and that's the aim of it(...)it's for them to have the tools to defend themselves, so they don't need someone to speak or an interpreter to defend them cause then they'll know more about their rights as they go. So that's the main thing." (KIC Interview, 12/09/12).

The key informants also had ideas about how to remedy the situation of limited funding. The Wellington Somali Council was actively trying to attract more donors and conducting their own fundraising. The representatives also detailed how they believed that there should be an increase in government funding since their work is so vital to the community. Many members of these organisations believe that the government needs to understand the importance of helping out organisations that cater to refugee services. PD explained how vital it is to help organisations like the Somali Council that actually understand the needs of the community and can really make a difference. She clarified saying, "I think they (government) should support centers like the Somali Council. Before I got involved with the Somali Council, I did not know how much they do for the community. But since I started working there, I've seen the differences they make in people's life(...)At the end of the day, the government is up there and 
people are down there. So they cannot know what is going on underneath. The only people who know are those who work with the community." (PD Interview, $10 / 10 / 12)$.

The organisations also relied a great deal on volunteer and public involvement to conduct their work. The Homework Centre run by the Somali Council was composed of volunteer tutors and all the people that help the families through Refugee Services are volunteers. This is a great way of conducting work for these organisations that do not possess a great deal of funds, but it can also be an inconsistent resource. KIB described the importance of volunteers for these organisations when she said," I just think realistically the government's not going to come through or to like the extent that it has to. And so, for example, the whole set up with Refugee Services is fantastic and I think it's actually about looking at how we can recruit more New Zealanders to give up their time to help. Because if more people got involved and like dedicated their time and energy for free, then it could potentially...you know, it would go so far." (KIB Interview, 07/09/12). The organisations believe that since New Zealand has made a commitment to bring these people over that they need to ensure that they are happy, safe and successful. As KIB states, "I think we made a humanitarian commitment to take these refugees, and if we expect them to contribute to our society, we actually need to invest in them and we need to invest more in those initial stages so that they actually have a chance." (KIB Interview, 07/09/12).

\section{Conclusion}

Organisations like Refugee Services and the Wellington Somali Council play a huge part in the lives of refugees in how their resettlement transition will occur. They provide services that are imperative for the success and safety of refugees and this was recognised by all the young women with whom I spoke.

The key informants I interviewed in these organisations concurred with the young Somali women in their analysis that family and community play a large part in the young women's success and resettlement in terms of their parental roles as well as the 
implications of the differing in services for refugees coming in through family reunification. In addition, the interviewees found that the current emigration to Australia was greatly impacting the cohesion of the Somali community as well as their abilities to function as reduced funding limited their provision of much-needed services. The emigration to Australia was a phenomenon that was not reflected in the literature and brought about an interesting aspect to the young women's resettlement as well as for the organisations. The emigration made the organisations change their focus on supporting a community with decreasing numbers and aiding Somali women in their transition to yet another country.

The resettlement process is a complex, multi-layered process and it is difficult to fully understand everything young women will have to consider, contemplate and navigate to reach their goals. So it is helpful to gain the insights from those who see their journey from a different perspective and can add wider perceptions regarding policy with refugees. Allowing for more views and insights to the young women's opinions and reflections by people who not only work for these organisations, but have experienced the resettlement process themselves, aids in giving a well-rounded, balanced and a richness to their experiences. 


\section{Chapter 7 - Conclusion}

When I first began this research, I had the aim of conducting a FPAR project with young Somali women that would be meaningful and that would empower the participants to create a positive change in their community. The project I have now completed is not identical to the one I initially envisioned, but I believe that it still created work that it is reflective of FPAR principles and that it was facilitated with the girls and gave them a new space to discuss pertinent topics concerning their lives and community. In this concluding chapter, I summarise my findings and give the practical implications that my work may have for the Somali community in Wellington as well as for the wider global context of refugee resettlement. I also review my research aims and questions regarding the young women's cultural maintenance and identity construction through the resettlement process and their recommendations to improve the situation for former refugees. Finally, I give my concluding remarks for this project.

\section{Methodological Findings}

From the beginning of my project, I was very determined to find methodological approaches and methods that would create a project that was for the girls, not about them. I researched various types of methodologies and came upon the ones I thought were most beneficial to our aims. I believe that using a FPAR approach was favourable for the girls as well as for me. Although I like to think that I did my research about Somali culture and immersed myself within the community to gain a better understanding of it, as an outsider one is never truly going to comprehend what and why these belief systems are so important.

By allowing the girls to take initiative and decide the direction the project was going to take, the research hit on topics that were relevant to the girls and things that were new and unexpected for me. I was able to hear about how they felt, why their culture and identity was so vital to their wellbeing and to gain a better understanding of how their community works and therefore, what can be done to help it. 
Although there were areas of the FPAR process I was not able to include, such as much more time for reflection from the girls, I believe the amount I was able to complete with them created a space that the young women used to express themselves in a way they may not have had the chance to do before. These girls had not been active in research before and therefore were also introduced to the aspects of FPAR with which they may not have been aware. The young women voiced a desire to use these methods to create projects in the future that would allow them to share their culture with their peers to help improve the perception of the Somali culture.

I also believe that adding the influence of Appreciative Inquiry into my FPAR project was incredibly helpful as it allowed the young girls to not only reflect on their experiences of resettling and navigating between two cultures, but also to rejoice in their many accomplishments. These young women have been through a great deal in helping their families succeed in this new environment while also working to pursue their own goals. It is important that they are able to reflect and be proud of all they have done and use this motivation to allow them to continue to succeed in the future. Using AI did not limit us from discussing difficulties and challenges in their resettlement process, but made sure that it wasn't always the focus and that the girls were able to also discuss their futures in a positive light. Research regarding refugee resettlement tends to focus on the negative and the problems former refugees face. Although presenting the obstacles in resettlement is necessary in order to improve the situation, it is also important to make room for individuals to celebrate their successes and focus on how their future can be positive as well.

Finally, I feel that using qualitative approaches was necessary for my project to obtain a holistic and meaningful product for my participants. By focusing on the stories and experiences of the young women and hearing the context with which their choices were made, I was allowed to build research that gave value to their capabilities and allowed them to better formulate ways to pursue and achieve their goals. A quantitative approach would have produced research about the girls instead of working with them. By working together and allowing the young women to participate in the creation of the 
project, I was able to help them create a space with which to share, celebrate and brainstorm for the communities and their future.

\section{$\underline{\text { Summary of Findings Regarding Resettlement and Identity Construction }}$}

Of my three main research questions, two were in regards to the young women's identity construction through their process of resettlement. My first question dealt with how balancing two separate cultures affected the resettlement process for young Somali women. This was an important component for the girls as it arose often and seemed to be an aspect that influenced most of their decisions in their lives.

As long as most of the young women can remember, they have been negotiating between two different cultural realms. Therefore it was a bit odd for them to discuss how they go about dealing with these two different worlds as it was so engrained in their being by the time they reached young adulthood. But after more reflection, the girls were able to verbalise the ways in which they would switch between each culture to fit into both. The literature on former refugee youth went into great detail about 'cultural switching' and how it can be a survival mechanism yet also at times harmful for identity construction (Phinney \& Devich Navarro, 1997; Hedegaard, 2005). Although the young women voiced certain occasions of feeling a tension between this balance, such as rejecting invites from Kiwi friends for sleepovers or coed sport outings, the overall feeling was that of acceptance and gratitude for being able to share in the benefits of each culture. The young women took on ambassadorial roles for each culture and this allowed them to discover and articulate the positives of each cultural realm. There were many aspects about New Zealand culture that the girls loved such as being able to attend university and a sense of more freedom for women. Yet they also loved being able to maintain the Somali culture, practice their Islamic religion and use the knowledge of both cultures to help their families adjust to life in Wellington.

It was apparent that arriving at a young age made the resettlement process easier for the young women. They learned the New Zealand cultural norms at the same time as Kiwi children. So they understood that at times it was not as easy for their older siblings and 
mothers to perform activities in New Zealand society as it was for them. Due to the intense emphasis put on family respect and connection in the Somali community, it became the role of these young women to become cultural translators, as well as literal translators, for their family. The girls all took this role seriously and without complaint. Although it meant taking on extra work through school or making the decision to find work in Australia, the young women all knew that their elders had made a huge effort in getting them to New Zealand and now they could repay their family for their sacrifices by helping them succeed in their new home. If anything, this responsibility only made the girls more mature, selfless and empowered to thrive in their own endeavors as they had more than selfish reasons to succeed.

Succeeding in New Zealand also impacted their views on maintaining their culture, giving insight into my second research question regarding how resettling in New Zealand influences the young women's self-identity and cultural maintenance. For the young women, they felt that growing up in New Zealand society actually made them follow their religious and Somali beliefs more than relatives back in Somalia. By showing the girls an alternative culture to their own, they were able to see things they liked and disliked about their own culture and were given a rare avenue with which to view their Somali culture with a different lens. Obviously growing up there was a bit of tension and a slight desire to rebel more as a teenager and attend events with which parents may be a bit hesitant. But it also taught them why there were these restrictions and beliefs and their parents were able to teach their children these traditions while giving relevant examples from the Kiwi culture. For instance, the girls saw how the drinking culture in New Zealand could cause their peers to make rash decisions or mistakes and the girls understood the reasons that their religion and culture does not allow them to drink. Being part of the Kiwi culture allowed the young women to see things that the Somali culture provided that in their opinion New Zealand society lacked. This included an incredibly strong connection to their family, traditional gender roles where the man of the household takes care of his family and Muslim customs that connected them spiritually to their community. The young women expressed how 
grateful they were to then be able to partake in the positive aspects of each culture and share attributes of each with their family and friends.

When the young women would explain what it meant for them to 'successfully resettle', it always involved finishing their education and getting a job in their chosen career. In order to complete this, the girls were all relocating to Australia for better opportunities along with most of the Somali community. This was the most unexpected component to arise out of my research and held great importance for the future of this community. The girls had expressed all the difficulties and challenges associated with resettlement that they and their family members had faced relocating to New Zealand, and here they are preparing for a second resettlement. This emigration showcased the young women's fortitude, determination to succeed and immense maturity. Often the girls were heading to Australia before their parents to find work and set up a home to make it easier for their family to move. This is a prime example of how these young women take on immense responsibility in not only pursing their own success, but aiding their families in any way possible. What is most interesting about this process from an academic standpoint is how most definitions of "successful resettlement" are in regards to going to school, finding employment and making the new host society their home. But in this instance, successful resettlement to these young women means leaving the country and finding these aspects elsewhere. The young women understood that as a community that may need to try harder than native New Zealanders to succeed, that they must take advantage of more opportunities and better options to allow their community to succeed. The girls all love New Zealand as it is the only home most of them have known but their drive to provide for their families and make a better life for themselves overrode any attachment. Once again, the young women's maturity and compassion for their families allowed them to go to great feats to ensure everyone reaches their dreams.

\section{$\underline{\text { Recommendations for Future Research }}$}

At the end of my research, I came upon more questions and areas that I would have liked to focus on if I had the time, in addition to areas that the young women explained could be focused on in the future in answer to my third research question on, what could 
be done in New Zealand to empower female former refugees. Firstly, due to time constraints and limitations imposed on me as I was working for academic gains at a university, I was not able to complete a FPAR project in the way I had hoped. In what I was able to accomplish with these young women was incredibly inspiring and allowed them to create a space to share their stories and opinions about their experiences. I believe using these methods can be beneficial and I would suggest using them on a project where there is more time to build a bond with the participants and allow them to take more control of the creation and production of the research. The young women discussed some ideas on community projects they could start within their Somali community as well as projects at Victoria University of Wellington that I would have loved the time to work with them on and implement along with my research.

Another area I was hoping to partake in with additional time was interviewing the mothers and aunties of the young women. The female elders in their community played such a large role in every aspect of the girls' lives that it is worth looking into their resettlement process and find out their opinions on the balance of cultures their daughters were facing. These women also faced the transition into New Zealand first hand while most of the young women I spoke with were too young to remember. It could be beneficial to gain the voices and narratives of the older women in the community as they faced the transition through the Mangere Centre and relocated their entire family into a new society and culture. Although the young women created some powerful ideas to help with this transition, the voices of the older women who experienced it first-hand could only enhance it further.

The Australian emigration was a component that I was not expecting and yet was a huge aspect in the girls' lives. It gave an insight into the great lengths these young women will endure to ensure they and their families achieve their goals. I think it would be incredibly interesting to perform a similar type project with a community of former refugees undergoing a second resettlement process. It would be beneficial to see how going through one resettlement process would impact the second and what difficulties they are still facing in the second host society. It would also be intriguing to complete a 
research project with Somalis who have made the decision to not venture over to Australia and how they feel the emigration has impacted the community in Wellington.

This second resettlement is an aspect not touched on by any literature I found and could be an incredibly useful project to refugee resettlement research.

The work I completed with these girls was inspiring, informative and empowering. However, this was a small group from one community within Wellington. The literature I reviewed concerning refugee resettlement indicated that there is not enough research on refugee youth under the age of 25 and even less concerning university age students (Chatty, 2007; Gifford et al., 2007). There are other refugee communities in Wellington and many former refugee students attending Victoria University of Wellington. It could be incredibly beneficial to implement projects with these young individuals, either separated by communities or as a mixed group, to gauge what they found successful in helping them reach this stage in their education and their ideas to help others in the future. It is so vital to allow former refugee youth to be given the chance to share their experiences, rejoice in their accomplishments and give their invaluable insights into how to make resettlement an easier process for everyone involved.

\section{$\underline{\text { Suggestions to Support Services and Government Agencies }}$}

In answer to my final research question regarding what could be done in New Zealand and globally to empower former refugee women, the young women and key informants came up with a number of recommendations to increase and improve the services already in existence, as well as new ideas to implement in the future. The opinions of the young women and key informants were that the services that were the most successful tended to be those initiated and run by former refugees. Organisations such as ChangeMakers Refugee Forum and the Wellington Somali Council were founded by former refugees and therefore able to focus on the real needs of the communities as well as how best to go about creating solutions for resettlement challenges. Organisations in existence should invoke a great deal more of former refugee participation and attempt to offer employment to these individuals to ensure their group is offering the most efficient and necessary services to the communities. 
Additionally, the topic of family reunification arose quite often in conversations with both the young women and the key informants as an obstacle in successful resettlement for individuals. I understand that the government is in a tight spot with offering more funding to this area, but it would be worth investigating. Certain organisations, including Refugee Services, attempted to do their best to help individuals in these situations by offering them volunteers. Although a family being reunited is a joyous occasion, it can also cause extra stress for the families to help their newly arrived relatives adjust to New Zealand without the added support services quota refugees receive. If the government could offer a few services to help refugees coming through the family reunification process, they would not only help those individuals succeed and contribute to society, but alleviate stress from their families as well.

Finally, there should be a push to increase services specific to women of all ages. The services I spoke with had many plans for services that would aid women such as women-only language courses, recreation classes and day care services for when they attend school. But due to lack of funding and volunteers, they are not always able to make these ideas a reality. It is so important for the host society to focus on women's empowerment not only to help them succeed, but also for the well-being of their families and the refugee community as a whole.

\section{Connection to Development Studies}

As I have mentioned in my introductory chapter, I have undertaken this work as a Development Studies student at Victoria University of Wellington. Therefore I need to be aware of not only how this project benefits the young women and refugee resettlement but also the wider context of global development.

Refugee resettlement is a relevant topic for most developed nations as they are receiving individuals on an annual basis. It is therefore important that these countries have enough support services and funding to allow these people to resettle successfully. 
The New Zealand government recognises this need as their Immigration Service emphasises the importance allowing refugees to fully participate in New Zealand society and expresses how allowing refugees to feel included and safe to express their culture will aid in the overall success and enrichment of New Zealand itself (NZIS, 2004). Although this is especially relevant to New Zealand has they hold one of the highest rates of acceptance of refugees in the world proportionate to population, the safety and success of refugees benefits every country that is accepting them through their boarders (NZIS, 2012).

In addition to the aspect of resettlement being an important component for the field of development, gender differences in the development world play an integral part in not only refugee resettlement, but in most areas of development. It is crucial to explore power constructions and the balance of these relationships in communities if policy making hopes to be successful (Weeks and Schensul, 1993). Often, by exploring these power structures in communities, gender inequality and how that affects the success and livelihoods of women is exposed (Weeks \& Schensul, 1993; Kees van Donge, 2006; Aziz et al, 2011). Development practitioners have long been concerned with women's rights and empowerment as they understand how crucial this is to the success of entire families and communities (Parameswaran, 2001; Aziz et al., 2011). The process of empowerment is a process where women are able to increase their self-reliance and gain access to control their choices and become active in changing their situation and community and transform existing gender systems that may limit their independence (Taylor, 1998; Irwin, 2006). Often the means to achieving this are through improved services to allow them to achieve education and employment (Kees van Donge, 2006; Irwin, 2006; Aziz et al., 2011). But policy makers are can be a bit too hasty in deciding the activities that could best enhance women's empowerment rather than completing the research to find out what would be most efficient from the women themselves (Weeks and Schensul, 1993, Aziz et al., 2011). By employing ethnographic and participatory methods, development practitioners are able to investigate the best means to reach these ends by people who understand the situation best (Kesby, 2000; Huisman, 2008). This 
then allows for the best policy to be enacted and allow for action to take place to change the situation for the better.

In addition to the importance of pursuing research regarding women, there is a lack in the development realm of research on girls and young women. For the field of development, this is crucial as this is the generation that is going to be taking on the development activities soon and are the ones most able to help their communities and elders succeed (Weeks and Schensul, 1993, Aziz et al., 2011). Girls are often ignored in these communities and development projects as the power structures and dynamics tend to be male centric (Reese, 2002; Rudmin, 2003). The mother's success is often a vital component in whether younger girls in the family will succeed so therefore it is crucial to push for women's empowerment to help generations of women achieve rights and development (Reese, 2002; Aziz et al., 2011; Chen \& Sheldon, 2012). I believe I have just completed research on a specific case study in New Zealand showcasing the need to produce projects geared towards gender equitable outcomes in the resettlement process that can then be used for a wider global context.

\section{Concluding Remarks}

This research has taught me a great deal, not only on the academic side with methodological processes and resettlement policies, but also about working with cultures and people different than myself. I learned how vital is it to enter in this kind of research being as equipped as possible regarding their customs and beliefs and to understand that one will never be truly prepared for the work one will do. As a researcher using FPAR aims and methods, I have had to be flexible and trust in the process. The young women took charge of the project and filled in the gaps when I was unsure. They opened up about painful and rewarding memories and opened my eyes to aspects to which I wasn't aware.

I also learned a great deal about what has been accomplished in the Wellington area to assist in refugee resettlement. There are many great organisations that are completing 
important work to assist refugees in their resettlement process. The young women I worked with had all received support from at least one of these organisations and voiced how it contributed to them being successful with work and school. Even with the organisations that exist, there is always area for improvement and hopefully this type of research will present the case for improving the resettlement process for former refugees.

Finally, this project allowed me to meet and interact with an amazing, resilient and compassionate community. I was in awe of how loving, protective and determined they were to ensure that no member was left behind and they would all succeed in this new country. The young women I had the great honour of working with had gone through immense hardship, stress and obstacles but that is not what defined them. They all had dreams of traveling and hopes of finding the perfect job for their career path. They hold steady to their Somali culture as they prepare to head to yet another country to start a new life. And I have absolutely no doubt in mind that they will reach those goals. 


\section{References}

Abrams, M.S. (1999). Intergenerational Transmission of Trauma: Recent Contributions from the Literature of Family Systems Approaches to Treatment. American Journal of Psychotherapy, 53, 225-231.

Aiken, S. (1999). Racism and Canadian Refugee Policy. Journal of Refugee Studies, 18(8), 1-9.

Alitolppa-Niitamo, A. (2004). Somali Youth in the Context of Schooling in Metropolitan Helsinki: A Framework for Assessing Variability in Educational Performance. Journal of Ethnic and Migration Studies, 30(1), 81-106.

Alway, J. (1995). The trouble with gender: Tales of the still-missing feminist revolution in sociological theory. Sociological Theory, (13), 209-228.

Aziz, A., Khan, K., \& Meenaz, S. (2011). Participatory action research as the approach for women's empowerment. Action Research, 9 (3), 303-323.

Banki, S. (2006). Burmese Refugees in Tokyo: Livelihoods in the Urban Environment. Journal of Refugee Studies, 19(3), 328-344.

Barnes, D. (2001). Resettled Refugees' Attachment to their Original and Subsequent Homelands: Long-term Vietnamese Refugees in Australia. Journal of Refugee Studies, 14(4), 394-411.

Beaglehole, A. (2009). 'Refugees', Te Ara - The Encyclopedia of New Zealand. Retrieved on the World Wide Web: http://www.teara.govt.nz/en/refugees

Bek-Pedersen, K. \& Montgomery, E. (2006). Narratives of the Past and Present: Young Refugees' Construction of a Family Identity in Exile. Journal of Refugee Studies, 19(1), 94-112.

Berry, J.W. (2001). A Psychology of Immigration. Journal of Social Issues, 57(3), 615631.

Bihi, A. (1999). Cultural Identity, Adaptation and Well Being of Somali Refugees in New Zealand. Unpublished Masters Thesis. Wellington: Victoria University of Wellington.

Braun, V. \& Clarke, V. (2006). Using thematic analysis in psychology. Qualitative Research in Psychology, (3), 77-101.

Briggs, J. (2005). The use of indigenous knowledge in development: Problems and challenges. Progress in Development Studies, 5(2), 99-114. 
Brydon-Miller, M., Greenwood, D., \& Maguire, P. (2003). Why action research? Action Research, (1), 9-28.

Bushe, G. R. (1995). Advances in Appreciative Inquiry as an Organization Development Intervention. Organization Development Journal, 13 (3), 14-22.

Bushe, G. (2007). Appreciative Inquiry Is Not (Just) About The Positive. OD Practitioner, 39 (4), 30-25.

Cahill, C. (2007). The Personal is Political: Developing new subjectives through participatory action research. Gender, Place and Culture, 13(3), 267-292.

Chataway, C. (1997). An examination of the constraints on mutual inquiry in a participatory action research project. Journal of Social Issues, 53(4), 747-765.

Chatty, D. (2007). Researching Refugee Youth in the Middle East: Reflections on the Importance of Comparative Research. Journal of Refugee Studies, 20(2), 265280.

Chen, S. and Sheldon, J.P. (2012). Arab American Emerging Adults' Bicultural Identity, Acculturation Stress and Perceptions of Parenting. Journal of Immigrant \& Refugee Studies, 10(4), 438-445.

CIA Factbook. (2013). Somalia. Central Intelligence Agency. Retrieved 7 December 2012 on the World Wide Web: https://www.cia.gov/library/publications/theworld-factbook/geos/so.html

Collie, P. (2007). No straight lines of tidy boxes: young Assyrian women negotiating identities and educational pathways in New Zealand. Unpublished Masters Thesis. Wellington: Victoria University of Wellington.

Collie, P., Kindon, S., Liu, J., \& Podsiadlowski, A. (2010). Mindful Identity Negotiations: The Acculturation of Young Assyrian Women in New Zealand. International Journal of Intercultural Relations, 34, 141-149.

Collie, P., Liu, J., Podsiadlowski, A. \& Kindon, S. (2010). You can't clap with one hand: Learnings to promote culturally grounded participatory action research with migrant and former refugee communities. International Journal of Intercultural Relations, (34), 141-149.

Cooperrider, D.L., and Barrett, F. J. (1990). Generative Metaphor Intervention: A New Approach for Working with Systems Divided by Conflict and Caught in Defensive Perception. The Journal of Applied Behavioral Science, 26 (2), 219239.

Cram, F. (2010). Appreciative Inquiry. MAI Review, (3), 1-13. 
Debski, S. (2008). An exploratory study of the concept of identity for some adult refugee women in the context of their resettlement in New Zealand. Unpublished Masters Thesis. Wellington: Victoria University of Wellington.

Deepak, A.C. (2005). Parenting and the process of migration, Possibilities within South Asian families. Child Welfare, 84(5), 585-606.

Devich-Navarro, M., \& Phinney, J. (1997). Variations in Bicultural Identification among African American and Mexican American Adolescents. Journal of Research on Adolescence, 7, 3-32.

Dona, G. \& Muggeridge, H. (2006). Back Home? Refugees' Experiences of their First Visit back to their Country of Origin. Journal of Refugee Studies, 19(4), 415432.

Eastmond, M. (2007). Stories as Lived Experience: Narratives in Forced Migration Research. Journal of Refugee Studies, 20(2), 248-264.

Ellis, H., Geltman, P., Keane, T., Kia-Keating, M., Kinzie, J.D., Knight, W.G., Lustig, S.L., \& Saxe, G.N. (2004).Review of Child and Adolescent Refugee Mental Health. Journal of the American Academy of Child and Adolescent Psychiatry, 43, 24-36.

Fangen, K. (2006). Humiliation Experienced by Somali Refugees in Norway. Journal of Refugee Studies, 19(1), 69-93.

Fiddian-Qasmiyeh, E. \& Qasmiyeh, Y. (2010). Muslim Asylum-Seekers and Refugees: Negotiating Identity, Politics and Religion in the UK. Journal of Refugee Studies, 23(3), 294-314.

Fonow, M. M. and Cook, J. (2005). Feminist Methodology: New Applications in the Academy and Public Policy. Signs: Journal of Women in Culture and Society, 30(22), 11-36.

Gatenby, B. and Humphries, M. (2000). Feminist Participatory Action Research: Methodological and Ethical Issues. Women's Studies International Forum, 23(1), 89-105.

Gibbon, M. (2002). Doing a doctorate using a participatory action research framework in the context of community health. Qualitative Health Research, (12), 546558. 
Gifford, S.M., Bakopanos, C., Kaplan, I., and Correa-Velez, I. (2007). Meaning or Measurement? Researching the Social Contexts of Health and Settlement among Newly-arrived Refugee Youth in Melbourne, Australia. Journal of Refugee Studies, 20(3), 414-440.

Great Britain Policy Unit (GBPU). (2001). Somalia Assessment. Country Information and Policy Unit, Home Office, Great Britain. Retrieved 13 January 2013 on the World Wide Web:

http://www.asylumlaw.org/docs/somalia/ind01bsomaliaca.pdf

Guerin, P. \& Guerin, B. (2002). Relocating Refugees in Developed Countries: the Poverty Experiences of Somali Resettling in New Zealand. In: Lyon, K., VoightGraf, C. Eds. $5^{\text {th }}$ International APMRN Conference, Fiji: Selected Papers. Wollongong, University of Wollongong.

Hedegaard, M. (2005). Strategies for dealing with conflicts in value positions between home and school: Influences on ethnic minority students' development of motives and identity. Culture and Psychology, 11(2), 187-205.

Hermans, H. (2001). The Dialogical Self: Toward a Theory of Personal and Cultural Positioning. Culture and Psychology, 7(3), 243-281.

Ho, B. S. (2002). Application of participatory action research to family-school intervention. School Psychology Review, (31), 106-121.

Horner, C., Khan, S., \& Paton, K. (2006). Supporting refugee-background students to achieve their goals. Postgraduate Research Report prepared for Victoria University of Wellington.

Hovil, J. (2007). Self-Settled Refugees in Uganda: An Alternative Approach to Development. Journal of Refugee Studies, 20(4), 599-620.

Huisman, K. (2008). 'Does This Mean You're Not Going to Come Visit Me Anymore?": An Inquiry into an Ethics of Reciprocity and Positionality in Feminist Ethnographic Research, Sociological Inquiry, 78(3), 372-396.

Humpage, L. (2009). A 'culturally unsafe' space? The Somali experience of Christchurch secondary schools. New Zealand Geographer, 65, 73-82.

Immigration New Zealand. (2012).Refugee Resettlement Factsheet. Immigration Department, New Zealand Government. Retrieved 17 October 2012 on the World Wide Web: http://www.immigration.govt.nz/migrant/general/generalinformation/media/refu geefactsheet.htm 2013 
Inhetveen, K. (2012). Translation Challenges: Qualitative interviewing in a multilingual field. Qualitative Sociology Review, 8(2), 28-45.

Irwin, K. (2006). Into the Dark Heart of Ethnography: The Lived Ethics and Inequality of Intimate Field Relationships. Qualitative Sociology, (29), 155-175.

Jasperse, M. (2009). Persevere in Adversity: Perceived Religious Discrimination and Islamic Identity as Predictors of Psychological Wellbeing in Muslim Women in New Zealand. Unpublished Masters Thesis. Wellington: Victoria University of Wellington.

Jordan, S and Yeomans, D. (1995). Critical Ethnography: Problems in Contemporary Theory and Practice. British Journal of Sociology of Education, (16), 389- 408.

Joyce, A., Earnest, J., de Mori, G., and Silvagni1, G. (2010). The Experiencing of Students from Refugee Backgrounds at Universities in Australia: Reflections on the Social, Emotional and Practical Challenges. Journal of Refugee Studies, 23(1), 82-97.

Kees van Donge, J. (2006). Ethnography and Participant Observation. In V. Desai \& R. Potter (Eds.). Doing Development Research (pg.180 -188). London” Sage Publications.

Kesby, M. (2000). Participatory diagramming: deploying qualitative methods through an action research epistemology. Area, 32(4), 423-435.

Kindon, S. L., Pain, R., \& Kesby, M. (Eds). (2007). Participatory action research approaches and methods: connecting people, participation and place. Routledge studies in human geography, 22. London: Routledge.

Kumsa, M. (2006). Refugee Voice 'No! I'm Not a Refugee!' The Poetics of Be-Longing among Young Oromos in Toronto. Journal of Refugee Studies, 19(2), 230-255.

Lee, S. (2001). More than "model minorities" or "delinquents": A Look at Hmong American High School Students. Harvard Educational Review, 71(3), 505-529.

Liev, M.H. (2008). Adaptation of Cambodians in New Zealand: Achievement, Cultural Identity and Community Development. Unpublished Doctorate Thesis. Auckland: University of Auckland.

Lustig, S. L., Kia-Keating, M., Knight, W. G., Geltman, P., Ellis, H., Kinzie, J. D., Keane, T. and Saxe, G. N. (2004). Review of Child and Adolescent Refugee Mental Health. Journal of the American Academy of Child and Adolescent Psychiatry, 43, 24-36. 
McHugh, T. and Kowalski, K. (2010). 'A new view of body image': A school-based participatory action research project with young Aboriginal women. Action Research, 9 (3), 220-241.

Makhoul, J., Alameddine, M. \& Afifi, R.A (2011). 'I felt that I was benefiting someone': youth as agents of change in a refugee community program. Health Education Research, 27(5), 914-926.

Metz, H.C. (1992). Somalia: A Country Study. Washington D.C.:GPO for the Library of Congress. Retrieved 12 December 2012 on the World Wide Web: http://countrystudies.us/somalia/

Miller P.J., Hengst, J.A. \& Wang, S-H. (2003). Ethnographic methods: Applications from developmental cultural psychology. In P.M. Carnic, J.E. Rhodes \& L. Yardley(Eds.). Qualitative Research in Psychology: Expanding Perspectives in Methodology and Design (pp.219-242). Washington D.C.: American Psychological Association.

Ministry of Youth Affairs New Zealand (MYANZ). (2002). Youth Development Strategy Aotearoa: Action for Child and Youth Development. Ministry of Youth Affairs, New Zealand Government. Retrieved 2 February 2013 on the World Wide Web: http://www.myd.govt.nz/resources-and-reports/publications/youthdevelopment-strategy-aotearoa.html

New Zealand Immigration Service (NZIS). (2004). The New Zealand Settlement Strategy in Outline: A Future Together. Department of Labour, Wellington. Retrieved 14 October 2012 on the World Wide Web: http://www.immigration.govt.nz/NR/rdonlyres/7137ABC7-4BAEBB09227914CECE50/0/NZImmigrationSettlementStrategyOuling.pdf

O'Rourke, D. (2011). Closing Pathways: refugee-background students and tertiary education. Kotuitui: New Zealand Journal of Social Sciences Online, 6(1-2), 2626.

Patton, M. (2003). Inquiry into Appreciative Evaluation. New Directions for Evaluation, (100), 85-98.

Pain, R. (2004). Social geography: participatory research. Progress in Human Geography, 28(5), 652-663.

Parameswaran, R. (2001). Feminist Media Ethnography in India: Exploring Power, Gender, and Culture in the Field. Qualitative Inquiry, 69(7), 69-103.

Phan, T. (2003). Life in School: Narratives of Resiliency Among Vietnamese-Canadian Youth. Adolescence 38(151), 555-566. 
Phinney, J. S., \& Devich-Navarro, M. (1997). Variations in bicultural identification among African American and Mexican American adolescents. Journal of Research on Adolescence, 7, 3-32.

Radcliffe, S. (2006). Culture in Development Thinking: geographies, actors and paradigms. In S. Radcliffe (Ed.). Culture and Development in a Globalizing World: Geographies, Actors and Paradigms. London: Routledge.

Reed, J. (2007). Appreciative Inquiry: Research for Change. Sage Publications: London.

Reese, L. (2002). Parental Strategies in Contrasting Cultural Settings: Families in Mexico and 'El Norte'. Anthropology and Education Quarterly, 33(1), 30-50.

Refugee Services. (2009). New Zealand Red Cross and Refugee Services. Retrieved 13 July 2012 on the World Wide Web: http://www.refugeeservices.org.nz/faqs

Rew, A. \& Rew, M. (2003). Development models 'out-of-place': Social research on methods to improve livelihoods in eastern India. Community Development Journal, 38(3), 213-224.

Richie, B. (2004). Feminist Ethnographies of Women in Prison. Feminist Studies, 30(2), 438-450.

Rocha, Z. (2012). Identity, dislocation and belonging: Chinese/European narratives of mixedness in Aotearoa/New Zealand. Identities, 19(6), 673-690.

Rudmin, F. (2003). Critical History of the Acculturation Psychology of Assimilation, Separation, Integration, and Marginalization. Review of General Psychology, 7(1), 3-37.

Schapiro, A. (1988). Adjustment and Identity Formation of Lao Refugee Adolescents. Smith College Studies in Social Work, 58(3), 157-181.

Sharp, J. (2005). Geography and Gender: Feminist Methodologies in Collaboration and in the Field. Progress in Human Geography, (29), 304 -309.

Spoonley, P., Peace, R., Butcher, A., \& O'Neill, D. (2005). Social cohesion: a policy and indicator framework for assessing immigrant and host outcomes. Social Policy Journal of New Zealand, 24, 85-111.

Stacey, J. (1988). Can There Be a Feminist Ethnography? Women's Studies International Forum, (11), 21-27.

Taylor, V. (1998). Feminist Methodology in Social Movements Research. Qualitative Sociology, 21(4), 357-379. 
United Nations High Commissioner for Refugees (UNHCR). (2001-2013). Who We Help: Refugees. Retrieved 16 July 2012 on the World Wide Web: http://www.unhcr.org/pages/49c3646c125.html

United States Commission on International Religious Freedom (USCIRF). (2009). The Commission's Watch List: Somalia. United States Commission on International Religious Freedom, USCIRF Annual Report. Retrieved 3 January 2013 on the World Wide Web: http://www.unhcr.org/refworld/docid/4a4f272bc.html

Waikato News. (2008). Research puts spotlight on Somali Community. Waikato News, Waikato University. Retrieved 27 September 2012 on the World Wide Web: http://www.waikato.ac.nz/news/archive.shtml?article=717

Ward, C. \& Kennedy, A. (2001). Coping with cross-cultural transition. Journal of Cross Cultural Psychology, 32(5), 636-642.

Weeks, M.R. \& Schensul, J.J. (1993). Ethnographic Research on Aids Risk Behavior and the Making of Policy. In D.M. Fetterman (Ed.). Speaking the Language of Power: Communication, Collaboration and Advocacy. Translating Ethnography into Action. (pp.50-69). Washington D.C.: The Farmer Press.

Wellington Somali Council (WSC). (2013). History of Somalia. Wellington Somali Council. Retrieved 5 August 2012 on the World Wide Web: http://www.somalinz.org/somali-community/history/

Whitney, D. (1998).Let's change the subject and change our organization: an appreciative inquiry approach to organization change. Career Development International, 3(7), $314-319$.

Wilkinson, L. (2002). Factors Influencing the Academic Success of Refugee Youth in Canada. Journal of Youth Studies, 5(2), 173-193.

Williams, L. (2004). Culture and community development: Towards new conceptualizations and practice. Community Development Journal, 39(4), 345359.

Visweswaran, K. (1997). Histories of feminist ethnography. Annual Review of Anthropology, (26), 591-621.

Zetter, R. (2007). More Labels, Fewer Refugees: Remaking the Refugee Label in an Era of Globalization. Journal of Refugee Studies, 20(2), 172-192. 


\section{Appendix A - Participant Information Sheet}

Researcher: Emily James: School of Geography, Earth and Environmental Sciences, Victoria University of Wellington

Supervisor: Dr. Sara Kindon: School of Geography, Earth and Environmental Sciences, Victoria University of Wellington

My name is Emily James and I am a Master's Student in Development Studies at Victoria University of Wellington. I am currently conducting research for my thesis which will have a focus on refugee resettlement in Wellington. I am inviting Somali women in the area to participate in the study.

The work will start with focus groups of about 4-7 participants where we discuss various topics including culture maintenance and resettlement. I plan on using a participatory approach which means that my questions will be drafted with the help a cultural advisor and all focus groups will be semi-structured to allow relevant topics to be discussed. [Omit name for confidentiality] is a first year student at Victoria University and she will be the cultural advisor on this project. She will assist in drafting the questions for focus groups and interviews to ensure that they are relevant and culturally appropriate. She will also be present for all meetings to help in any translation issues and to make sure it is a safe space for everyone to share. After about 2-3 focus groups, participants can then choose if they wish to engage in one-on-one interviews with me. The questions will be around the same general themes, but again, the direction of the discussion will be determined based on what the participants want to discuss. My cultural advisor will be on hand in case there is need for translation.

I will also be conducting around 4-10 semi-structured interviews with key contacts in organizations that provide services and support structures to refugee communities. The emphasis will once again be on resettlement for young Somali women refugees, but from a different perspective. I want to see what organisations are doing to help in the resettlement process for these refugees and what they ideas are to improve the situation for future refugees.

I believe this viewpoint would be invaluable for my project because it would compliment your experiences with resettling into New Zealand by adding the policy side of why you may face some of these obstacles. You also have expertise in the area and will be able to give valuable recommendations into how these areas can be improved and the ways for it to be done.

Pending consent, focus groups and interviews will be recorded and transcribed by the researcher. No other person besides me and my supervisor, Dr. Sara Kindon, will see the transcripts. Should any participant feel the need to withdraw from the project, they may do so without question at any time before 30 October 2012 . 
All transcripts and notes will be stored in an electronic file secured with a password only known by the researcher and all information will be destroyed five years after the end of the project.

Information from focus groups and interviews will be put into a written report as a thesis. Participants can choose to not to have their names used in these written documents, can opt to not be recorded and have the option to turn off the tape recorder at any point throughout all focus groups and interviews. All material collected will be kept confidential. The thesis will be submitted for marking to the School of Geography, Earth and Environmental Sciences and deposited in the University Library. This project has been approved by the Human Ethics Committee of Victoria University of Wellington.

If you have any questions or would like more information on the project, please contact me at Emily.James@ vuw.ac.nz or Dr. Sara Kindon at Sara.Kindon@ vuw.ac.nz (Phone: 04 4636194).

Emily James 


\section{Appendix B - Consent to Participate in Research - Interviews}

\section{For "You can never be on one side alone": Some Young Somali-Kiwi Women's Narratives about Identity, Resettlement and Community Development in Wellington, Aotearoa New Zealand"}

I have been given and have understood an explanation of this research project. I have had an opportunity to ask questions and have them answered to my satisfaction.

- I understand that all information I provide will be kept confidential to the researcher and supervisor.

$\circ$ I understand that the published results will not use my name and that no information I provide will in any way identify me.

I I understand that the tape recording of focus groups and interviews will be destroyed after five years at the end of the project.

- I understand that the data I provide will not be used for any other purpose or released to others without my permission.

- I understand that I can withdraw myself or any information I have provided (without having to give reasons) anytime before 30 October 2012.

○ I understand that the information will be destroyed by 30 February 2018.

I would like to receive an executive summary of the results of this research when it is completed.

Contact Email

By signing this form, I agree to take part in this research.

Name (please print):

Signed:

Date: 


\section{Appendix C - Consent to Participate in Research - Focus Group}

\section{For "You can never be on one side alone": Some Young Somali-Kiwi Women's Narratives about Identity, Resettlement and Community Development in Wellington, Aotearoa New Zealand"}

I have been given and have understood an explanation of this research project. I have had an opportunity to ask questions and have them answered to my satisfaction.

- I understand that all information I provide will be kept confidential to the researcher and supervisor.

$\circ$ I understand that the published results will not use my name and that no information I provide will in any way identify me.

- I understand that the tape recording of focus groups and interviews will be destroyed after five years at the end of the project.

- I understand that the data I provide will not be used for any other purpose or released to others without my permission.

○ I understand that the information will be destroyed by 30 February 2018.

- I would like to receive an executive summary of the results of this research when it is completed.

\section{Contact Email}

By signing this form, I agree to take part in this research.

Name (please print):

Signed:

Date: 


\section{Appendix D - Semi-Structured Interview Script for Young Somali Women}

\section{Resettlement in New Zealand}

What has your experience been like coming to New Zealand?

Was there anyone that helped you settle here? Any organisations?

What do you like about living here?

What do you not like about living in New Zealand?

What do you consider to be "successful resettlement" in New Zealand?

What would you need to do to achieve that?

What will your life be like in 5 years with successful resettlement?

\section{Cultural Maintenance}

What ways do you maintain your culture individually? How does your family maintain your culture? Your community?

Why is it important to maintain your culture?

What are some of the things you like most about your culture? How do these help now you are living in New Zealand?

Do you think there is a difference between the ways older people in the community maintain their culture than younger Somalis?

What do you think about Kiwi culture? How does it help Somali culture?

What ways is it hard to maintain your Somali culture in New Zealand?

\section{$\underline{\text { Future Recommendations }}$}

What are some misconceptions you think Kiwis have about Somalis?

How do you think Somalis are treated in New Zealand?

What support could be added to make the transition easier?

What is something that could have made your transition to New Zealand easier?

If you could give advice to someone coming to New Zealand, what would you tell them? 


\section{Appendix E - Semi-Structured Interview Script for Key Informants}

\section{Section A: Background / Services}

Could you please state your name and current occupation?

How long have you been in this role?

What does this role entail? How do you specifically work with refugee-background people?

What sorts of services and support structures does (organization) provide to the refugeebackground community?

For Somali refugee-background people?

What has really worked with these services?

How would you describe "successful resettlement"?

Are there areas that (organization) would like to expand in the future?

What would you need in order to make this happen?

\section{Section B: Somali Culture}

What has been your experience working with the Somali community?

How would you describe their culture?

How do you think Somali culture compliments Kiwi culture? What can they bring or teach to this new community?

Is there something unique about Somali culture that can make resettlement a different experience than other refugee communities?

What can be done to make this transition easier?

What types of services does (organization) provide in regards to resettlement?

How often do people from the Somali community take advantage of these services?

How much of these services are run or initiated by refugee-background people?

Are there plans to reach out to more of the community? 


\section{Section C: Somali Young Women}

Approximately how many young Somali women partake in the services (organization) provides?

What are most of the girls doing at present? Going to university? Working?

Why do you think that is?

Are there differences Somali women face in resettlement compared to men?

Do you have services that reflect those differences?

Why do you think there is a trend in women moving to Australia?

What could be done here to make it a competitor for Australia?

\section{Section D: Future Recommendations}

What are some of the achievements you've seen with resettling?

With those, were there support services that helped them get there?

What kind of impact do you see with your services in regards to successful resettlement for Somali refugees?

What does (organization) hope to accomplish in the next 5 years?

What do you need in order to make this happen?

What would you do to improve the resettlement transition for future refugees?

Any additional questions or comments? 